Characterizing phenotypes of Mycobacterium tuberculosis and exploring anti-mycobacterial compounds through high content screening

Sadaf Kalsum 


\section{Characterizing phenotypes of Mycobacterium tuberculosis and exploring anti-mycobacterial compounds through high content screening}

Sadaf Kalsum

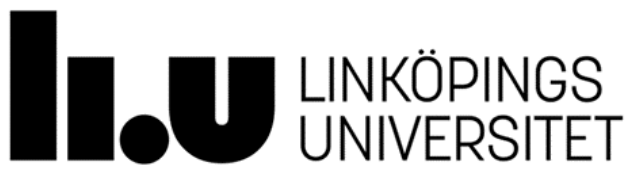

Division of Microbiology and Molecular Medicine Department of Clinical and Experimental Medicine Faculty of Medicine and Health Sciences Linköping University, SE-581 83 Linköping, Sweden Linköping [2018] 
(C) Sadaf Kalsum, 2018

Paper I was published in Journal of Ethnopharmacology

Paper II was published in Frontiers in Cellular and Infection Microbiology

Cover: A fluorescence microscopy image of mCherry-expressing cording phenotype of Mycobacterium tuberculosis (red) and nuclei (blue) of primary human macrophages.

ISSN: 0345-0082

ISBN 978-91-7685-154-8

Printed by LiU-Tryck, Linköping 2018 
Dedicated to the

loving memory of

my beloved mother 

Achievements and Success are never be miraculous. They take late nights, early mornings, determination and consistent hard work.

Sohail Abbas 
Supervisor

Maria Lerm, Linköping University, Sweden

Co-supervisors

Thomas Lundbäck, Karolinska Institute, Sweden

Annika Jenmalm Jensen, Karolinska Institute, Sweden

Lena Serrander, Linköping University Hospital, Sweden

Faculty opponent

Priscille Bordin, Pasteur Institute, France

Funding

This work was funded by the Ekhaga Foundation, Carl Trygger Foundation, the Swedish Research Council, the Swedish Heart-Lung Foundation and Olav Thon Foundation and in-kind support by the SciLifeLab platform Chemical Biology Consortium Sweden sponsored by the Swedish Research Council, the SciLifeLab and Karolinska Institute (www.cbcs.se). 


\section{Table of contents}

Abstract 1

Populärvetenskaplig Sammanfattning 3

List of Papers 4

Abbreviations 5

Chapter 1: Background 7

A Brief History

Epidemiology

The Bacillus $\quad 8$

$\begin{array}{ll}\text { Virulence Factors } & 9\end{array}$

Cell Envelope $\quad 9$

$\begin{array}{ll}\text { Secretory Proteins } & 10\end{array}$

TB - an Infection Leading to a Disease $\quad 11$

$\begin{array}{ll}\text { The Granuloma } & 12\end{array}$

Diagnosis $\quad 15$

Treatment 16

$\begin{array}{ll}\text { Vaccination } & 16\end{array}$

Chapter 2: Mycobacteria and Innate Immunity 17

$\begin{array}{ll}\text { Human Lung Morphology } & 17\end{array}$

Innate Immunity in the Lung $\quad 17$

$\begin{array}{ll}\text { Innate Immune Cells } & 17\end{array}$

Macrophages and their Phenotypes 18

Pattern Recognition Receptors 19

Toll-like Receptors 19

Nucleotide-Binding Oligomerization Domain (Nod)-like Receptors 20

Complement Receptors 20

C-type Lectin Receptors

Cytokine Production 22

The Inside Battle of Macrophages with Mtb 24

Chapter 3: Macrophage Cell Death Induced by Cording Phenotype of Mtb 26

Biofilm 26

Cording in Mycobacterial Biofilm 26

$\begin{array}{ll}\text { Cell Death } & 29\end{array}$

Etosis Leading to Extracellular Traps 30

Macrophage Extracellular Traps 31

Chapter 4: TB Treatment 33

Mechanism of Action and Resistance against First-Line Antibiotics 34 
Drug-Resistant TB 35

Second-Line Drugs $\quad 37$

New Drugs in Pipeline $\quad 37$

Drug Screening 38

Screening Approaches in TB 39

High Content Screening $\quad 40$

Assay Development 40

Hit Identification and Beyond 41

$\begin{array}{ll}\text { Aims } & 43\end{array}$

Results and Discussion $\quad 44$

Concluding Remarks $\quad 49$

References $\quad 51$

$\begin{array}{ll}\text { Acknowledgement } & 75\end{array}$ 


\section{Abstract}

Tuberculosis (TB), an airborne disease and one of the top 10 causes of death globally, is caused by Mycobacterium tuberculosis (Mtb). Current standard therapy for TB treatment includes multiple drugs for a period of at least 6 months. The long therapy duration is to sterilize a small sub-population of drug-tolerant bacteria, a characteristic related to biofilm formation, which otherwise responsible for disease relapse. On the other hand, because of such a long treatment period, patient adherence to therapy becomes difficult, which results in the emergence of multidrug-resistant (MDR) or, in worst cases, extensively drug-resistant (XDR)-TB. TB is primarily a disease of lungs and alveolar macrophages are one of the first host cell types to encounter Mtb following aerosol transmission. A well-established role of macrophages in immune defense is phagocytosis, but recent studies also demonstrated that upon interaction with large aggregates of microbes or cord-forming mycobacterial species, macrophages could produce extracellular traps known as macrophage extracellular traps (METs). METs have a DNA backbone with embeds histones and could trap a wide range of microorganisms, but may or may not be able to kill them. Natural products are always a promising starting point for drug discovery because of their wide range of activity. A large number of world's population is still using extracts from different parts of plants as the primary source of medicines against diseases including TB. Today much effort is being invested by academia in screening campaigns that allows for fast discovery of new active compounds. Thanks to the use of automated technology such as automated microscopy or automated image analysis (known as high content screening, HCS) phenotypic drug discovery has become easier to perform. Therefore, the identification of highly effective compounds to combat infectious diseases like TB can be facilitated by the use of host-pathogen assays at the early stages of drug screening studies.

This thesis describes the characterization and antibiotic sensitivity of different phenotypes of Mtb namely planktonic, cord-forming and biofilm-producing phenotypes that arise due to different culture conditions. The culture of Mtb with a high percentage of a detergent (Tween-80) and standing condition promoted planktonic phenotype while a culture with a low amount of Tween-80 and more aeration due to shaking promoted cording and biofilm phenotypes. Primary human macrophages upon interaction with the shaken culture of wild-type Mtb died by releasing METs. Whereas, the shaken cultures of early secreted antigenic target-6 (ESAT-6), an important virulence factor of Mtb, deletion mutant strain could not induce MET formation showing that the cord formation is related to virulence. Moreover, the biofilm phenotype of Mtb is more tolerant to two first-line antibiotics isoniazid (INH) and rifampicin (RIF) as compared to cording and planktonic phenotypes which demand a search of more effective TB therapy. A screening campaign based on a whole-cell assay using different ethanolic crude extracts of many African plants lead to the discovery of a hit, i.e., a chloroform fraction of Khaya senegalensis bark, which showed non-significant inhibition of intracellular growth of a virulent strain of Mtb was selected for further purification and evaluation. Lastly, we have also developed and validated an HCS assay to explore new compounds against intracellular Mtb in human macrophages. INH and RIF, which were found most effective in 
our system were used in a combination as a positive control to calculate a Z' factor value, which confirmed our assay to be suitable for HCS.

In conclusion, this thesis not only highlights the biology of TB infection, but also discusses the development of a pathophysiologically relevant assay that can be used in the identification of novel compound(s) that has either direct anti-mycobacterial activity (antibiotic), acts by stimulating the host cell immune mechanisms (immunomodulator) or acts by counteracting virulence factors (virulence blocker). 


\section{Populärvetenskaplig Sammanfattning}

Tuberkulos (TB) är en luftburen lungsjukdom som orsakas av Mycobacterium tuberculosis (Mtb), och är en av de 10 främsta dödsorsakerna i världen idag. Nuvarande behandling av TB innebär minst 6 månaders kur med flera olika antibiotikum. Det som försvårar behandlingen är speciella egenskaper hos Mtb, som att de växer långsamt, kan bilda biofilmer, samt kan växa i långa trådlika formationer. Men olika resistenta infektioner förekommer också, vilket ytterligare försvårar eller omöjliggör lyckad behandling. Immunceller i lungan, framförallt makrofager, tar upp Mtb när den kommer ner i lungan. En nyligen upptäckt funktion hos dessa makrofager är att de kan skicka ut nät som bland annat består av DNA. Dessa nät (som kallas METs) kan fånga upp bakterier som befinner sig utanför cellerna, men även döda bakterierna i vissa fall. När Mtb växer i trådlika formationer får makrofagerna svårare att ta upp bakterierna och istället kastar de ut METs för att försvara sig.

Det finns ett stort behov av nya läkemedel och antibiotika för att effektivare kunna behandla TB. Naturprodukter har historiskt varit en källa för nya läkemedelsupptäckter, och med dagens teknologi kan automatiserade screening av extrakt från växter användas för att snabbt hitta aktiva substanser. Det finns olika screening teknologier och automatiserade bildanalyser, men oftast tar man inte hänsyn till substansernas effekt inne i humana celler. Eftersom Mtb är en bakterie som gärna gömmer sig inne i människans makrofager är det ytterst relevant att använda sig av metoder som även studerar bakterier inne i celler och hur cellernas funktion påverkas.

I min avhandling har jag beskrivit olika fenotyper av Mtb, nämligen encelliga, trådlika och biofilmer. De olika fenotyperna beror på den miljö som bakteriekulturerna odlas i. Jag kunde visa att Mtb som växer i trådlika formationer påverkade de humana cellerna annorlunda och gjorde att de kastade ut METs som en försvarsmekanism. Jag visar också att de olika fenotyperna får en ändrad antibiotika-känslighet. Bakterierna som växer i biofilm visade sig vara mer toleranta mot de två primära antibiotikumen för behandling av $\mathrm{TB}$, isoniazid (INH) och rifampicin (RIF), än de trådlika och encelliga. Jag genomförde en screening av olika växtextrakt från Sudan där jag studerade deras effekt att hämma tillväxt av Mtb i humana makrofager. Vi fann en kloroform-fraktion av barken från Khaya senegalensis som visade god effekt och som möjligtvis skulle kunna utvecklas till ett nytt TB läkemedel. Jag gick sedan vidare och utvecklade en metod för högkapacitets-screening som bygger på bildanalys för att screena en mängd olika substanser med hänsyn till deras effekt på att avdöda Mtb inne i humana celler. Denna metod är högst relevant för att kunna upptäcka nya substanser som kan användas $\mathrm{i}$ behandling av TB. 


\section{List of Papers}

\section{Paper 1}

Kalsum S, Braian C, Koeken V.A.C.M, Raffetseder J, Lindroth M, van Crevel R, Lerm M. The Cording Phenotype of Mycobacterium tuberculosis induces the Formation of Extracellular Traps in Human Macrophages. Frontier in Cellular and Infection Microbiology. 2017;7:278.

\section{Paper 2}

Kalsum S, Das J, Wlodarczyk M, Lerm M. The Effect of Antibiotics on Planktonic, Cord and Biofilm Phenotypes of Mycobacterium tuberculosis. Manuscript

\section{Paper 3}

Abuzeid N, Kalsum S, Koshy RJ, Larsson M, Glader M, Andersson H, Raffetseder J, Pienaar E, Eklund D, Alhassan M.S, AlGadir H.A, Koko W.S, Schön T, M. Mesaik A, Abdalla O.M, Khalid A, Lerm M. Antimycobacterial activity of selected medicinal plants traditionally used in Sudan to treat infectious diseases. Journal of Ethnopharmacology 2014;157:134-9.

\section{Paper 4}

Kalsum S, Otrocka M, Welin A, Schön T, Lundbäck T, Lerm M. A high content screening assay for novel anti-mycobacterial compounds using primary human macrophages and virulent Mycobacterium tuberculosis. Manuscript 


\section{Abbreviations}

\begin{tabular}{|c|c|}
\hline ADMET & absorption, distribution, metabolism, excretion and toxicity \\
\hline AECs & airway epithelial cells \\
\hline AIDS & Acquired immune deficiency syndrome \\
\hline AMI & amikacin \\
\hline BAL & bronchoalveolar lavage \\
\hline $\mathrm{BCG}$ & Bacille Calmette and Guerin \\
\hline CFP-10 & $10 \mathrm{kDa}$ culture filtrate protein \\
\hline CLOF & clofazimine \\
\hline CLRs & C-type lectins receptors \\
\hline CR & complement receptors \\
\hline DCs & dendritic cells \\
\hline DC-SIGN & dendritic cell-specific intracellular adhesion molecule-grabbing non integrin \\
\hline Dectin-1 & dendritic cell-specific receptor-1 \\
\hline DOTS & directly observed treatment, short-course \\
\hline DR-TB & drug resistant $\mathrm{TB}$ \\
\hline EEA1 & early endosomal antigen 1 \\
\hline EMB & ethambutol \\
\hline ESAT-6 & $6 \mathrm{kDa}$ early secreted antigenic target \\
\hline ESX & ESAT-6 secretion system \\
\hline ETs & extracellular traps \\
\hline FDA & food and drug administraion \\
\hline $\mathrm{HCA}$ & high content analysis \\
\hline $\mathrm{HCI}$ & high content imaging \\
\hline HCS & high content screening \\
\hline HIV & human immunodeficiency virus \\
\hline hMDMs & human monocyte-derived macrophages \\
\hline HTS & high throughput screening \\
\hline IC50 & half maximal inhibitory concentration \\
\hline IFN- $\gamma$ & interferon-gamma \\
\hline IGRAs & IFN- $\gamma$ release assays \\
\hline KAN & kanamycin \\
\hline IL & Interleukin \\
\hline IL-1 & Interleukin-1 \\
\hline IL-10 & Interleukin-10 \\
\hline IL-4 & Interleukin-4 \\
\hline INH & isoniazid \\
\hline iNOS & inducible nitric oxide synthase \\
\hline LAM & lipoarabinomannan \\
\hline LIN & linezolid \\
\hline LM & lipomannan \\
\hline LTBI & latent $\mathrm{TB}$ infection \\
\hline ManLAM & mannose-capped LAM \\
\hline MDMs & monocyte-derived macrophages \\
\hline MDR & multidrug-resistant \\
\hline METs & macrophage extracellular traps \\
\hline MOX & moxifloxacin \\
\hline
\end{tabular}




\begin{tabular}{|c|c|}
\hline MR & mannose receptor \\
\hline Mtb & Mycobacterium tuberculosis \\
\hline MTBC & Mycobacterium tuberculosis complex \\
\hline MyD88 & Myeloid differentiation factor 88 \\
\hline NETs & neutrophil extracellular traps \\
\hline NK cells & natural killer cells \\
\hline NLR & nucleotide-binding oligomerization domain-like receptor \\
\hline NO & nitric oxide \\
\hline PADs & peptidylarginine deiminases \\
\hline PAMPs & pathogen-associated molecular patterns \\
\hline PAS & para-aminosalicylic acid \\
\hline PBMCs & peripheral blood mononuclear cells \\
\hline $\mathrm{PI} 3 \mathrm{~K}$ & phosphatidylinositol 3-kinase \\
\hline PIM & phosphatidyl-myo-inositol mannoside \\
\hline PknG & protein kinase $\mathrm{G}$ \\
\hline PMNs & polymorphonuclear neutrophils \\
\hline POA & pyrazinoic acid \\
\hline PPD & purified protein derivative \\
\hline PRRs & pattern recognition receptors \\
\hline PtpA & protein tyrosine phosphatase \\
\hline PZA & pyrazinamide \\
\hline $\mathrm{R}$ & rough colonies \\
\hline RD1 & region of difference 1 \\
\hline RIF & rifampicin \\
\hline RNIs & reactive nitrogen intermediates \\
\hline$S$ & smooth colonies \\
\hline $\mathrm{Sec}$ & secretion pathway \\
\hline SLE & systemic lupus erythematosus \\
\hline SM & streptomycin \\
\hline SPs & surfactant proteins \\
\hline SR & scavenger receptor \\
\hline TACO & Tryptophan aspartate containing coat protein \\
\hline Tat & twin-arginine translocase \\
\hline TB & tuberculosis \\
\hline TDM & trehalose dimycolate \\
\hline Th1 & T helper 1 cells \\
\hline TLRs & Toll-like receptors \\
\hline TNF- $\alpha$ & tumour necrosis factor- $\alpha$ \\
\hline TST & tuberculin skin test \\
\hline Tween-80 & polysorbate- 80 \\
\hline vATPase & vacuolar $\mathrm{H}^{+}$-ATPase \\
\hline WHO & World Health Organization \\
\hline XDR & extensively drug-resistant \\
\hline zmp1 & zinc metalloprotease \\
\hline
\end{tabular}




\section{Chapter 1: Background}

\section{A Brief History}

Tuberculosis (TB), caused by Mycobacterium tuberculosis (Mtb, has existed for millennia and remains one of the major causes of human suffering and death. TB which was long considered as an inherited disease was first revealed as an infection in 1882 by a German microbiologist Robert Koch, who isolated the causative agent by using methylene blue staining [1]. TB has plagued humankind throughout recorded and archaeological history, claiming more lives than any other infectious agent [2]. The age of Mtb has been estimated to be more than 150 million years old while the common ancestor of Mycobacterium tuberculosis complex (MTBC) occurred roughly 15,000 to 20,000 years ago [2]. Evidence for TB has been found in Egyptian mummies from the pre-dynastic era, as revealed by Pott's lesions, skeletal changes in the spine, a typical characteristic associated with TB. Early Egyptian arts also carries witness of TB, but there is no written evidence of TB lesions in Egyptian papyri. Rather, the first description was found in India and China showing the migration of humans carrying the disease [2,3]. Historical texts also showed that this prevalent disease was recognized by different names in different times, such as "phthisis" or "consumption" by Hippocrates and "Scrofula" in the European in middle ages. The name "King's Evil" in England and France refers to the idea that the disease can only be cured by a Royal touch [4]. As Mtb is an obligate pathogen with no environmental reservoir, its persistence is related to the density of human population. In the $18^{\text {th }}$ century, TB had dramatically increased in North America and Europe because of poor socioeconomic conditions and industrial revolution and was known as "robber of youth" affecting mostly young adults and later by much-feared name "white plaque" as it was responsible for the death of one-fourth of all adults in Europe [5]. But then a major reversal occurred in the lifestyle of the European population, which shifted towards improved social conditions (housing, nutrition and income) and nature adaptation, also decreasing the TB-associated death tolls. Furthermore, isolation of TB patients in sanatoria, where the patients were treated with rest, healthy nutrition and exposure of sunlight, further decreased the number of TB cases in the $19^{\text {th }}$ and $20^{\text {th }}$ century [5]. The reduction in TB incidence became more rapid following the introduction of antimicrobial drugs such as Streptomycin (SM, the first antibiotic against TB discovered in 1943), Isoniazid (INH, 1952) and rifampicin (RIF, 1963) [5]. With the advent of effective chemotherapy in the mid-1950s, the sanatoria began to close as hospital care no longer was required. A study performed in Madras showed no difference in clinical outcome among the patients who were sent to a sanatorium or took treatment at home [6]. Nowadays, TB is still a major health problem and one of the reasons is that $\mathrm{Mtb}$ continues to evolve resistance to drugs and therefore a combined strategy is needed based on improving drug treatment, diagnostic instrument and prevention strategy in order to eradicate TB till 2030 as committed by World Health Organization (WHO) known as "the TB End Strategy" [7].

\section{Epidemiology}

TB is still today a global epidemic and one of the top ten causes of mortality worldwide. WHO estimated 1.3 million TB deaths globally in 2017 and an additional 0.5 million deaths among 
people with TB/HIV (human immunodeficiency virus) coinfection [7]. TB epidemiology is heterogeneously distributed worldwide with great prevalence in the densely populated developing countries. Six countries were accounted for $60 \%$ of these new cases namely; India, Indonesia, China, Nigeria, Philippines, Pakistan and South Africa. TB is a poverty-related disease which disproportionately affects the poorest, the most vulnerable and marginalized population groups where it occurs. WHO also confirmed in their report that out of these new cases $2.7 \%$ occurred in the European region [7].

In 2014, WHO introduced a new comprehensive approach to fight TB named "the TB End Strategy" where the global incidence rate of less than one per million of the population should be achieved by 2030 [7]. Although a declining trend in TB incidence, prevalence and mortality have been observed over the last decade, elimination of the disease at the global level is still out of reach due to several social, epidemiological and clinical factors.

Treatment of this devastating disease requires administration of multiple drugs (known as first-line drugs) for a period of at least six months. The long treatment period challenges the patients' compliance and consequently, limits the overall effectiveness of treatment regimen resulting in the emergence of multidrug-resistant (MDR) or, in the worst case, extensively drug-resistant (XDR)-TB [8]. MDR/XDR-TB, the major threat to global TB control, are treated with second and third-line antibiotics which have even longer treatment duration and at a higher cost. Moreover, they are associated with expanded mortality due to lower effectiveness and more side effects [9]. It is estimated that MDR-TB affects 480000 people annually with only a fraction of these patients receiving appropriate treatment. Treatment of early-stage TB in high burden countries and latent TB infection (LTBI) in low TB-burden countries is highly required.

\section{The Bacillus}

Mycobacteria are facultative intracellular bacteria that reside within phagocytic cells, particularly macrophages. They are obligate aerobic, non-motile, non-sporulation, weakly Gram-positive, acid-fast bacilli that appear microscopically as straight or slightly curved rods. They are 1 to $4 \mu \mathrm{m}$ long and 0.3 to $0.6 \mu \mathrm{m}$ wide. The Mycobacterium species belong to the family of Mycobacteriaceae, in the Corynebacterinae sub-group of the actinomycetes line [10]. Most mycobacteria species are saprophytic soil occupants like Streptomyces, but Mtb meets the definition of human parasite as it spreads among people with no extra-human reservoir. Mycobacteria divide at a significantly slower rate (around 16 to 20 hours) compared to other bacteria, which usually divide within minutes. Classically, the Mycobacterium species can be divided into a group of fast-growers (colonies seen within a week) and slow-growers (colonies grow in 2-3 weeks). The group of fast-growers only has one critical human pathogen, $M$. abscessus, while the slow-growers include two highly successful pathogens apart from Mtb; $M$. leprae, the causative agent of leprosy and M. ulcerans, the agent of Buruli ulcer. Other opportunistic human pathogens belonging to slow-growers include $M$. avium, $M$. intracellulare, M. marinum and M. kansasii [11].

Mtb is part of a complex known as MTBC, a group of mycobacteria that shares $>99 \%$ DNA sequence identity. However, they differ significantly in morphology, biochemistry, host tropism and pathogenicity. This group includes Mtb, M. africanum (exclusively human pathogens), M. microti (a rodent pathogen) M. capreae (causes TB in sheep and goats), $M$. 
pinnipedii (sea lions) and $M$. bovis (broad host range). M. canettii, a very rare variant of the MTBC was first isolated from a TB patient in the 1960s. M. canettii strains show unusual smooth (S) colony morphology and are known as smooth tubercle bacilli [12]. The concept postulated a decade ago that TB was originated from animals and was transferred to humans during animal domestication, was rejected by genetic information [13] and instead, Mtb seems to be evolved from $M$. canettii [14].

\section{Virulence Factors}

The virulence factors of Mtb can be divided into two groups: cell envelope components and secreted proteins.

\section{The Cell Envelope}

The composition and complexity of the mycobacterial cell envelope is the most distinctive feature of the Mycobacterium genus. The cell envelope of mycobacteria according to the most recent model is organized into three superposed compartments: a typical bilayer phospholipid plasma membrane, the cell wall core and the outermost layer, also called the capsule in pathogenic species $[10,15]$.

In mycobacteria, $30 \%$ of the genome is devoted to synthesize and metabolize a fascinating diversity of lipids (30-60\% of dry cell weight). The cell wall core consists of an inner phospholipid bilayer (typical for all bacteria) anchored with peptidoglycan (providing rigidity to cell envelope) covalently linked to arabinogalactan which is esterified with long chain mycolic acids of the outer lipid bilayer. In 1982, it was proposed that the cell wall core has a thick, asymmetrical, lipid-rich bilayer, other than the one which is found in the plasma membrane. This lipid bilayer is composed of an inner leaflet of mycolic acids and outer leaflet of free intercalating lipids and glycolipids. The nature and composition of these non-covalently bound lipids vary between mycobacterial species [16].

Specialized phagocytic receptors essentially mediate the entry of Mtb inside host phagocytic cells and many of mycobacterial cell wall glycolipids are the keys to the entry points (phagocytic receptors) of phagocytes [10]. Once inside the host cells, cell wall lipids also play the foremost part in the survival of mycobacteria [17]. Mycobacterial lipoarabinomannan (LAM) has been shown to block phagosome maturation [18] plus the high contents of a variety of lipids and carbohydrates provide a solid resistance sheet to antibiotics and disinfectants. Mycobacterial cell wall lipids can also modulate the innate and adaptive immunity in many ways [10]. Thus, anti-mycobacterial agents such as INH and ethambutol (EMB), which act by inhibiting biosynthesis or assembly of mycobacterial cell envelop components have proven useful in treating TB. These two drugs which are part of the first-line treatment regimen of TB inhibit mycolic acid synthesis and arabinogalactan, respectively [19].

The capsule is mainly composed of polysaccharides, proteins and small amounts of lipids (mostly present in the inner part of the capsule) and is considered to have a different molecular composition in pathogenic and non-pathogenic species [20]. The mycobacterial capsule can only be seen through a conventional electron microscope when the bacterial cultures have been grown in detergent-free medium without agitation [21]. Glucan is the most abundant polysaccharide present in the capsule, whereas the capsular proteins are a complex 
mixture of polypeptides. They may be either secreted proteins being transported to the extracellular medium or may be cell envelope-associated or cytoplasmic proteins [21].

The privileged position of the capsule, i.e., present at the interface between the bacilli and host cells show its essential role in the interaction with the host during phagocytosis. The secretory proteins act as virulence factors and are involved in bacterial translocation from the phagosome into the cytosol [22].

\section{Secretory Proteins}

A significant virulence factor of pathogenic bacteria is the protein export system. Mycobacteria like all other bacteria can export the cytoplasmic synthesized proteins to the external environment or the cell envelope. For this, Mtb possesses two highly conserved protein export systems, the general secretion (Sec) pathway and Twin-arginine translocase (Tat) export pathway that transport the majority of bacterial proteins. These two systems are omnipresent in the bacterial kingdom and transport proteins containing unique $\mathrm{N}$-terminal sequences at the cytoplasmic membrane. Both of these systems export proteins that is essential for bacterial viability and virulence factors that contribute to pathogenesis [23].

Another pathway is called type VII (T7SS)/ $6 \mathrm{kDa}$ early secreted antigenic target (ESAT-6) secretion system (ESX) originally identified in MTBC. Although the ESX systems were first discovered in mycobacteria, they also exist in a small subset of Gram-positive bacteria like Staphylococcus aureus. These systems are responsible for the export of small, highly immunogenic proteins lacking the classical $\mathrm{N}$-terminal signal sequences. The mycobacteria have five ESX pathways named ESX-1 through ESX-5. Each of the five EXS loci has a pair of genes encoding secreted ESX proteins and a set of genes encoding the secretory machinery [24]. The first identified and best-characterized ESX system is ESX-1. The EXS-1 locus has two genes called as esxA and esxB at its center which encodes ESAT-6 and ESAT-6 like protein, CFP-10 (10 kDa culture filtrate protein). Both of the proteins are exported together in 1:1 complex and each protein depend on the other for its export [25]. ESX1 system is considered a significant virulence factor as the absence of this system is responsible for the attenuation of the live vaccine strain of $M$. bovis known as Bacille Calmette and Guerin (BCG). During prolonged in vitro growth, the genomic region of difference 1 (RD1) was deleted in this attenuated strain which lacks the major part of ESX-1 locus. The RD1 region is present in the genome of Mtb and M. bovis. ESAT-6 and CFP-10 also form the basis of immunological diagnosis of Mtb infection in the interferon-gamma (IFN- $\gamma$ ) release assays (IGRAs) [16].

In order to establish a successful infection, mycobacteria also require iron acquisition and EXS-3 secretary system is involved in such an essential attribute of the bacteria [26]. Also, heme that is required to build iron is transported across the membrane through MmLp, a protein in the cell envelope [19]. 

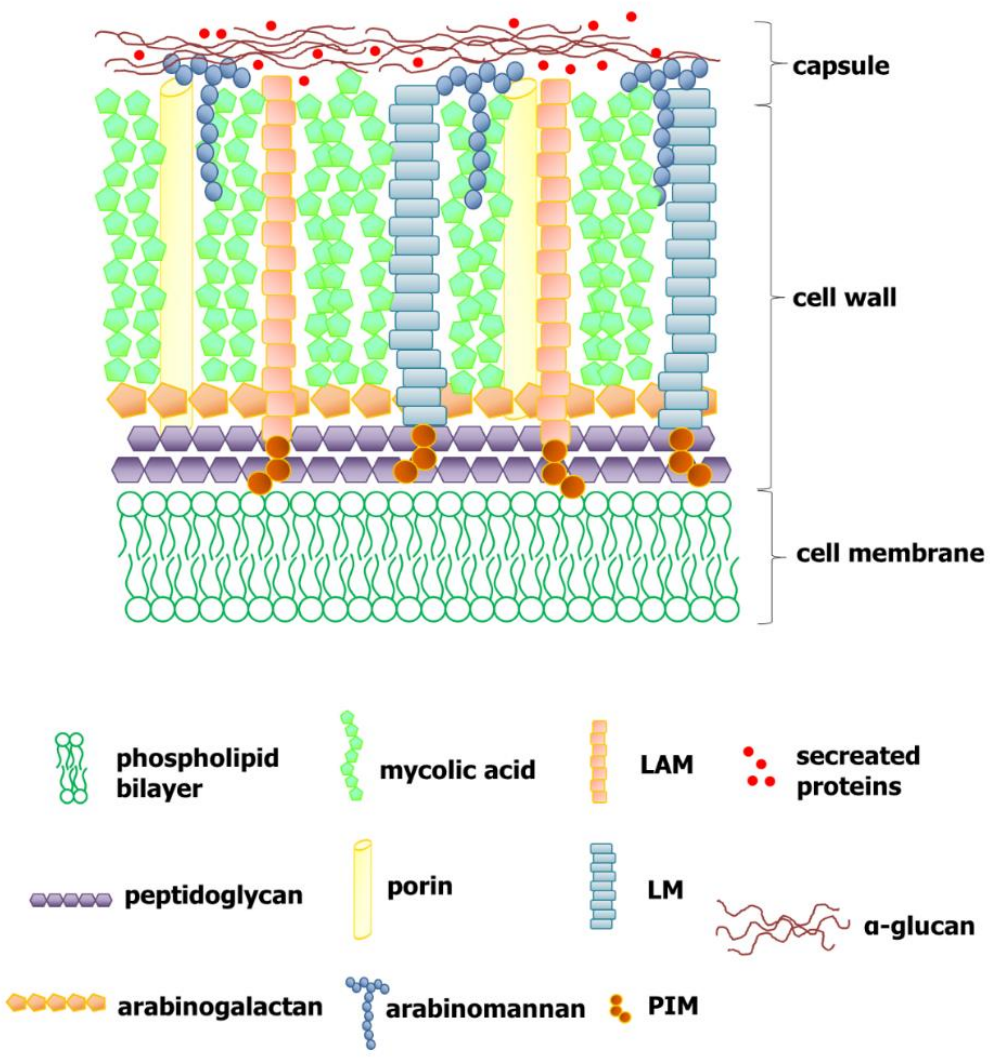

Figure 1. Schematic representation of the Mtb cell envelope. LAM = lipoarabinomannan, LM = lipomannan, PIM = phosphatidyl-myo-inositol mannoside.

\section{TB - an Infection Leading to a Disease}

The human is the only known natural reservoir of Mtb and to keep its existence in nature, Mtb should drive succeeding cycles of infection, disease and transformation to a new host. Active pulmonary TB patients are highly contagious as they cough Mtb-carrying droplet nuclei (infectious droplet) into the atmosphere and this cough-induced aerosol generation is the principal mechanism through which TB spreads. The residues of the dried respiratory droplet are small in size (5 to $10 \mu \mathrm{m}$ in diameter) and contain low TB dose (1-10 bacteria) [8]. TB is primarily a lung infection but can cause multi-systemic disease [27]. Arrival of Mtb into the lung can result in a few possible outcomes. First, host phagocytic cells could effectively eliminate the bacteria. Second, an immediate onset of an active disease called primary TB could take place. The third option, which is the most common, the bacteria and host coexist pacifically, a condition often referred to as latent TB infection or LTBI. Lastly, the onset of disease can occur many years after the latent infection called reactivation TB. Regardless of 
this, TB has often been considered as a distinct binary state of infection (asymptomatic) or disease (symptomatic) [28]. The body's ability to maintain an asymptomatic state of infection where the bacteria is dormant or persistence is dependent upon the integrity of the host's immune system. During LTBI, which occurs in $90 \%$ of infected individuals, the immune cells accumulate at the site of infection to form granuloma or tubercle. On the one hand, this characteristic structure suppresses the bacteria replication and prevent its dissemination, but on the other hand, it also provides a protective shield to bacteria from immune cells. LTBI can be defined as a clinical condition referring to an organism persisting for many years within a host without evidence of clinically manifested active TB, but with evidence of infection such as positive tuberculin skin test (TST) or the Interferon-gamma release assay (IGRA) test. Moreover, people having LTBI cannot transmit the disease [29].

The virulence factors of Mtb allow the bacteria to counter host-exerted harmful environment, interfere with host signaling pathways, evade immune clearance, survive and replicate in the host. Primary disease or reactivation is generally considered as the failure of the host's immunity. It develops in a significant minority of individuals (almost 5 to $10 \%$ of the infected individuals) and can result in fatal outcomes if left untreated [30]. Many risk factors also contribute to active TB such as HIV, diabetes mellitus, malnutrition, transplantation, cigarette smoking, alcoholism, senescence, etc. A key event in the pathogenesis of active pulmonary TB is necrosis at the site of infection or cavitation. So, the presence of a lung cavity together with acid-fast positive bacilli in sputum and coughing reflects the degree of infectiousness. The liquefactive necrotic lesions are also an ideal environment for the growth of extracellular bacteria as macrophages cannot survive in necrotic lesions. These lesions burst into the surrounding blood vessel or airways, facilitating systematic dissemination and to the outside environment through coughing and thereby starting a new cycle [31].

The classic symptom of active pulmonary TB includes a chronic cough associated with hemoptysis (due to blood vessels disruption), respiratory insufficiency, weight loss and night sweats. Many patients also experience fever, chest pain and weakness [30].

\section{The Granuloma}

Granulomas are a prominent histopathological feature of TB and thus TB is known as chronic granulomatous disease. A TB granuloma is a well-organized structure that has an innate immune microenvironment, formed primarily through the coalescence of recruited macrophages around Mtb-infected macrophages, but the involvement of adaptive immunity make it a more stable and dynamic structure [32]. Granuloma makes the boundary wall between protection and pathology and the stability of these structures are driven by the ratio of proinflammatory and anti-inflammatory cytokines and chemokines along with cellular and molecular events. The TB granuloma has been classically thought of as a host protective device designed to wall-off the pathogen, but it also provides a niche for bacterial persistence to maximize its chances of transmission and where bacteria are more recalcitrant to TB treatment [33].

Granulomas are heterogeneous structures that vary even within a single host. The mechanistic inside in the behavior of Mtb-containing granulomas mostly comes from animal models such as zebrafish, mice, rabbit, guinea pig and non-human primates [34]. The 
bacterium-host interaction within the granulomatous tissue results in histologically different types of granulomas in human: solid granulomas are formed at the initial stage of infection and prevail during LTBI while necrotic granulomas are seen in the early stage of active TB and caseous granulomas are signs of severe TB [35]. Although the mouse is the most common animal model used to study TB, it does not develop the cavitating, necrotic granulomas as seen in other animals [36-38]. However, new mouse models have been shown to generate mature granulomas $[39,40]$. Infected alveolar macrophages through induction of pro-inflammatory cytokines recruit mononuclear phagocytes, the building block of granuloma, to form an inflammatory focus which matures into granuloma. Recruited Dendritic cells (DCs) exit the granuloma and enter the lymphatic nodes where they trigger the adaptive immunity. T-cells mediated immunity develops after two to three weeks of infection. A typical solid granuloma structure consists of a variety of infected and non-infected phagocytes including different macrophage subsets (differentiated foamy macrophages, epithelioid cells and large multinucleated giant cells) that are interspersed with recruited natural killer (NK) cells, DCs and neutrophils and are surrounded by lymphocytes, including T-cells and B-cells, in association with a fibrous cuff of collagen [41]. Once the bacteria are trapped into this structure, hypoxia, nutrient starvation and pressure from the adaptive immunity put the mycobacterial growth in check $[35,42]$.

Many studies challenge the host protective nature of granuloma. Granuloma formation is dependent on ESAT-6 as shown in an in vitro lung tissue model [43]. The RD1-deleted strain of M. marinum displays more delayed and small granuloma formation than wild-type bacteria [44]. Zebrafish models also show that mycobacteria use granuloma for its benefit and can escape engulfing macrophages using ESAT-6 [45].

Granuloma formation is a dynamic process where more and more cells move in the structure and grow in size [46]. As the disease progresses, small and solid granulomas will advance to form large, mature necrotic granulomas. Necrotic granulomas are non-cavitating closed granulomas that contain a central necrotic area that is acellular and have hypoxic environment. The central part shows a cheese-like appearance under the microscope. The entrapped bacteria in such granulomas start replicating and become metabolically active. Caseous granulomas are typical of TB where the central necrotic area becomes entirely acellular and liquefied. In the central lesion, high oxygen content is re-established, which promotes logarithmical growth of extracellular bacteria resulting in the characteristic cording phenotype [42,47]. Neutrophil may play a villain role here and not only contribute to the progression of the disease but may also trigger the initial necrosis. Granuloma necrosis and caseation give rise to lung cavity as the liquefied region subsequently spill out its necrotic debris which also releases the captive bacteria into nearby tissues or airways, promoting Mtb transmission [48,49]. 

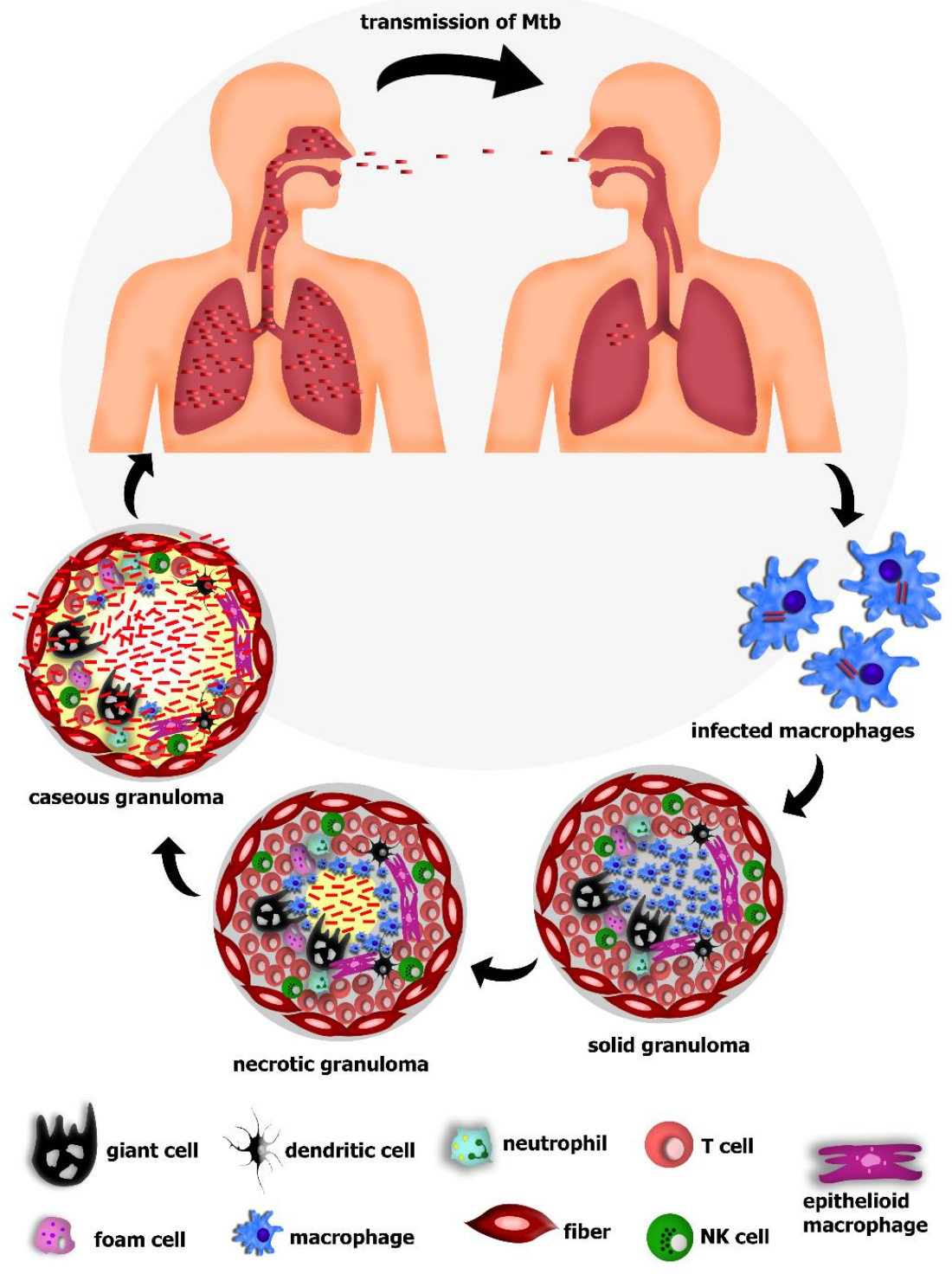

Figure 2. Life cycle of Mtb. A schematic illustration of how Mtb transmits from individuals with active TB to naïve individuals. If successful, it passes through different stages of granuloma to eventually cause disruption of the caseous granuloma and spread to new individuals. 


\section{Diagnosis}

In low- and middle-income countries, active pulmonary $\mathrm{TB}$ is usually diagnosed by the patient's appropriate history, clinical symptoms and/or microbiologic evaluation of Mtb by sputum-smear microscopy, culture techniques and chest X-ray. Sputum microscopy involves the examination of the Ziehl-Neelsen-stained specimen on a glass slide under a light microscope. Individuals harboring the largest numbers of acid-fast bacilli in their sputum are considered the most infectious. Although direct microscopy has the advantages of being a simple and inexpensive test, it lacks sensitivity, especially when the number of bacteria is low in the tested sputum, as is often the case in children and very debilitated individuals. Use of fluorescence microscopy can increase the sensitivity, but this, in turn, becomes expensive. Microbial culture also remains as an essential inexpensive traditional diagnostic test, but it also has some limitations such as of Biosafety laboratory 3, time-consuming and requires rapid transportation of sample to the laboratory [50]. In the absence of clinical disease, LTBI is indirectly diagnosed by the presence of a specific cellular immune response directed towards mycobacterial antigens such as with the tuberculin skin test (TST). TST was discovered in 1907 and was an important contributor to the decline of TB in the Western World and still remains the most cost-effective test. This epidemiological surveillance method, currently disseminated throughout the world, is based upon the intradermal injection of purified protein derivative (PPD). The PPD solution contains different TB antigens. A patient who mounts the cell-mediated response to tuberculin antigen has a delayed-type hypersensitivity response usually within 48-72 hours, causing measurable induration at the injection site, due to the migration of mononuclear cells to the area as a result of an inflammatory process. The test should be performed by an experienced person, as a result depends upon exact intradermal injection and it is difficult to interpret. The response can be attributable to the infection of Mtb, exposure to nontuberculous mycobacteria, or receipt to BCG vaccine [51]. In 2011, the Interferon-gamma release assay (IGRA) was introduced. It is also an immunological test involving the detection of IFN- $\gamma$, a typical cytokine released by lymphocytes in response to three important mycobacterial proteins, i.e., ESAT-6, CFP-10 and TB7.7. Although IGRA is a widely used diagnostic method, it also suffers from some limitations like lack of data in children and immunocompromised patients [51]. The majority of new diagnostic technology in the pipeline are molecular tests. Since the global plan was introduced by WHO many new molecular diagnostic tests have emerged. These tests have the technical capacity to overcome the limitations of conventional laboratory techniques, discussed earlier. The majority of molecular tests have been aimed at the detection of Mtb specific nucleic acids, both in DNA and RNA, by using amplification techniques such as loop-associated isothermal amplification and simultaneous amplification testing. The major advantage of molecular detection modalities is the speed of detection, high sensitivity and ease of use. Xpert Mtb/RIF is also a highly specific and sensitive method involving the detection of gene mutations that are related with the resistance to rifampicin by sequencing and nucleic acid hybridization [52]. Overall, there is still a need of community-based, cost-effective, sensitive, user-friendly and rapid diagnostic tests. 


\section{Treatment}

Approximately 70 years ago there was no drug to treat $\mathrm{TB}$ and the drugs, which were discovered in the 1950s and 1960s are still used as first-line anti-TB drugs. Treatment of TB is a difficult task as it requires administration of multiple drugs over a long period of time. The standard chemotherapeutic regimen to treat TB consists of first-line drugs such as INH, RIF, pyrazinamide (PZA) and EMB for an initial two-month phase followed by a continuation phase with INH and RIF for four months. Resistance to anti-TB drugs is a phenomenon that occurs mainly due to poorly managed TB care and because of ineffective treatment, TB becomes a devastating disease throughout the world. Drug-resistant TB (DR-TB), essentially a man-made problem, is an emerging global health threat. The DR-TB is treated with second-line drugs which is a more complex, longer, expensive and poorly tolerated regimen than standard treatment. MDR-TB is defined as TB with resistance to, at least, the two most potent first-line drugs, INH and RIF, while XDR-TB is defined as MDR-TB plus additional resistance to second-line drugs, namely, at least, any of the fluoroquinolones and any of the three injectable drugs (amikacin (AMI), kanamycin (KAN) and capreomycin). The treatment of LTBI usually employs a single antibiotic while active TB disease is best treated using a combination of different antibiotics in order to reduce the risk of antibiotic resistance against the bacteria [53,54]. (TB treatment is discussed in detail later in a separate chapter).

\section{Vaccination}

So far, BCG is the only licensed TB vaccine for human use. The vaccine was prepared in the early $20^{\text {th }}$ century by Calmette and Guerin consisting of a live attenuated strain of M. bovis which was passaged over 200 times. The vaccine was first administered orally in 1921. Since then the vaccine has been extensively studied in clinical trials to evaluate its efficacy for preventing TB. The studies showed that although it is effective in protecting disseminated TB in infants, children and TB meningitis, it shows variable effectiveness in protection against pulmonary TB in adults. A study also showed that revaccinating with BCG during adolescence in a population vaccinated with BCG at birth does not improve the protective efficacy [55]. This vaccine is also not suitable for HIV patients as it contains a live mycobacterium. Therefore, a more effective TB vaccine is required that has a significant effect on global TB control [56]. 


\section{Chapter 2: Mycobacteria and Innate Immunity}

\section{Human Lung Morphology}

The lung microenvironment is the primary site of TB infection and thus act as the initial "battlefield" between host and pathogen. The restraint of innate (and ultimately adaptive) immunity occurs throughout the entire body and thus in the lung as well. The human lung can be divided into two functionally distinct compartments: conducting airways and the lung parenchyma [57]. The conducting airways of the lung, consist of trachea, bronchi and terminal bronchioles, have ciliated epithelium and mucus secretion that contribute to biophysical host defense. Mucus, together with the coordinated beating of cilia, forms the mucociliary escalator, towards pharynx, for the particles having a diameter more than $10 \mu \mathrm{m}$ where their removal is aided by coughing, sneezing and swallowing [36]. Multiple immune cell lineages are also present in the airway mucosa out of which the most abundant are DCs and macrophages. Lymphocytes can also be found either intercalated between airway epithelial cells or within the underlying lamina propria [58]. The parenchymal lung is composed of respiratory bronchioles that extend to alveolar ducts and further branched into blind-ended alveolar sacs containing a number of alveoli. The main three cell types in the alveolus are type I and II alveolar epithelial cells and alveolar macrophages. These cells are coated by alveolar fluid and surfactant produced by type II alveolar epithelial cells. Bronchoalveolar lavage (BAL) shows that in the steady-state conditions, alveolar macrophages are the most abundant cells (more than $90 \%$ of the total cell population) in the alveolar space, the remainder being mainly DCs and T cells [57].

\section{Innate Immunity in the Lung}

Innate immunity is the most primitive system in multicellular organisms that provides early host defense against a wide variety of pathogens. The fundamental basis of this system is recognition of pathogenic biosensors known as pathogen-associated molecular patterns (PAMPs) by a series of secreted, cell surface and intracellular conserved structures named pattern recognition receptors (PRRs). This recognition is followed by the phagocytosis and killing of many microbes through activating cellular defense and early humoral mechanisms [36]. Here, we will discuss mostly the role of macrophages as an innate immunity component against the mycobacterial defense in human lungs.

\section{Innate Immune Cells}

Epithelial cells being first host cells encountering invaded pathogens, play an essential role in host defense, inflammation and regulate innate and adaptive immune responses [59]. Airway epithelial cells (AECs) mainly secrete surfactant phospholipid and proteins as well as lysozymes and antimicrobial peptides. Surfactant produced by type II AECs contains surfactant proteins (SPs) such as SP-A, SP-B, SP-C and SP-D. SP-A enhances macrophage phagocytosis of Mtb while SP-D agglutinates Mtb, which decreases macrophage phagocytosis [60]. These cells also secrete a lot of antimicrobial peptides out of which LL-37, $\beta$-defensin 2 and hepcidin play an important role in innate immunity against Mtb infection [61]. DCs are mostly present 
in the conducting airways. DCs can phagocytose Mtb, but they cannot kill it. They can sense bacteria through multiple PRRs and following ligation they migrate to the lymph node for antigen processing and presentation [36]. Polymorphonuclear Neutrophils (PMNs) are professional phagocytes that are well-known key determinant of innate immune response to bacterial infection. In case of Mtb infection, PMNs are among the first innate immune cells to migrate from blood to lung at the early stage of infection, but there is no strong evidence of their direct anti-mycobacterial role in controlling Mtb infection in TB patients' lungs [62]. However, a study performed on TB contacts showed an inverse relation between risk of mycobacterial infection and neutrophil counts and that Mtb killing is mediated by antimicrobial peptides [63]. Different studies generated conflicting results about PMNs anti-mycobacterial activity [64,65]. Apart from their direct role, studies showed that Mtb-induced apoptotic neutrophils could cause the maturation of DCs and could also enhance the capacity of infected macrophages to control the infection [66,67]. Efferocytosis is the process of engulfment of apoptotic cells mainly by macrophages, resulting in the improved killing of mycobacteria, which could be mediated by engulfed neutrophil antimicrobial contents like $\alpha$-defensin [68]. Clinical studies and animal models based on active TB disease have shown neutrophils as predominant cells not only in serum and BAL fluid but also within the inflammatory lung granulomas [69,70]. Furthermore, neutrophils can also capture mycobacteria in neutrophil extracellular traps (NETs) composed of DNA and antimicrobial peptides [71]. NK cells are granular innate lymphocytes that are known to produce cytokines, antimicrobial mediators and hold potent cytolytic capacity that can be suppressed by Mtb [72]. They are found in high number in the pleural fluid of TB patients [73]. They can recognize and lyse Mtb infected macrophages using NKp46 receptors [74]. They are an essential source of IFN- $\gamma$ in BCG vaccinated infants and thus essential for driving the memory response associated with BCG vaccination. NK cells may also be involved in "trained immunity" in BCG vaccinated individuals. Activated NK cells produce IL-22 which promote phagolysosomal fusion in infected macrophages [75].

The adaptive immune response to Mtb becomes detectable 3-8 weeks after infection, and $\mathrm{CD} 4^{+} \mathrm{T}$ cells play a critical role in the outcome of infection [76,77]. Many innate immune cells have shown their role in activating $\mathrm{T}$ cells, but DCs are critical and required for migration to the lymph node [78-81]. $\mathrm{CD}^{+} \mathrm{T}$ cells also play an important role in TB patients [82]. The central role of T helper 1 cells (Th1) in the defense against Mtb infection is the release of IFN$\gamma$, a primary mediator of macrophage activation (discussed later).

\section{Macrophages and their Phenotypes}

Macrophages are endowed with remarkable essential roles for homeostasis, development of tissue and host defense. Macrophages, developed from progenitors in the bone marrow, differentiated into mature monocytes in the periphery and further into macrophages when recruited to the tissue to maintain homeostasis or as a result of inflammation or infection. They are present in almost all tissues throughout the body but are more abundant in the gastrointestinal tract, spleen, liver, lungs and brain. These cells recognize, bind and internalize foreign particles through the cell surface receptors and in response mediate antimicrobial activity and can prime adaptive immunity through cytokine production [83]. The Alveolar 
macrophages stand as guardians at the alveolar-blood interface and constitute the first phagocyte defense against particulates including Mtb. The fate of alveolar macrophages and Mtb interaction depends upon alveolar macrophages' intrinsic capacity, inhaled Mtb strain's pathogenic characteristic and the inflammatory microenvironment at the site of infection. Alveolar macrophages are enriched by a subset of surface PRRs to clear microbes without causing excessive inflammation. So, alveolar macrophages have high phagocytic and clearance properties, but reduced antimicrobial properties and poor antigen presentation capabilities and thus, Mtb take advantage of alveolar macrophages' properties to reside and multiply within them [83].

Macrophages also express heterogenous phenotypes in response to altered microenvironmental cues which reflects their plasticity and adaption to different anatomical and immunological locations. Thus, the function of macrophages correlates with the microenvironment especially the type and concentration of cytokines [84]. Macrophages have been categorized into two major reversible phenotypes: the pro-inflammatory, "classically" activated M1 type macrophages (differentiated in in vitro culture by LPS, TLR ligand or IFN- $\gamma$ ) and the immunoregulatory, "alternatively" activated M2 type macrophages (differentiated in in vitro culture by $\mathrm{T}$ helper 2 (Th2), (interleukin) IL-4, IL-13 and glucocorticoids) [85]. M1 macrophages are associated with the high microbicidal activity, synthesis and release of pro-inflammatory cytokines, efficient antigen presentation, phagocytosis and cytotoxic activity against cancer cells. Murine M1 macrophages also mediate the synthesis of reactive oxygen species (ROS) and release of nitric oxide (NO). M2 macrophages mediate Th2 type immune response. They produce a large amount of the antiinflammatory cytokine IL-10 and are associated with tissue repair. Macrophage heterogeneity has a direct impact on Mtb interactions in different tissue environments [84]. At the granuloma level, macrophages show a spectrum of functions and their polarization drive the formation, development and outcome of the granuloma [86]. A study based on a mouse model showed that the initial stage of granuloma formation contains a higher percentage of M1 macrophages characterized by increased expression of inducible nitric oxide synthase (iNOS) [19,87]. Mycobacteria have the potential to modulate macrophage polarization [88].

\section{Pattern Recognition Receptors (PRRs)}

Small particulates $(<5 \mu \mathrm{M})$ can avoid the upper airway ciliary beat, the cough reflex and mucus clearance mechanism to travel down the trachea and bronchi to ultimately settle into the alveolus. Macrophages express an array of PRRs at the cholesterol-rich domain of the plasma membrane that play an important role in the recognition of mycobacteria. The best known among PRRs are Toll-like receptors (TLRs), nucleotide-binding oligomerization domain-like receptor (NLR), C-type lectins receptors (CLRs), scavenger (SRs) and complement receptors (CRs).

\section{Toll-like Receptors (TLRs)}

TLRs represent a structurally conserved family of transmembrane PRRs that are expressed by many pulmonary cells including alveolar macrophages, epithelial cells and DCs $[36,89,90]$. Out of 10 human TLRs, only TLR1, 2, 4, 6 (exposed on the surface) and 9 (expressed intracellularly) recognize mycobacterial components [91]. TLR2 alone is activated by 
mycobacterial cell wall lipids like lipomannan (LM), LAM and phosphatidyl-myo-inositol mannoside (PIM) and a 19-kDa lipoprotein, while a heterodimer formation with TLR1 or TLR6 is required to recognize diacylated or triacylated lipoproteins [92]. TLR4 is ligated with heat shock protein 65, secreted by different mycobacterial species and TLR9 recognizes mycobacterial CpG motifs [91,93]. Many of the TLRs' downstream signal transduction is mediated by binding to the adaptor protein Myeloid differentiation factor 88 (MyD88) which induces the expression of NF-kB through a cascade of protein recruitment [94]. A study showed that MyD88-deficient mice are highly susceptible to mycobacterial infection [95]. TLR2 stimulates the production of IL- $1 \beta$, tumor necrosis factor- $\alpha$ (TNF- $\alpha$ ) and IL-12 in macrophages while TLR4 induces autophagy that could enhance mycobacterial localization within the autophagosome [96,97]. Studies also showed impaired granuloma formation and defective control of chronic mycobacterial infection in TLR2-deficient mice [97]. On the side of mycobacterial benefit, mycobacteria use many strategies to inhibit pro-inflammatory cytokine production mediated through TLR2 [91]. ESAT-6 of mycobacteria can for example bind to TLR2 and inhibit IL-12 stimulation in RAW macrophages [98,99].

\section{Nucleotide-Binding Oligomerization Domain (NOD)-like Receptors (NLRs)}

Although Mtb is an intra-phagosomal pathogen, it can escape the phagosome and enter into the cytoplasm [100] where it can activate the intracellular PRRs. The NOD-like receptors (NLRs) are cytosolic sensors of the PRR family and so far more than 20 members of these receptors have been identified in humans [97]. NOD1 and NOD2 are the first identified NLRs and also the most studied ones as well. NOD2 activation by mycobacterial antigen results in high expression and activity of iNOS and NO production in human macrophages and this activity is mediated by NF-kB induction [101]. NOD2 is also involved in IL-1 $\beta$ production and macrophages and DCs derived from NOD2-deficient mice showed impaired production of proinflammatory cytokines and NO upon pathogenic mycobacterial infection [102,103]. Mycobacterial growth in human alveolar macrophages can be restricted through proinflammatory cytokine release following NOD1 stimulation [104].

Another member of the NLR family that can sense mycobacterial antigen is NLRP3 which is known to form a multi-protein complex structure called the inflammasome. Increased expression of IL-1 $\beta$ in human macrophages is mediated by activation of the NLRP3 inflammasome and caspase- 1 by ESAT-6 [105]. IL-1 $\beta$ is an important pro-inflammatory cytokine in the innate immunity against mycobacteria [92]. Our group has shown that genetic variation in macrophage's NLRP3 inflammasome and its adaptor protein CARD8 results in better control of Mtb infection through increased IL-1 $\beta$ production [106]. Mycobacteria could inhibit inflammasome activation for its protection and thus decrease the production of IL-1 $\beta$, by using a zinc metalloprotease (zmp1) [107].

\section{Complement Receptors (CRs)}

CR1, CR3 and CR4, expressed on the surface of phagocytic cells, promote pathogenic mycobacterial ingestion both in an opsonized and non-opsonized way. For opsonized entry, CR3 is the main receptor involved, while non-opsonized entry is mediated through both CR1 and CR3 receptors [108]. In case of non-opsonized phagocytosis, Mtb capsular polysaccharides 
are used as ligands [109]. However, it is still unclear if this route of entry is critical for inhibition of mycobacterial growth by the host cell.

\section{C-type Lectin Receptors}

This is another family of cell surface receptors that recognize extracellular carbohydrate-based PAMPs on pathogens. The main receptors involved in mycobacterial infection are mannose receptors (MRs), dendritic cell-specific intracellular adhesion molecule-grabbing non-integrin (DC-SIGN) and dendritic cell-specific receptor-1 (Dectin-1).

Dectin-1 is expressed on all phagocytic cells and a subset of T-cells. It recognizes Mtb through an uncharacterized ligand and ligation results in inhibition of growth of non-virulent strains of mycobacteria, but not virulent strains. In airway epithelial cells Dectin-1 and TLR2 in conjugation promote cytokine production, in DCs its activation triggers the production of IL-12 and in human monocyte-derived macrophages (hMDMs) it promotes Th1/Th17 response and production of IL-1, IL23, TNF and IL-16 [110].

DC-SIGN is mainly expressed on mature and immature DCs, but can also be found in a small set of macrophages. Its expression on macrophages can be upregulated by stimulation with IL-4 and IL-13 [111]. This receptor specifically recognizes the mannosylated residues of the mycobacterial cell wall, like mannose-capped LAM (ManLAM) and PIM. It also plays an important role in Mtb-DC interaction and also serves as an adhesion receptor in DC-T cells interaction. DC-SIGN has an immunosuppressive effect as it causes the release of the antiinflammatory cytokine IL-10 during mycobacterial infection [83].

Mannose receptors (MRs), expressed on alveolar macrophages, monocyte-derived macrophages (MDMs) and DCs, are ligated with ManLAM and PIM. Like DC-SIGN they also activate the release of anti-inflammatory cytokines, for example, IL-4, IL-10, and IL-13 and inhibit the production of IL-12 in response to mycobacterial infection. They also delay the phagosome-lysosome fusion and thus promote mycobacterial infection [83].

Scavenger receptors (SRs) represent a broad family of cell surface receptors expressed on monocytes and macrophages and mediate binding of mycobacteria to hMDMs when CRs and MRs are being repressed [112]. Fc $\gamma$ Rs expressed on alveolar macrophages recognizes IgGopsonized bacteria, promote phagolysosome fusion, thus aiding in mycobacteria killing [83]. CD14 is highly expressed on monocytes and macrophages and causes the release of IL-18 by recognizing LAM of mycobacteria. This receptor works in combination with TLR2 and 4 to release inflammatory cytokines from human macrophages [112]. 


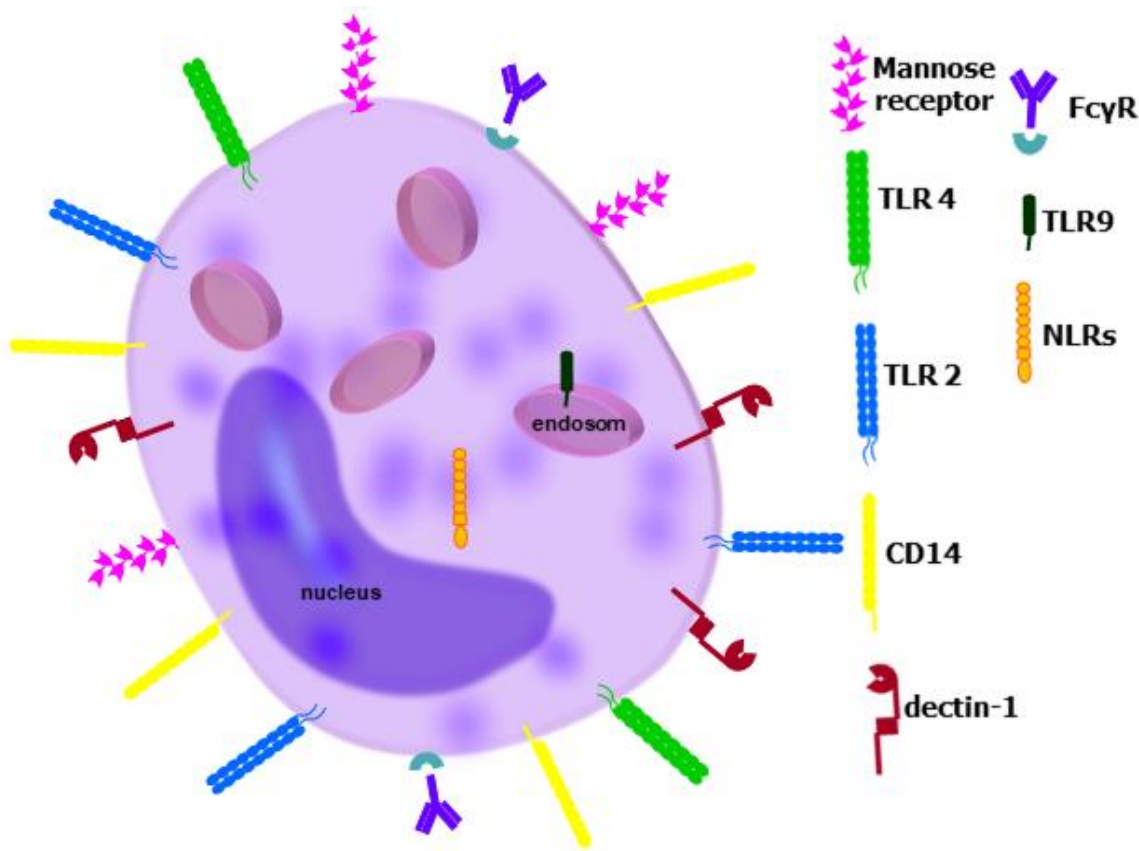

Figure 3. Different PRRs of macrophages involve in Mtb infection.

\section{Cytokine Production}

Cytokines are soluble polypeptide cellular secretions that occur when the body's homeostasis has been disrupted for example during infection. During Mtb infection, both pro-inflammatory and anti-inflammatory cytokines are released depending on the context. There are some cytokines that have both pro and anti-inflammatory effects.

Tumour Necrosis Factor- $\boldsymbol{\alpha}$ (TNF- $\boldsymbol{\alpha})$ has been known since long as a key player in mycobacterial infection as it is involved in the activation of macrophages and can trigger the maturation program in DCs and thereby induce activation of T-cells [113]. Phagocytic cells are the main source of this prototype pro-inflammatory cytokine that is found in abundant quantity in BAL and serum of patients with active pulmonary TB [114]. Mice deficient in TNF- $\alpha$ receptors or TNF- $\alpha$ production showed rapid susceptibility to Mtb growth although the specific reason behind this increased susceptibility is not completely understood [115]. $\mathrm{TNF}^{-/-}$mice also showed decreased reactive nitrogen intermediates production by macrophages [115], delay in chemokines expression, and defective granuloma biogenesis and integrity [116,117]. Interleukin-1 Family (IL-1) contains 11 mediators and regulators of inflammation out of which IL-1 $\alpha$, IL-1 $\beta$ and IL-18 have been studied with respect to innate immunity against Mtb infection [118]. Although IL-1 $\alpha$ plays an important role in host defense against Mtb infection [119], IL-1 $\beta$ has a non-redundant function that cannot be compensated by other cytokines [120]. Monocytes/ macrophages and DCs are the sources of IL-1 $\beta$, a matured form of pro-IL$1 \beta$ and this maturation is mediated by the enzyme Caspase- 1 which in turn is activated by the 
inflammasome (mentioned earlier) and as with TNF- $\alpha$, it is also released in high quantity at the site of infection of active TB patients [97,121]. IL-18, originally identified as a Th1 differentiating factor, is also released as a pro-cytokine and induces IFN- $\gamma$ response in synergy with IL-12 [122]. However, its protective role in Mtb infection is controversial as in some instances, it showed a minor role in protective immunity against Mtb infection [123,124], but in another condition, it is documented as potent as MyD88 in controlling TB in mice [125]. IFN $\gamma$ is a potential substitute marker of Mtb infection. As mentioned earlier, its production is regulated by IL-12 and IL-18. Although it is produced by many innate and humoral immune cells, CD4+ and CD8+ T cells are the primary sources of IFN- $\gamma$. Its classic function in host defense against Mtb infection is macrophage activation and induction of respiratory burst in infected macrophages [126]. IFN- $\gamma$ synergizes with TNF- $\alpha$ in activating macrophages, as blocking of endogenously produced TNF- $\alpha$ reduced IFN- $\gamma$-mediated macrophage activation [127]. TB patients demonstrate a high plasma level of IFN- $\gamma$ which decrease upon treatment [128]. Its contribution in Mtb killing is by promoting antigen-presentation and recruiting CD4+ T-lymphocytes and/or cytotoxic T lymphocytes [129]. On the other hand, Mtb could suppress IFN- $\gamma$ production by peripheral blood mononuclear cells (PBMCs) in patients with active disease and also inhibit macrophages from responding adequately to IFN- $\gamma$ [130,131]. Interleukin-12 (IL-12) produced by phagocytic cells upon Mtb phagocytosis is also detected in the lung infiltrates and granulomas of patients with active TB [132]. As described earlier it induces IFN- $\gamma$ production together with IL-18. One of the earlier studies showed that IL-12 supplementation to the Mtb-susceptible Balb/c mice doubled their survival time and delayed the lung pathology [133]. Interleukin-6 (IL-6) possesses both pro- and anti-inflammatory properties as in one study IL-6 deficient mice were shown to be highly susceptible to Mtb during early infection [134], but opposite to this, it was also shown to inhibit the production of TNF- $\alpha$ and IL-1 $\beta$ induced by LPS [135]. Interleukin-23 (IL-23) also secreted from innate immune cells works in synergy with IL-12 in protection against Mtb infection. The protective role of IL-23 is more prominent in the later stage of the disease. IL-12 and IL-23 are also connected with adaptive immunity by means of Th1 and Th17 cell activation and production. Th17 cells are critical in controlling TB as active TB patients showed a reduced number of these cells [129].

The war between human immunity and Mtb has been going on for the duration of mankind's existence. Mtb is a strong opponent which counteract human immunity in all possible ways. One of the ways is the induction of anti-inflammatory cytokines. Interleukin4 (IL-4) and Interleukin-10 (IL-10) are the two anti-inflammatory cytokines which Mtb uses in its favor against host defenses. IL-4 is involved in the deactivation of macrophages [136] and downregulation of IL- 2 receptors expression [137]. IL-4 can be considered as a potential marker of active TB as it is present in high quantity in active TB patients and also those with cavitary TB $[138,139]$. It could also downregulate TLR-2 and TNF and increase the production of IL-10 [129,140]. IL-10 causes a deleterious effect in TB infection by downregulating the macrophages MHC class II expression and thereby suppressing the T cell proliferation [141]. It can downregulate the production of IL-12 and TNF- $\alpha$ expression. It facilitates Mtb growth by inhibiting phagosome maturation. Elevated levels of IL-10 have been found in BAL and sputum of TB patients [142]. However, there is a study which shows an opposite picture of IL- 
10 with a protective role in chronic lung inflammation in mice infected with Mtb while another study shows a similar level of bacterial burden in mice deficient of IL-4 and IL-10 as compared to wild-type mice [143,144].

\section{The Inside Battle of Macrophages with Mtb}

The binding and recognition of bacteria including mycobacteria by macrophages' PRRs initiates an active mechanism and the resulting signaling cascade induces local remodeling of the actin cytoskeleton to form a phagocytosis cup which later encloses to form a large vacuole (approx. $0.5 \mu \mathrm{m}$ ) called "phagosome" with the sequential recruitment of Rab-GTPase proteins into the phagosome membrane showing progression from early to late stage of maturation. Once closed, the phagosome undergoes highly choreographic maturation progress through subsequent fusion and fission events with trans-Golgi transport vesicles, early endosomes, late endosomes and finally, with lysosomes to form a phagolysosome [145]. These interactions cause an acquisition and loss of different stage-specific markers. The newly formed phagosome displays a composition similar to that of the plasma membrane from where it originated, but it acquires the characteristic of early endosomes by recruitment of Rab5 and early endosomal antigen 1 (EEA1). Later as the maturation process continues the phagosome sheds all markers of the early endosome and acquire Rab7 and lysosome-associated membrane glycoproteins (LAMPs), late endosome proteins and finally, the phagosome develops lysosome traits by accumulating proton pump ATPase, MHC class II molecules and various hydrolases including several members of the cathepsin family [146]. MHC class II molecules shuttle the degraded antigenic fragments from the phagolysosome to the plasma membrane where they function in the activation of $\mathrm{T}$ cells in order to generate the adaptive immunity. Beside peptides, microbial lipids are also presented to the adaptive immunity. Vacuolar $\mathrm{H}^{+}$-ATPase (vATPase) is the main driving force for acidifying the phagosomal lumen (4.5 to $5 \mathrm{pH}$ ) during its biogenesis. The low $\mathrm{pH}$ is the prerequisite for the optimal enzymatic activity of most lysosomal digestive enzymes for intracellular bacteria clearance in the phagosome milieu [145].

The notorious success of Mtb as a highly adaptive human pathogen rest upon the modulation of macrophages' phagosomes to make it a preferential niche as the mycobacterial phagosome does not fully acidify with an abnormally high $\mathrm{pH}$ of 6.3-6.5 since it does not fuse with pre-formed lysosomes [36]. Moreover, several reports show that mycobacterial phagosomes are characterized by the persistence of early endosome markers and little acquisition of late endosomal markers. Mycobacterial secreted protein tyrosine phosphatase (PtpA) have been shown to directly interact with the $\mathrm{H}$ subunit of V-ATPase resulting in blocking the assembly of protein pump and subsequent recruitment to the vacuole [147]. Mycobacteria continuously produce lipids during macrophage infection that contribute to mycobacterial pathogenicity. Mycobacterial surface lipid trehalose dimycolate (TDM), in its intact form, acts as a barrier for fusion between phagosome and lysosome [148]. Mycobacterial glycolipid ManLAM and secreted phosphatase SapM can inhibit phagosome maturation by inhibiting the calcium increase in the cytosol, causing a disruption in $\mathrm{Ca} / \mathrm{Calmodulin}$ complex formation with phosphatidylinositol 3-kinase (PI3K). PI3K generates Phosphatidylinositol 3phosphate (PI3P) formation at the phagosomal membrane, which is used as a docking site for several proteins involved in phagosome maturation. The vacuole of immature phagosome also 
cannot recruit PI3P binding protein EEA1 which is responsible for delivery of lysosomal hydrolases, cathepsins and vATPase [149]. Mycobacterial protein kinase G (PknG), a serine/threonine kinase, which has significant structural similarity with eukaryotic serine/threonine kinase, is present in the genome of all pathogenic mycobacteria and is required for the survival of mycobacteria inside the phagosome as PknG-deficient strains cannot resist lysosomal transfer and rapidly gets degraded [150]. A study showed that Mtb zmp1 also play an important role in its survival by interfering with the phagolysosome biogenesis [107]. Mycobacteria apart from producing virulent factor have also evolved mechanisms to utilize host molecules for its survival. Host cell plasma membrane cholesterol is essential for mycobacterial entry and the presence of cholesterol in the mycobacterial phagosome also interfere with phagosome-lysosome fusion. Thus, Mtb utilizes cholesterol to survive in the chronically infected macrophages $[151,152]$. The tryptophan aspartate containing coat protein (TACO) also known as coronin-1 is recruited and retained in the phagosomal membrane of viable mycobacteria, but not found in phagosomes enclosing dead bacteria [153,154]. Coronin1 causes an influx of calcium and activates calcium-calcineurin signaling to block phagosomelysosome fusion however this blockade can be overcome by calcineurin inhibitors [155]. In vitro studies by electron microscopy images have shown that Mtb can also translocate from the phagosome to the macrophage cytosol. M. marinum use an actin-based propulsion system for this escape while in case of Mtb, the ESX-1 system plays an important role [36,156]. Mycobacterial capacity to block their transfer to lysosome is operational in non-activated macrophages, but once macrophages become activated as by cytokines TNF- $\alpha$ and IFN- $\gamma$, mycobacteria are rapidly transferred to lysosomes where they are destroyed by antibacterial activities.

In murine macrophages, the most powerful and important antimicrobial mechanism of action is iNOS and release of NO following activation of TLR by bacterial lipopeptides. However, TLR-induced anti-mycobacterial activity of hMDMs is not dependent upon iNOS activity nor could NO be detected in these cells, but one cannot completely exclude the role of NO in human macrophages. Stimulation of murine macrophages with IFN- $\gamma$ results in autophagy, the cellular process by which a cell degrades its own intracellular compartments. Autophagy is discussed in more detail later.

Rook in 1986 and Crowle in 1987 were the first to show the importance of active VitD3 hormone $(1,25 \mathrm{D} 3)$ in reducing the mycobacterial load in infected human monocytes and macrophages in in vitro experiments in a concentration-dependent manner [157,158]. Activation of the VitD pathway is dependent upon TLR2/1 [159]. The activity is regulated by P13K and mediated through NADPH dependent phagocyte oxidase and downregulation of TACO. Several antimicrobial peptides released from macrophages also have a direct role in Mtb infection such as cathelicidin, DEFB4 and hepcidin. In humans, cathelicidin and DEFB4 are regulated by VitD, but not hepcidin [160]. 


\section{Chapter 3: Macrophage Cell Death Induced by the Cording Phenotype of Mtb}

\section{Biofilm}

The old concept that some bacteria grow more preferably on surfaces in colonial form (biofilm form) than in free-floating form (called planktonic form) was first studied by Antonie van Leeuwenhoek as he used the word "animalcules" meaning aggregates after examining the human tooth plaque using a microscope of his design [161]. In a biofilm, a microbe could switch its lifestyle from single-cell planktonic form to sessile multicellular communities with different patterns of gene expression. This predominant lifestyle of microbes is formed in an extremely diverse environment in response to a variety of environmental triggers. Biofilm is defined as a sessile community of one or more microorganisms, enclosed in a self-generated exopolymer matrix that can settle and proliferate on the biotic or abiotic surfaces [162]. The exopolymer matrix is an insoluble and slimily secretion that is primarily composed of polysaccharides, protein and extracellular DNA and provides nutrition, structural stability and protects the internal cells from inhospitable conditions [162].

These structured consortia constitute a protective mode of growth against environmental challenges, dehydration and antibiotics exposure. From a clinical perspective, a hallmark of a successful pathogen is to colonize the host for a long period of time against the continuous challenges of hostile environment and biofilm confers both resistance to antimicrobials and protection from host defense. The bacteria inside the biofilms are metabolically inactive, non-dividing and several orders of magnitude more recalcitrant to antibiotics named as persister cells by Joseph Bigger in 1944 [163,164]. Although the persisters are found in small numbers inside the biofilm they are capable of repopulating the biofilm following sub-effective antimicrobial treatment. So far there is no clinical drug in use that target explicitly biofilms [163]. The biofilms are well documented for Pseudomonas aeruginosa, Vibrio cholera, Escherichia coli, Staphylococcus aureus, Staphylococcus epidermidis, and Bacillus subtilis [165].

\section{Cording in Mycobacterial Biofilm}

Mtb also fulfills the same criteria of colonization in biofilms as by any other microbe. As early as 1882, Robert Koch first showed that mycobacteria grown in culture, aggregates to form a rope-like structure known as a serpentine cord. Later on, other studies also showed the ability of mycobacteria to form multicellular colonies on hydrophobic solid surfaces or floating as pellicle at the liquid-air interface in a growth medium that resembles biofilm [166]. Several mycobacterial species have been found to exist in multicellular communities in the environment as well as in the clinical setting. Like other organisms, the development of mycobacterial biofilm is highly dynamic and complex and follows the same strategy such as an initial step of surface adhesion or reversible attachment which is then followed by irreversible surface attachment, biofilm maturation (includes sessile growth, matrix synthesis) and dispersion [167]. In previous studies on mycobacterial biofilm, the researchers agreed that 
unlike other bacteria, the initial attachment of mycobacteria to the surface for biofilm formation does not favor by any proteinaceous filaments nor is the three-dimensional structure of mycobacterial biofilm enclosed in usual polysaccharides rather the cell wall components that are involved in biofilm formation, include glycopeptidolipid and mycolic acids [168]. Even though the mycobacteria are non-flagellated microorganisms, they showed a sliding movement on the solid medium surface and this movement is favored by glycopeptidolipid $[169,170]$. The characteristic architecture of mycobacterial biofilm is predominantly waxy meaning it is primarily composed of lipid which could be free mycolic acid, keto-mycolic acid, short chain fatty acid in mycobacterial mycolic acid or polyketide synthase1 generated unknown lipids $[168,171]$. However, in a recent paper, it has been shown that the extracellular material of in vitro Mtb biofilm formed as a result of intracellular thiol reductive stress is primarily composed of polysaccharides with cellulose being the main component [172]. The polysaccharides-rich mycobacterial capsule is also present in the detergent-free medium. Thus, the mycobacterial biofilm is an assemblage of various molecules where the subset of core component could be shared by many mycobacterial species [173].

Observation of biofilms through confocal or scanning electron microscopy revealed that mycobacterial cell clusters grew as long rods or tight bundles aligned in parallels. The orientation of the long axis of each cell within the cord is parallel to the long axis of the cord $[174,175]$. Cord formation or biofilm-like pellicle growth of mycobacteria was initially associated with a surface glycolipid secreted by viable mycobacterial cells known as the cord factor [176] which was chemically identified as TDM in a later study [177]. TDM, the most prominent and abundant mycolic acid-containing compound, is highly toxic when used in an oily vehicle. It is critical for the intracellular survival of Mtb as removal of TDM from mycobacterial surface enhances the mycobacterial killing by murine macrophages [178]. Aggregation of TDM coated beads in structures resembling cords showed the strong correlation between TDM and cord formation [179]. It is also involved in a number of host-pathogen interactions such as prevention of calcium-mediated phagosome-lysosome fusion, induction of pro-inflammatory cytokines and granulomatous disease in mice [148,180,181]. Mycobacteria constantly produce TDM and the excessive amount is released in the surrounding environment. Different mycobacterial strains were isolated from pulmonary or extra-pulmonary TB patients and compared on the basis of TDM production. The bacteria isolated from lungs produced more TDM as compared to extra-pulmonary bacteria and also grew faster in the form of thin spreading pellicle resembling cords [182]. TDM also plays an important role in the development of caseating granulomas as administration of TDM in an oil emulsion with/without Mtb in the lungs of mice produced caseating granuloma with Mtb located in fat cells [183]. On the other hand, data showing that TDM is only toxic when present in the oily vehicle, and its presence in all mycobacteria and not only in virulent species questioned its role as a virulent factor of mycobacteria [175,184]. Therefore, even after numerous investigations, the precise role of TDM and clinical pathogenesis of mycobacteria has not been clearly established.

Mycobacteria when cultured in liquid medium without detergent showed strong propensity to attach to each other to form a variety of microscopic or macroscopic pellicle. To overcome this pellicle formation and to get homogenous planktonic growth in in vitro cultures 
of Mtb, Dubos and Middlebrook in 1947 introduced the use of a dispersing agent polysorbate80 (Tween-80) which is still used as a key medium ingredient to grow broth culture of $M$. tuberculosis and other mycobacterial species in the laboratory [173]. Later, studies showed that the use of Tween- 80 has a direct influence on the physical and biological characteristics of the bacteria, especially at high concentration. Addition of Tween-80 in the growth medium of mycobacterial culture manipulate the cell wall's lipid composition, adversely affects the virulence of bacteria, enhance susceptibility towards antibiotics and erosion of mycobacterial capsule, an important virulence factor of mycobacteria [185-187].

Cord formation is the first phenotypic characteristic that is related to the virulence of the bacteria. Some mycobacterial species can generate interchangeable morphotypes on agar medium known as rough $(\mathrm{R})$ and smooth $(\mathrm{S})$ colonies, for example, M. abscessus a fastgrowing mycobacterial species, is responsible for pulmonary infections in patients with cystic fibrosis [175]. R colonies of M. abscessus form irregular dry surface with many wrinkles and crest on solid medium, spreading-climbing pellicle or veil on detergent free liquid medium and showed cording morphology under the microscope. Such morphotype is more pathogenic and has more survival time both in vitro and in vivo. [188,189]. In the 1930s, the mycobacterial strain H37 isolated from TB patients was dissociated into a virulent strain H37Rv and avirulent strain H37Ra by serial passaging on a different medium. In 1947, Middlebrook by establishing the correlation between morphological characteristic and virulence showed that H37Ra does not display cording morphology. Moreover, this strain of Mtb is infectious, but does not replicate in macrophages and is not virulent to animal models in comparison to BCG which is an attenuated strain of $M$. bovis, but retained the ability to replicate in human and mice and shows cording morphology [190,191].

In vivo persistence of Mtb against antibiotics and the host immune cells are the characteristics that could be associated with biofilm formation. Mycobacteria promote diverse microenvironment in the same host. The necrotic lesions or cavities in active TB show hypoxic condition and contain extracellular bacteria that are tolerant to antibiotics and immune cells. The current treatment of tuberculosis involves daily administration of multiple antibiotics for six months despite the fact that the majority of bacteria dies in the first 2 weeks. Thus, the prolonged therapy is to eradicate a small sub-population of non-replicating or slow replicating variants occupying the bacteriostatic environment of the calcified lung lesions although the molecular mechanism underlying the mycobacterial persistence is not known [192]. These persisters can be identified in the negative culture smear of treated patients. An animal study showed that mycobacteria which survive the drug treatment colonize the microenvironment of necrotic lesions [193]. Other mycobacterial species have also been shown to form multicellular communities in animal models $[194,195]$. The tolerance of mycobacterial biofilm is believed to be the cumulative effect of the extrinsic factors such as biofilm matrix and intrinsic physiological adaption in the resident population. However, there are still lacking strong evidence that could show that Mtb in vivo lifestyle is biofilm and it contributes to the drug tolerance [167]. Finally, extracellular mycobacteria found in the caseum of granuloma showed cording phenotype 


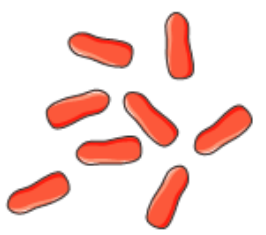

Planktonic

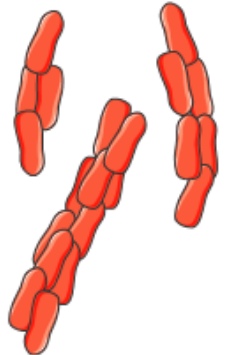

Cords

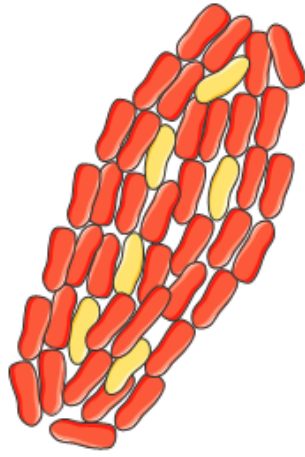

Biofilm

Figure 4. Different phenotypes of Mtb. Biofilm phenotype shows the presence of a small sub-population of persisters.

\section{Cell Death}

Cell death is the primitive and fundamental defense mechanism of the innate immune system against the invading pathogens. Mtb as a facultative intracellular pathogen must exit its infected host to enter and establish infection in a new host and for this, it uses the niche of mononuclear phagocytes. As TB pathogenesis is influenced by the death modality of Mtb-infected macrophages therefore, different cellular fates are very important. Macrophage defense mechanisms include apoptosis and autophagy, but mycobacteria try to manipulate it and lead the cells towards necrosis [196]. The sensing of the intracellular pathogen by macrophages at the initial stage of infection results in autophagy. Autophagy is a regulated homeostatic response conserved in all living cells degrading their own dysfunctional or unnecessary cellular components. In autophagy, the damaged organelles are sequestered into a double-membrane vesicle called autophagosome that is transported to lysosome to become autophagolysosome. Mtb is one of the first bacteria that recognize as the target of autophagic removal [196]. In vitro IFN- $\gamma$ stimulation, Vitamin D3 treatment and TLR4 signaling induce autophagy-mediated intracellular killing of mycobacteria [197-199]. Mycobacteria as a successful human pathogen could impair autophagy at the step of autophagosome-lysosome fusion through an ESX-1 mediated mechanism and use the intracellular environment as a replicating niche [200]. Apoptosis is an energy-dependent tightly regulated process for host cell defense to minimize inflammation. This process not only eliminates the replicating niche, but also expose the pathogen to humoral immunity. In apoptosis, the dying cells enclosed its fragmented nuclear and cytoplasmic contents into membrane-bounded apoptotic bodies. The apoptotic bodies released the "find me" and "eat me" signals that attract neighbouring phagocytic cells to clear them by a process called efferocytosis. The major players in apoptosis are caspases, adaptor proteins, TNF receptors and Bcl-2 family of proteins while phosphatidylserine plays an 
important role in clearing of the apoptotic bodies. The attenuated strain H37Ra and BCG are strong inducers of apoptosis while the virulent strain H37Rv infection has retained various mechanisms to actively block macrophage apoptosis and undergo necrosis [195,201]. Apoptosis is related with reduced mycobacterial viability in vitro however, a study based on live imaging of zebra fish showed that mycobacteria-induced apoptosis through ESAT-6 is host detrimental and enable bacteria to proliferate during granuloma formation [202]. Necrosis, a result of pathological or physiological accidental events, is the loss of outer cell membrane integrity with the release of cytoplasmic and nuclear contents to the extracellular space and provokes inflammation. The cytotoxic activity of mycobacteria in heavily infected macrophages allow their dissemination and disease progression. The necrotic debris or caseum provides the ideal growth environment to the bacteria which grow massively and form serpentine cords [196].

\section{Etosis Leading to Extracellular Traps}

So far, fourteen novel cell death models have been unraveled and one of them is NETosis, reported by Brinkman group in 2004 [203] and named by Steinberg in 2007 [204]. In this programmed cell death, neutrophils are able to kill pathogens outside the cells by disgorging their chromatin into surrounding environment in the form of threads called neutrophil extracellular traps (NETs) [205]. Later on, researchers discovered that the release of chromatin in the form of extracellular traps (ETs) is a more general phenomenon shown by many other immune cells (eosinophil, mast cells and macrophages) through a variety of stimulants, microorganisms and their product and so the cell death was renamed by a more generalized term ETosis by Wartha et al. [206]. ETosis is a well-conserved cell death found in many animals other than humans such as ox, horse, fish, cat and mouse and even in a plant where it plays a key role in protection of roots tips against fungal infection. In contrast to apoptosis, the initial step in ETosis is the decondensation of DNA and the disintegration of the nuclear and granular membrane and they also do not display the "eat-me" signal to prevent their pre-emptive clearance by neighboring phagocytes, but the plasma membrane remains intact, similar to apoptosis. The process of ET formation has been extensively studied in neutrophil. The novel series of cellular events involve in NET formation includes ROS production followed by transport of elastase and myeloperoxidase from granules to the nucleus, histone modification, cytoplasmic membrane disruption and release of chromatin [207]. The unique ultra-structure of NETs composed of long chromatin filaments with 15-17 nm in diameter, decorated with 30 different proteins with a major percentage of histone. NETs are not only released in the form of long filaments but can also form a web-like structure. These network of clouds are formed by joining the ETs of more than one cells [208,209]. Another important step in ET formation is citrullination of histone. Citrullination or deamination is the conversion of arginine into citrulline catalyzed by peptidylarginine deiminases (PADs). In human five PADs enzymes are known, out of which Ca-dependent enzyme PAD4 catalyzes histone citrullination in neutrophils [210]. Inhibition of PAD4 prevent citrullination and significantly reduce NET release [211]. A study based on eosinophil showed that ETs can also release from viable cells without nuclear destruction. These ETs are composed of mitochondrial DNA, lack nuclear histones and possess antibacterial activity [212]. The physiological importance of ETosis is disclosed by many in vivo studies where ETs have been 
found excessively at the site of inflammation caused by infection or non-infection [209]. ETs entrap microorganisms due to the electrostatic interaction between negatively charged chromatin fibrils and positively charged bacterial surface and can kill a variety of microbes $[203,213]$. However, there are some pathogens including Mtb that can be trapped by NETs but are able to escape the NETs-mediated killing [214]. Some staphylococcus and streptococcus species express endonucleases that can digest NET-DNA scaffold and release the microbes from NET-mediated killing [215,216]. NETs have also been found in the serum and blood circulation of active TB patients showing its role in cavitary TB [49,217,218]. Although NETs are believed to be an effective defense mechanism against pathogens, recent research showed that excessive NET formation has been implicated in several pathological conditions like sepsis, atherosclerosis and autoimmune diseases like systemic lupus erythematosus (SLE) and psoriasis suggesting that NET formation is related with exacerbated immune responses and tissue damage. Extracellular DNase I enzyme which plays a vital role in the clearance of necrotic cell's DNA is also important for NETs clearance. In SLE, 30\% of patients are unable to degrade NETs because of low activity of serum DNase I [207]. An in vitro study showed that hMDMs can remove NETs in a cytochalasin D-dependent manner and that this clearance is enhanced if NETs are pre-processed with DNase I [219].

\section{Macrophage Extracellular Traps}

Macrophages have also been reported to use the alternative weapon of ETs to capture pathogens. Chow et al. first revealed that Statin, a drug used to regulate sterol synthesis pathway, potentially mediate the formation of ETs in murine macrophages and named them as macrophage extracellular traps (METs). These METs were capable of inhibiting the growth of entrapped Staphylococcus aureus [220]. Like Statin, diverse pathogens (including both fast and slow growing mycobacteria species) and chemical stimuli can also induce MET formation in many subsets and cell lines of macrophages, as described by other studies [221] . In addition to direct contact with microbes, bacterial virulence factor such as the ESX-1 system of Mtb in the presence of INF- $\gamma$ and leukotoxin from Mannheimia hemolytic can induce MET formation in hMDMs and in bovine macrophages respectively [222,223]. METs share many properties with other ETs such as they are composed of histone-DNA backbone and contain different antimicrobial peptides, can or cannot be dependent upon NADPH oxidase, the DNA is derived from either nucleus or mitochondria, are found in tissues during disease conditions and the filaments can be degraded by DNase I and micrococcal nuclease. However, METs are released in much lesser extent as compared to NETs [224,225]. METs have shown potential microbicidal activity against a variety of microorganisms, but are still less effective as compared to the intracellular killing. On the other hand, M. massiliense, a fast-growing mycobacterial species, has been shown to enhance the bacterial growth potentially by providing a scaffold for bacterial aggregation [226]. Overall, the MET formation has not been as extensively studied as the NET formation and the differential response of MET formation is due to differences in experimental conditions or if some kind of macrophages is more prone to MET formation than other [221].

A recent study showed that ETs from neutrophils are produced in response to large pathogens, such as Candida albicans hyphae and extracellular aggregates of M. bovis, but not 
in response to small yeasts or single bacteria, suggesting that neutrophils can sense microbe size and selectively produce NETs [227]. Furthermore, it has been demonstrated that nonsonicated bacteria induce more METs than sonicated bacteria, which indicates that mycobacterial clumps are more efficient at promoting extracellular traps [223]. Additionally, cord-forming M. abscessus induces the release of DNA meshwork by PBMCs, a phenomenon which is not observed with non-cording strains [228]. Therefore, the formation of ETs might be a defense mechanism against microbes that are too big to be ingested by innate immune cells.

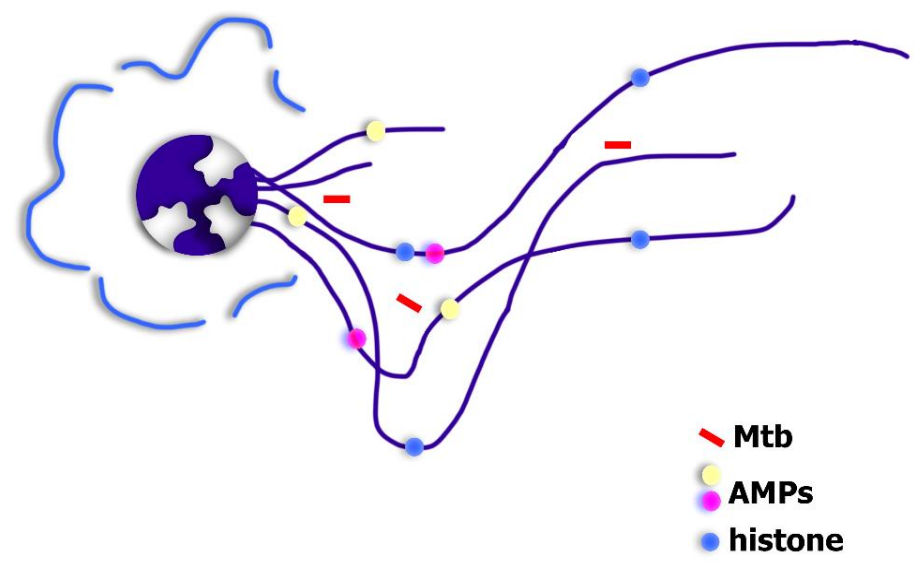

Figure 5. Macrophage extracellular traps. Mtb $=$ Mycobacterium tuberculosis, $\mathrm{AMPs}=$ antimicrobial peptides [226]. 


\section{Chapter 4: TB Treatment}

Following the identification of the antibacterial activity of penicillin, researchers started to evaluate the efficacy of natural and chemical compounds in animal models. An era of chemotherapy of TB began in 1943 when the antibiotic Streptomycin (SM), a natural substance isolated from Streptomyces griseus was introduced and showed its efficacy against Mtb, first in an animal model and then in human. The drug affects polypeptide synthesis. In 1946, it was shown to reduce the TB mortality rate from $27 \%$ to $7 \%$ with 6 months of treatment [229]. SM was good, but far from perfect and just after 5 years, the drug did not remain effective anymore because of the development of antibiotic resistance. Four years later, after the discovery of SM, a new synthetic compound, para-aminosalicylic acid (PAS) was synthesized by a Swedish scientist showing anti-mycobacterial properties. Both drugs were moderately active, had large side effects and quickly developed resistance. By that time, the British medical research council by clinical trials showed that these drugs are more effective when used in combination than alone hence, the first combination of anti-TB drugs were started [5]. In 1951, Isoniazid (INH) was discovered by two different pharmaceutical industries at the same time. The drug was found to be vastly superior to all other anti-TB drugs used at that time and was unique as being less expensive, well-tolerated and safe. Initially, because of its properties, INH was also used alone for TB treatment, but soon it was found out that the drug got resistance and the disease could relapse. Hence in 1959, to prevent drug resistance the first successful, chemotherapeutic regimen based on the combination of INH, SM and PAS was used [230]. So, for almost 20 years, the standard chemotherapy was composed of all three drugs in combination for 2 to 3 months followed by administration of INH and PAS for additional 12 months [231]. Despite such prolonged treatment, there were around $10 \%$ of relapse cases after the discontinuation of treatment. In 1954, pyrazinamide (PZA) was discovered, but it was very toxic at the prescribed dosage while ethambutol (EMB) was discovered in 1961 by random screening of compounds against $\mathrm{Mtb}$ in vitro [232,233]. Animal studies showed the effectiveness of EMB for INH and SM resistant strains and was used in the retreatment regimen. Later, the drug was found to be more effective than PAS even in low doses and replaced it. Finally, Rifamycin was discovered in 1957 in Italy during the investigation of antibiotic properties of a soil bacterium, Nocardia mediterranei, but was not used until the late 1960s when a modified compound rifampicin (RIF) was designed. In 1972, trial on regimens including RIF showed good result with the reduction of treatment time to 9 months. Finally, the rejuvenation of PZA at low doses allowed the development of "short-course" anti-TB chemotherapy for 6 months [230]. The chemotherapeutic regimen that rose up after numerous trials for the treatment of drug-susceptible pulmonary TB in both adults and children was named as first-line drugs (also known as short-course chemotherapy) and is consist of INH, RIF, PZA and EMB for initial 2 months (intensive phase), trailed by a continuous phase of INH and RIF for 4 months (continuous phase). This regimen is routinely practiced in many countries now [229]. Microbiology monitoring of the efficacy of the prescribed regimen is mandatory particularly at the end of the intensive and continuous phases of the treatment. The 
development of chemotherapeutic regimen that can shorten the TB treatment further is the main goal of TB research.

\section{Mechanism of Action and Resistance against First-Line Antibiotics}

INH, a synthetic drug, chemically known as an isonicotinic acid hydrazide, is the most clinically successful compound ever developed to treat TB. It has bactericidal effect against actively-dividing bacteria. In the first 2 days of treatment INH reduces almost $95 \%$ of bacterial load, but after this period it serves to limits the emergence of RIF's resistance. It has also been used as a prophylactic drug for LTBI to prevent reactivation of the disease as the tubercle bacilli could revert from non-growing form to growing form and therefore, become susceptible to INH [234]. The drug has been the subject of intensive research since its discovery and shown to cause multiple effects on tubercle bacillus, but the major breakthrough in understanding its mechanism of action came from a study showing that it interferes with mycolic acid synthesis [235]; yet, the exact nature of activity leading to cell death is still unclear. It is a prodrug that enters the mycobacterial cell through passive diffusion through the cell wall. Inside the bacterium, it is activated by mycobacterial catalase-peroxidase $K a t G$. The generated metabolite produces different ROS, out of which the isonicotinoyl radical inhibits the enzyme enoyl-ACP reductase InhA, involved in mycolic acid biosynthesis [234]. Mutation occurs either in the $K a t G$ gene or in the promoter region of inhA gene [236]. RIF is a semi-synthetic hydrazone derivative of rifamycin. This complex molecule is bactericidal and inhibits initiation of RNS synthesis through impairing the $\beta$ subunit of bacterial RNA polymerase enzyme $[237,238]$. The drug kills both actively dividing bacteria and resting or persistent bacteria with a sporadic metabolic burst. RIF is also used in a regimen for treating LTBI [239]. Resistance is due to a mutation in rpoB gene [240]. PZA is the pyrazine analog of nicotinamide. Unlike other TB drugs, PZA is most effective against old non-growing bacteria, but it works only in acidic $\mathrm{pH}$ of 5.5 [241] and environment formed in active inflammation [242] and because of this fact PZA is shown to be most effective in mice [243], but lacks activity in in vitro culture [244]. The clinically used weak acids, aspirin and ibuprofen, could also enhance PZA activity in the mouse model [245]. PZA is a part of the first-line drugs against drug-sensitive TB, but are also frequently used for DR-TB. It is also a prodrug that enters the cells by both active and passive mechanism, activated with mycobacterial amidase enzyme called pyrazinamidase, encoded by gene pncA, to its active, pyrazinoic acid (POA) [246]. The POA is initially formed in the cytoplasmic compartment which has no bactericidal activity and then it is excreted out where a small part of POA is converted into uncharged protonated POA in an acidic environment which enters the cell again passively, accumulates and kills the bacterial cell [246,247]. It acts through many different pathways such as membrane transport disruption [248], synthesis of fatty acid synthetase [249] and inhibition of trans-translation of Mtb [181]. Mutation occurs in $p n c A$ gene that encodes for pyrazinamidase enzyme [250]. EMB is bacteriostatic in action and acts on extracellular bacteria. It is rapidly taken up by both replicating and non-replicating mycobacteria, but it is active only against replicating bacilli. Initial studies addressed the issue of interfering the drug with the role of polyamines and divalent cations in RNA synthesis [251], but later on, inhibition of arabinogalactan biosynthesis appeared as its main mechanism of action against mycobacteria [252]. It also inhibits the biosynthesis of arabinan core of LAM and can also impair glucose metabolism [253,254]. EMB acts through inhibiting the 
arabinosyltransferases enzymes [253]. Its main role in first-line treatment is to prevent the emergence of resistance to RIF and PZA when unrecognized resistance to INH is already present. Resistance was found in the cluster of genes associated with arabinogalactan biosynthesis [255,256].

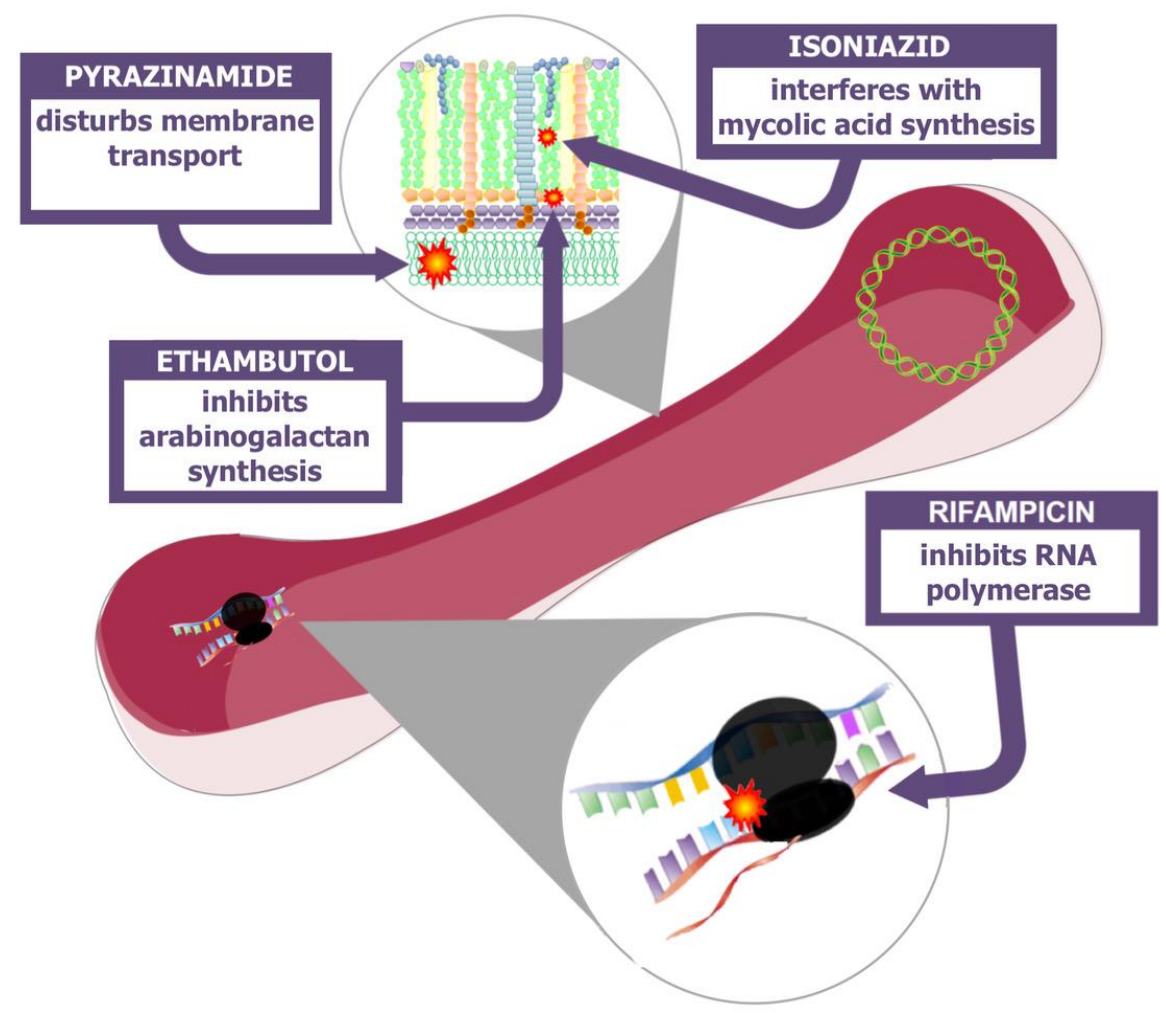

Figure 6. Mechanism of action of first-line antibiotics against Mtb.

\section{Drug-Resistant TB}

The necessity of treating TB with a multi-drug regimen was driven from the fact that Mtb possesses several clinically important biological properties that make it a difficult target to treat. Mtb is a tough and resilient microorganism that acquires unique strategies to prolong its residence within the host. It is a slow-growing bacteria with approx. 12 to 18 hours generation time and it hampers antibacterial treatment since most antibiotics interfere with cell division processes. It has high lipids contents in its cell wall plus the low number of pores provide a solid resistance shield to many antibacterial compounds. Moreover, the cells are hydrophobic and tend to clump together [257]. TB may have a long latent period (vary from months, years and even decades) between infection and clinical illness. In cavitary TB, many different subpopulations of bacteria are present along with drug-sensitive bacteria such as persisters, extracellular bacteria and a population that is found either inside the macrophages or inside the 
solid caseous foci. [230]. The presence of so many sub-populations during infection represents a challenge in TB drug discovery.

Drug resistance is a biological phenomenon that has been seen in Mtb since the advent of the first antibiotic and the cases of increased drug resistance have continued to occur as the TB chemotherapy has evolved. One of the key challenges in TB treatment is the long duration and complexity of the drug combinations and completion rates of long therapies are lower than expected. DR-TB may either result from the primary infection with drug-resistant bacteria (primary drug resistance) or may develop in the course of the patient's treatment when nonoptimal treatment durations or regimens are used (acquired drug resistance) [258]. There is a high risk of acquired DR-TB in HIV co-infected patients because of the malabsorption of the TB drugs [259]. Given the length, complexity and adverse event profile of TB treatments, patient adherence can be difficult to maintain and misuse of drug treatment could result in the emergence of mutated strains with DR-TB. It is paradoxical that Mtb continues to evolve resistance especially in those settings that are least able to deal with it. The situation becomes particularly detrimental if resistance is not identified before the onset of therapy [260]. DR is connected with more costly and longer treatment and inappropriate treatment can have lifethreatening results [257]. DR strains of Mtb pose a serious obstacle to progress in global TB control. Therefore, every effort should be made to promote adherence to the therapy. WHO in 1993 recommended a strategy of DOTS as a backbone of TB control and treatment throughout the world. DOTS implies the need of supervised chemotherapy of a standard treatment by a health care worker even in a resource-limited setting with the goal of increasing completion rate up to $85 \%$. This is also to avoid all the problems associated with self-administration and allow rapid management of adverse events related to the drug intake [8]. This resulted in the decline of TB cases over the past few decades, but despite progress, major gaps exist such as in immune-compromised people (due to AIDS, cancer chemotherapy and organ transplantation), there is increased prevalence of DR-TB [261]. A study based on clinical trials found no improvement in the results between close supervision and other ways of chemotherapy means that it is only the medicine that could improve the TB cases [262]. INH resistance is the most commonly encountered form of anti-TB drugs resistance, whether in isolation and in combination with other drugs. By definition, MDR-TB is resistant to most effective first-line anti-TB drugs: INH and RIF. Based on WHO suggestion four effective drugs should be prescribed in MDR-TB. All regimens should include one first-line drugs (in most cases it is PZA), one of the injectable second-line drugs (AMI, capreomycin or KAN), a fluoroquinolone and other oral second-line drugs such as ethionamide, and cycloserine. The duration of the first phase should depend upon culture conversion, but it should last at least 8 months whereas the duration of the second phase should be longer than 20 months [232,263]. Such prolonged and complicated therapy is not only expensive and possess limited sterilizing capacity, but also cause adverse, toxic side effects, challenging patient compliance to treatment [263]. These dire limitations emphasize the need for new treatment and management strategies for both drug-sensitive and drug-resistant TB. Misuse and mismanagement of second-line drugs may lead to the emergence of XDR- strains. In 2006, XDR-TB was introduced and was characterized as Mtb resistant to either INH or RIF among the first-line antibiotics, any 
fluoroquinolone and at least one of three injectable second-line antibiotics (AMI, capreomycin, and KAN). XDR-TB now possess a more serious threat [258].

\section{Second-Line Drugs}

Globally, the cure rate of DR-TB is lower because the second-line drugs used to treat DR-TB are mostly weak, toxic and used for long duration of 18 to 24 months. The treatment regimen for DR-TB generally include at least four drugs based on drug sensitivity testing of infecting strain plus the patient's treatment history. The synthetic compounds Fluoroquinolones are very key components of the regimen used for MDR-TB. These bactericidal drugs inhibit DNA gyrase causing failure of bacterial DNA supercoiling, inhibiting DNA replication leading to bacterial death [264]. The two most active fluoroquinolones against Mtb are moxifloxacin (MOX) and levofloxacin (LEV) [265,266]. MOX has shown same bactericidal activity as INH against replicating bacteria both in murine models of TB [267,268] and in the human [269]. MOX improved the culture conversion when it was used to replace EMB in the intensive phase of therapy [270]. 90\% of fluoroquinolone resistance is conferred by point mutations in the gyrA gene and therefore susceptibility to fluoroquinolones of clinical isolates should be confirmed if the drug of this class is to be used for TB treatment [264]. Aminoglycosides inhibit protein synthesis by acting on a 30S subunit of the ribosome. Other than SM, this class also includes anti-TB drugs like amikacin (AMI) and kanamycin (KAN). They are often referred to as second-line injectable drugs in the context of treatment of DR-TB. AMI is a semi-synthetic product of KAN which in turn is derived from Streptomyces kanamycetus, a soil bacteria [271]. Linezolid (LIN) belongs to oxazolidinones that inhibits protein synthesis by blocking translation, is used to treat XDR-TB. Its major limitation is a high frequency of hematological side effects which increase with dose and duration of treatment [272]. Clofazimine (CLOF) was first synthesized in 1954 and was highly effective against Mtb in in vitro and mice models, but not effective in the guinea pig and monkey model owing to its poor absorption in later animals, which discouraged its use in TB treatment and instead it was used as an anti-leprosy agent [273]. The drug undergoes enzymatic reduction by mycobacterial type 2 NADH dehydrogenase enzyme and upon subsequent oxidation, leads to the formation of ROS [274]. The drug has now been reused in the treatment of MDR-TB. This drug has very low-frequency of resistance development and at sub-inhibitory concentration, it also inhibits the emergence of resistance to INH in Mtb [273]. CLOF has also been shown to be effective against mycobacterial persisters [275].

\section{New Drugs in the Pipeline}

The Global Alliance for TB drug development showed that new drugs should be developed with an aim to shorten the current treatment, be effective against susceptible and resistant strains, be compatible with antiretroviral therapies for HIV/TB co-infected patients and improve treatment of latent infection. Due to the subsequent rise of DR-Mtb strains coupled with the twinning of TB with HIV/AIDS, the demand to create novel, better medications and regimens for the treatment has been raised. TB treatment regimen has been decreased from 2 years to 6 months, but still very far from ideal. One of the key difficulties in the field of TB medication advancement is that the remedial unit is a mixed regimen, not a solitary medication. Moreover, finding a new drug that is effective against persisters is critically important to 
achieve the goal of completely eradicating TB and potentially shortening the therapy. The best example, in this case, is PZA that is primarily active against persisters and its inclusion in the regimen shorten the TB therapy to 6 months. Pharmaceutical industries showed little potential in TB drug discovery, so the major research investment seen over the past few years in the field of TB drug development has been done by academia but still the progress is slow [276] as the new drugs with potent activity against Mtb has faced the chronic under-funding for TB research as well as insufficient capacity for clinical trials. Delamanid (OPC-67683) is a nitro-dihydroimidazooxazole derivative and a pro-drug that requires reduction of its nitro group by Mtb [277]. It disrupts the metabolism of the cell wall by inhibiting the synthesis of mycolic acid [278]. A regimen containing delamanid, RIF and PZA eradicate bacteria faster than the standard regimen in a murine model [278]. It is effective against both replicating and nonreplicating bacilli [279]. It could upgrade treatment alternative for patients with MDR-TB [277]. It is well-tolerated and also shows good early bactericidal activity in patients with newly diagnosed smear-positive pulmonary TB [280]. Bedaquiline (TMC 207) is a diarylquinoline that kills Mtb by inhibiting membrane-bound ATPase synthesis, resulting in depletion of cellular ATP levels [281,282]. Its early bactericidal activity is similar in magnitude to INH and RIF [283]. It is highly active against many mycobacterial species and also exhibits potent in vitro activity against both drug-susceptible and drug-resistant Mtb strains [281,282]. The drug is a promising new anti-TB drug for MDR-TB as its addition into the standard regimen for MDR-TB reduces the time to culture conversion [284] and prevent the emergence of further resistance to the drugs included in the backbone regimens. However, one study showed more death in the bedaquiline group than the placebo group [285]. Pretonamide (PA-824) is a derivative of metronidazole and is also a pro-drug [286]. It acts on ketomycolate, a fundamental part of the Mtb cell wall and causes respiratory poisoning through the intracellular release of nitric oxide [287]. The drug showed bactericidal activity in both active TB [288] and LTBI [289] in a murine model. It is in combination with MOX and PZA more effective than standard therapy in TB patients [290].

\section{Drug Screening}

Drug discovery is an interdisciplinary, complex, time consuming and expensive process. The introduction of new therapeutic solutions can take more than a decade. Drug discovery projects are fuelled by high throughput screening (HTS) in both academia and pharmaceutical industries and involve automation of standardization of biological and biochemical assays. Traditional HTS can be divided into the target-based and phenotypic screening. Advances in molecular biology and genomics initiated the era of target-based screening in the 1980s and it became a dominant approach to drug discovery in pharmaceutical industries. In target-based screening, the starting point is a defined target (typically a protein) that is identified in basic research and is hypothesized to have an important role in the disease. G protein-coupled receptors, ion channels and enzymes are the most common and successful molecular targets in the drug discovery [291]. This approach had worked well in communicable and non-communicable diseases, but it has had no substantive success against bacterial infectious diseases, including TB. Hits identified by target-based screening mostly failed in late-stage drug development because of multiple factors. A study showed that during 1999 - 2008 from food and drug administration (FDA) approved drugs were mostly discovered from phenotypic screening 
approach as compared to target-based screening [292]. From 2011, the historical drug discovery approach, i.e., phenotypic screening again gain acceptance over the target-based screening. Phenotypic screening explores compounds that ameliorate the disease phenotype in predictive host settings. Consequently, the majority of current screening modalities are utilizing whole-cell determinations of compound potency for bactericidal activities on pathogenic and non-pathogenic mycobacteria [293]. Advances in computational techniques and hardware have enabled virtual screening that is an effective alternative strategy for accelerating and economizing the drug discovery and developmental process. It is more applicable where the structure information is available such as protein structure for structurebased virtual screening or set of known actives in case of ligand-based virtual screening. The first is based on docking a large number of compounds against the 3D structure of the target, while the later based on similarity procedure which states that similar compounds cause similar biological effects [294].

\section{Screening Approaches in TB}

With the sequencing of Mtb genome in 1998, efforts have continued to identify and interrogate specific and vital TB biochemical targets. The underlying problem with the target-based approach in case of TB remains the same as other infectious diseases that is the translation of potent, selective in vitro biochemical activity into the whole-cell, anti-mycobacterial activity. Even though several HTS screening campaigns have been performed against carefully selected targets both in vitro and in silico [295], but none of the highly significant inhibitor caught against the Mtb enzyme shows same effectiveness against the whole bacteria [296,297]. Despite numerous biochemical target-based screening campaigns, success in identifying TB drug candidates has been limited. As a result, there is a pronounced trend toward returning to the phenotypic screening strategy and it is also important to recognize that all current TB drugs were either identified by or derived from Mtb whole-cell screening "hits". Mtb is found in various growth conditions in its host and the most challenging approach in case of phenotypic screening is to replicate such conditions in the screening assay. Screening of chemical compounds has been performed in several mycobacterial models. The main model used is the whole bacterial cell either virulent or a virulent. For primary screening, BCG is a common surrogate to Mtb because of $99 \%$ identical genome and safer handling. M. smegmatis and $M$. marinum, fast growers are used as a substitute for slow-growing Mtb. Bedaquiline, a newly discovered anti-TB drug mentioned earlier, is derived by chemical optimization of a lead compound originally identified from screening campaign against M. smegmatis model [298]. Although technically convenient, the use of Mtb surrogates could lead to the identification of compounds ineffective against Mtb and studies suggested that compounds active against Mtb are best identified in screening against Mtb itself and not by a model organism [299]. Moreover, as Mtb likely exist in different physiological states during infection, there is also an increase trend to target Mtb inside its host cell such as macrophage model since macrophages are the primary target of Mtb [300]. Although being more complex, the testing of drugs in the hostpathogen model has more advantages as it highlights the physiologically relevant phenotype of the pathogen. In case of TB, primary human macrophages are the natural host of Mtb, but human or murine cell lines have been used in phenotypic screening assays as they provide an unlimited number of relatively homogenous cells with consistent phenotype. As TB is treated 
by multiple drugs, another approach is to identify host-directed compounds that augment immunity against Mtb infection and could be used alongside anti-mycobacterial drugs [301]. The drugs that have proven successful in curing other infections are also tested for antimycobacterial activity to be included in the current regimen to shorten the duration of treatment. The most common example is MOX which is highly effective in rapidly reducing the bacterial load in a murine mouse model, but did not show any improvement in reducing the duration of treatment in Phase III trials [266,302].

\section{High Content Screening}

High content screening (HCS) is the application of high content analysis (HCA) to screening of chemical libraries. Previously HCA was defined as an analytical technology which combines the automated fluorescence microscopy with quantitative image analysis. However, in recent years other cell-based analysis techniques have also been used such as flow cytometry, etc. and therefore, now it is defined more broadly as any technique used to analyze intact cells or cellular compartments by high multiplexing. The fluorescence imaging-based HCA is now known as high content imaging (HCI). Automated microscopy and automated image analysis are being applied to all stages of drug discovery and development pipeline. HCI enables measuring complex phenotypic outcomes that are more closely linked to disease state while also providing the preliminary, cell-level assessment of certain aspects of absorption, distribution, metabolism, excretion and toxicity (ADMET) in primary screening. The power of HCI resides in its ability to assess different endpoints simultaneously at the level of individual protein, organelle, whole cell, cell populations, or even an entire organism [303].

\section{Assay Development}

Assay development is critical for successful HTS and establishing a reliable and reproducible assay might involve months to years of optimization for developing protocols best suited for desired screening. In case of cell-based HTS, the selection of an appropriate biological system is followed by optimization, to best address the biological question of interest such as titration of cell density and culture conditions, titration of the reagents used, addition of the change agent and determination of its optimal concentration, the incubation time and the detection of induced changes. The assay must also be adapted to a robust multi-well set-up, scaled for automated sample handling and should have a minimum number of experimental steps. There is no general rule defining the features of a cell type that render it suitable for cell-based assay, but cell morphology is a critical feature to consider such as the ideal morphology of cells is flat with minimal tendency to form clusters. A review paper based on literature published for HCS assays reported that cell lines represent $85 \%$ of total cells used in HCS assays, whereas only $15 \%$ are based on primary cells. The identification of an appropriate positive control, representing strong inhibition of the assay readout, is another critical step in assay development. The positive control should also be titrated to provide diagnostic information for each experiment. Sensitivity to compound solvent (especially dimethyl sulfoxide, DMSO) should also be determined. Assay reproducibility from well-to-well, plate-to-plate and day-today should be evaluated using both positive and solvent controls [304]. The most widely accepted measurement of assay quality and readiness is the Z' factor. The Z' factor is calculated at the assay optimization stage using the positive and negative controls and is based on the 
means and standard deviations of positive and negative controls. A meaningful Z' value is computed by using multiple repeats. $Z$ ' value $\geq 0.5$ indicates excellent assay while an assay with $Z^{\prime}$ value between 0 and 0.5 is considered marginal. Once the assay has achieved an acceptable Z' value, a pilot screen can be performed with a small number of chemical compounds to validate the assay before use in HTS. Other critical issues to be considered are the analysis, interpretation and data mining of the assay data. Appropriate strategies for data analysis and interpretation should be considered [305].

Along with several other aspects, the choice of compound libraries is also critical for the success of the screening. Novartis revealed that natural products have significantly higher hit rates as compared to synthetic compounds in HTS screening campaigns [306]. The need to develop less toxic and more potent compounds against TB has also led to the involvement of natural products in the discovery. For as long as man can remember, nature has been used as a source of medicinal products and all possible sources of nature, plants have been viewed as an important source of new drugs in the last 20 years, nearly $50 \%$ of the drugs approved by FDA in the United States of America have been derivatives of natural products. Moreover, about $75 \%$ of all the approved drugs are derived from medicinal plants [307]. In the case of TB, natural remedies, especially those derived from ethnobotanically-selected plants, are still being used worldwide [308]. Nature's biosynthetic engine produces innumerate bioactive secondary metabolites that have been shown to act on myriads of the target with very different potential and activity pattern. There have been several efforts to screen and isolate novel anti-TB compounds from natural products. There is also an increasing optimism that novel anti-TB agents may be sourced from endophytes, microorganisms that form a symbiotic relationship with their host plants and marine organisms [309,310]. The problems that hinder the use of natural products in drug discovery are the low availability of compounds and high relative structure complexity. Another obstacle is that the isolated active product in most cases needs follow-up improvement to be more potent and as most of the natural product-based research is performed in an academic environment, therefore, follow-up studies are usually lacking.

\section{Hit Identification and Beyond}

In primary screening, several different potential hits might be discovered, but typically not all of them would have equally desirable qualities. The definition of "hit" can vary, but in general, a hit is a chemical compound that showed desired activity in the primary screening. Successive hits will be processed through a funnel of hit optimization where it is provided with successive series of chemical modification and a series of assays. Primary screening is usually performed with single concentrations whereas the next step is to generate a dose-response curve of the obtained hit(s). The dose-response curve provides the half maximal inhibitory concentration (IC50) which is used to compare the potencies of the hits. The next step is to examine the surviving hits in another assay (usually called secondary assay) that has detection technology distinct from the primary screening assay. It is also important as it removes the false positives, compounds interfered with assay detection methodologies and selected as hits in the primary assay. The hit optimization phase also involves continuous chemical examination of the hits. During all these steps chemical compounds with structure similarities (analogs) are clustered together in groups. The chemical compounds within each cluster are examined for their 
structure-activity relationship to identify the essential elements in the structure associated with the activity. The target here is to determine some common chemical core that can be modified with different chemical groups to improve the potency, efficacy and selectivity of the compound. That is why it is preferable to start the screening with small and simple molecule as often the chemical modification lead to increase molecular weight which can affect the safety and tolerability of the compound. Therefore, chemical compounds libraries mostly contain "drug-like" compounds that have a small molecular weight. The compounds acquired or synthesized during the modification process are again tested in in vitro assay to determine the ADMET properties. Moreover, physiochemical and pharmacokinetic measurements need to be determined before formulation for in vivo studies [311]. The metabolic stability of a compound is another key factor that can be checked by in vitro assay. The compound solubility profile is also set up. In case of infectious diseases the compound should also be tested for its specificity against the desired pathogen and evaluate against the multi-drug resistant strains, the strain to be used in in vivo animal models and clinical strains [312]. The hit optimization program results in the identification of new analog with improved potency and high efficacy. The final lead scaffold may bear little resemblance to the original hit identified through screening chemical libraries.

The hit molecule(s) obtained from the optimization process is then processed in the hitto-lead phase with a target to make a more potent and selective compound known as "lead". The lead compound is further optimized to maintain favorable properties of the compound while further removing the deficiencies of the molecule. This whole process is known as "lead optimization phase" and it provides information to prepare the candidate drug to begin the preclinical trials [311]. 


\section{Aims}

\section{Paper 1}

The study aimed to investigate the cording phenotype of Mycobacterium tuberculosis and it's interaction with primary human macrophages.

\section{Paper 2}

The study was performed to observe the drug sensitivity of different phenotypes of Mycobacterium tuberculosis against isoniazid and rifampicin.

\section{Paper 3}

In this study, we searched for novel anti-mycobacterial agents from crude extracts of African plants selected on the basis of ethnobotanical knowledge.

\section{Paper 4}

We aimed at developing a high content screening assay to explore new active compounds against intracellular Mycobacterium tuberculosis using primary human macrophages. 


\section{Results and Discussion}

$\mathrm{TB}$, primarily a respiratory infection caused by Mtb, remains one of the greatest threats to human health. It is well-established now that TB comprises of different stages of infection with continuous struggle of survival between the bacterium and the host. In case of healthy individuals, after inhalation of the bacteria, the primary outcome of the infection is the development of LTBI as the host immune system succeeded in the struggle to some extent. However, Mtb has evolved many strategies to circumvent host defense mechanisms and such individuals can later develop active disease if the immune system is compromised by any mean. This battle between Mtb and host immune system has become more complicated with the development of DR-Mtb strains which emphasizes the urgency of new TB control measures.

Since the discovery of Mtb, the formation of serpentine cords or pellicles, a biofilmlike structure, at the liquid-air interface in a variety of in vitro media has been known as a characteristic sign of these bacteria. In cords, bacilli grow in a coiled structure along their long axes. This intrinsic property of Mtb has also been shown in material isolated from TB patients. Alveolar macrophages isolated from resected lungs of pulmonary TB patients were demonstrated to carry cord-forming Mtb [313]. The cord formation in in vitro cultures depends upon the culture conditions [171]. Our lab routinely cultures Mtb with Tween-80 in the broth in standing cultures for a week, which promotes the planktonic phenotype of Mtb (Paper 1, Figure 1A and E). Therefore, in order to promote cord formation, we reduced the concentration of Tween- 80 along with increased aeration of the culture medium by shaking the culture tube (Paper 1, Figure 1D). As the ability to form cords is related to biofilm formation, we in a subsequent study observed the growth of bacteria harvested from both cultures over a period of time through live cell imaging (Paper 2, Figure 1 D-F). Here, we used area cut-offs to define three different phenotypes: small, dispersed aggregates harvested from standing culture as the planktonic phenotype; organized aggregates harvested from shaken cultures as cords; and finally, large sheets also harvested from shaken culture were named as biofilm phenotype (Paper 2, Figure 1 A-C). Development of a cavity in active TB represents a transition from a predominantly intracellular infection to extracellular life of the bacilli. This transition also contributes to the complexity of host microenvironment that contributes to the excessive growth of extracellular bacteria [184]. In this regard, a study showed that Mtb isolated from the sputum of pulmonary TB patients containing cavities grew faster in form of cords in contrast to Mtb isolated from extra pulmonary sites that grew as discrete patches. We also observed a rapid growth of bacteria that coincided with the formation of aggregates after infection of human macrophages (Paper 1, Figure 6).

During the last decades, evidence has accumulated that phagocytic cells also release extracellular traps, beside their primary function of phagocytosis, upon interaction with diverse pathogens ranging from yeast to bacteria [208]. The monocyte/macrophage lineage plays an important role in eliminating mycobacterial infections. Several recent studies also showed this phenomenon in macrophages in response to microbes, including mycobacteria, named as METs [225,228,314]. Although the primary function of METs has been attributed to their antimicrobial effect [220], this is not always the case. A study performed using M. massiliense 
revealed that METs were used as an interaction path by the bacteria with cells where the bacteria can grow to form aggregates [226]. Another concept is that phagocytes release ETs only when the size of the microbe is too big to phagocytose. This concept is further corroborated with our finding that the cording phenotype of Mtb significantly induces the release of more METs at the same MOI in hMDMs as compared to planktonic phenotype after $24 \mathrm{~h}$ of infection (Paper 1, Figure 2). Our finding is also consistent with another study showing $M$. abscessus that do not form cords were readily phagocytosed, while cord-forming $M$. abscessus were surrounded by a meshwork containing DNA and histones [228]. METs from hMDMs were released both in the form of long filaments and a web-like structure formed by joining the METs of more than one cells (Paper 1, Figure 3). METs formed in our system shares many properties with METs described in other studies [223,225]. The structures were stained green with a non-cell-permeable dye specific for dsDNA named picogreen. DNase I treatment efficiently removed the formed structures as determined by fluorescence microscopy, which confirmed that these extracellular traps were composed of DNA. These structures could also be stained with an antibody specific for histone, a key component of METs (Paper 1, Figure 4). ROS production by NADPH oxidase is an essential signal leading to the release of ETs by neutrophil [71,315]. However, the dependency of ROS for the production of METs varies between the types of macrophage used [222,225]. We found that METs released by primary human macrophages by cording mycobacteria was not dependent on ROS production. Moreover, DPI (a NADPH-oxidase-dependent ROS production inhibitor) also did not show an inhibiting effect on METs (Paper 1, Figure 5).

By the mid- $20^{\text {th }}$ century, virulence of Mtb was correlated with the cording phenotype and was studied in a variety of models [190], but it remains unknown if the physical aggregation of Mtb enhances virulence or the aggregation merely indicates the presence of a specific virulence factor. However, many studies relate cording with the lipid composition of the mycobacterial cell wall $[179,316]$. Mice infected with BCG to developed a LTBI model demonstrated that the mice that could not control the infection showed bacteria growing as cords within macrophages and dendritic cells of granuloma [317]. ESX-1 secretion system is a significant virulence factor in mycobacterial infection and a study showed that ESAT-6, one of the two key substrates of ESX-1, is responsible for METs induction by hMDMs [223]. In order to evaluate the role of ESAT-6 of our cording phenotype in inducing METs from hMDMs, we utilized an ESAT-6 mutant strain and treated in the same way as wild-type Mtb to induce cording phenotype. Although the bacteria from ESAT-6 mutant strain formed organized aggregates resembling cords of wild-type but they could not trigger the release of METs from primary human macrophages (Paper 1, Figure 7). Finally, five clinical strains that have been proven epidemiologically to be at the two extremes of the transmission spectrum (i.e., grade of infectivity) were investigated with respect to their ability to induce MET formation in hMDMs. Irrespective of transmission ability, all clinical strains were equally capable to induce METs (Paper 1, Figure 8).

The goal of WHO to eradicate the disease by 2030 requires an urgent need of the development of an anti-TB regimen that can efficiently sterilize both drug-sensitive and drugresistant strains of Mtb. This also requires the understanding of various factors involve in $\mathrm{TB}$ pathophysiology such as the presence of drug-tolerant phenotype of Mtb. Biofilm development 
is an important factor in antibiotic tolerance. With mycobacteria, the biofilm phenotype showed tolerance to antibiotics both in vitro and in vivo studies [5]. We observed the cultures with all three phenotypes of Mtb over time through live cell imaging in the presence of several concentrations of the two first-line antibiotics, i.e. INH and RIF. The dose-response curves were plotted and IC50 values were calculated. The IC50 values revealed that the biofilm phenotype was more tolerant to the antibiotic used, as shown by a previous study where the in vitro mycobacterial biofilm display more resistance to INH and RIF as compared to planktonic cultures with more than $10 \%$ of bacteria surviving at the highest concentration of INH used [171]. Moreover, both drugs in combination effectively inhibited the growth of all three phenotypes but were not able to completely eradicate the bacteria (Paper 2, Figure 2).

In summary, different culture conditions promote different phenotypes of Mtb that are distinct in case of growth, virulence and sensitivity towards antibiotics. The unique characteristics of Mtb infection in the lungs and various intracellular lifestyles of Mtb in the TB lesions of the same host necessitates the discovery of new drugs that are effective against all phenotypes and can eradicate the bacteria within a short duration of time.

Drug discovery is a time-consuming and complicated process that requires tremendous capital investment and still associated with low success rate. Now-a-days, academia is contributing more to discovering new anti-TB drugs than pharmaceutical industries. In phenotypic, whole-cell approaches (i.e., bacterial culture-based) of phenotypic screening, compounds are screened for their ability to inhibit bacterial growth and tested against the organism's entire set of potential targets at once. Three new anti-TB drugs namely: bedaquilin, delamanid and pretonamanid were discovered by the phenotypic whole-cell-screening approach [278,286,298]. Natural products, especially from plants, have been widely exploited as a valuable source for drug development as they are extremely rich in chemical diversity and have privileged antimicrobial activities. In the case of TB, natural remedies are still being used worldwide. As TB is more prevalent in developing countries, therefore, the conversion of natural products into potent anti-TB drugs could aid in decreasing the catastrophic expenses due to TB on low-income families.

African plants are a well-known source of compounds having anti-mycobacterial activity [307]. In this study, 46 Sudanese medicinal plants were collected based on ethnobotanical knowledge and 50 crude extracts were prepared from different parts of the plants using ethanol. In the initial screening, the 50 ethanolic crude extracts were evaluated for their anti-mycobacterial activity against an avirulent strain of Mtb (H37Ra) in broth by using a luminometry-based method. INH was used as a positive control. Three compounds that effectively inhibited the growth of Mtb at a low concentration of $6.25 \mu \mathrm{g} / \mathrm{ml}$ were selected as hits; Khaya senegalensis (bark and leaves) and Rosmarinus officinalis (leaves) (Paper 3, Figure S1B and C). These extracts were then subjected to fractionation with various solvents from high to low polarity. The use of a variety of solvents for fractionation is a critical step in screening using plant extracts, as it separates biologically active compounds from cytotoxic ones which have also been observed in further testing in this study. The second screening, performed on the fractions, lead to the identification of five fractions that significantly inhibited 
the bacterial growth at the same concentration (Paper 3, Figure 1). It was expected that some of the fractions would lose their activity during the fractionation procedure [318].

In order to rule out cytotoxicity, the active fractions were then tested for their effect on macrophage viability. The cell viability assay was based on calcein measurement inside the cells and resulted in the selection of two fractions (chloroform and ethyl acetate fractions of Khaya senegalensis bark) at the concentration of $0.1 \mathrm{mg} / \mathrm{ml}$ (Paper 3, Figure 2). The IC50 values calculated by dose-response curves using 10 different concentrations of the two fractions further revealed their high potency against the H37Ra strain in broth culture (Paper 3, Figure 3) [307].

Finally, the intracellular activity of two fractions (chloroform and ethyl acetate of Khaya senegalensis bark) were evaluated by treating the H37Rv-infected hMDMs with 0.1 $\mathrm{mg} / \mathrm{ml}$ concentration. Only the chloroform fraction slightly and non-significantly reduced the intracellular bacterial growth of a virulent Mtb strain (Paper 3, Figure 4). This could be due to the fraction still being a mixture of many compounds, which need further purification in order to get the pure biologically active compound.

Both academia and pharmaceutical industries now utilize HTS, to identify new compounds because of the automation of standardize biological and biochemical assays. In case of cell-based HTS, the choice of a model system for primary screening is the most critical point in assay development reflecting host-pathogen interaction, therefore, many screening assays that target Mtb inside its host cell utilize macrophages as a host cell model. In this study, we developed a phenotypic HCS assay using primary human macrophages and a virulent strain of Mtb that represents the most relevant host-pathogen interaction model, as the intracellular lifestyle of M. tuberculosis varies within the host cell [300].

The steps followed involve assay optimization, validation, and automation. HTS demands that the assay should be robust and reproducible. To validate the assay, a number of quality control experiments should be performed to check the variability within and between the plates. A statistical measure of the quality of an assay is the Z-factor. A Z-factor value > 0.5 shows good separation between positive and negative controls.

In the assay optimization step, we tested a wide range of MOIs along with different incubation times. The read-out of intracellular bacteria number and cell viability, obtained from automated image analysis performed on captured images of fixed cells, showed that MOI1 at day 6 best addresses our biological question of interest (Paper 4, Figure 1). Finally, the information obtained through image analysis software revealed that the Mtb-expressing mCherry-infected hMDMs were used in future experiments (Paper 4, Figure 2).

Positive control selection is another critical step in assay development. To achieve this goal, a dose-response experiment was performed using different selected first- and second-line antibiotics and IC50 values were calculated. As expected RIF and INH were found most effective in inhibiting intracellular growth of Mtb alone (Paper 4, Figure 3) or in combination tested by a checker board approach (Paper 4, Figure 4). Thus, the most effective concentration to be used in combination were $0.1 \mu \mathrm{g} / \mathrm{ml}$ each to be used as a positive control in the further experiment. 
In the next step, two assay plates using two different donors were prepared with mCherry-infected macrophages and treated with either DMSO (negative control) or a combination of INH+RIF (positive control) and analyzed using different read-outs. In order to determine the quality of the assay, the $Z$ ' factor was also calculated for different read-outs. The repetitive assay analysis using image analysis software showed that bacteria integrated intensity was a parameter for assay read out gave us an acceptable Z' factor value (Paper 4, Figure 5).

Further, we validated our assay with a set of known anti-TB drugs (Paper 4, Figure 6). Four of the antibiotics namely INH, RIF, MOX and LEV were identified as hits in our system. This result is supported by another study performed using a human macrophage cell line [319]. Both MOX and LEV have early bactericidal activity in pulmonary patients. However, LEV is required in a high dose as compared to MOX [265]. The reason why other antibiotics could not be identified as hits in the system is unclear. One reason could be that a special environment is needed for action as in case of PZA, which has been shown to require a low $\mathrm{pH}$ for action [241]. Another reason could be that the drug is effective only against extracellular bacteria as in the case of AMI [320]. Finally, the drugs may not be very potent against Mtb as in case of EMB [321] and CLOF [322]. 


\section{Concluding Remarks}

This thesis covers two important areas of TB research, i.e., mycobacterial virulence and drug discovery.

Our data reveal that Mtb growth in specific culture conditions can induce different phenotypes of Mtb. Furthermore, the cording phenotype triggers the formation of extracellular traps from primary human macrophages in an ESAT-6 dependent manner that links cording with virulence. Subsequently, we also show that the biofilm phenotype is less sensitive to known anti-TB drugs as compared to cording and planktonic phenotypes. This data also contributes to the understanding of the long duration of TB treatment.

The work done under the topic of drug discovery provided us a hit as a chloroform fraction of Khaya senegalensis bark showed anti-mycobacterial efficacy. The hit was obtained from the whole-cell screening of crude extracts from different parts of African plants and contains an active compound that after further fractionation and purification will be an important addition to the TB drug development pipeline. Finally, we have also developed a simple and robust HCS screening assay to identify novel compounds against the intracellular growth of Mtb. The assay was developed using a virulent strain of Mtb and primary human macrophages. It represents the most relevant pathophysiological condition of Mtb infection and will provide additional aid in identifying the compounds that can target different pathways of host-pathogen interactions.

The overall conclusion is that different phenotypes of Mtb are distinct in many aspects, such as their sensitivity toward antibiotics. Therefore, there is an urgent need of new agents to improve treatment success and combat the disease. By screening for active compounds against Mtb infection using human cells we can find potential drug candidates that target different aspects of mycobacterial survival during infection. 


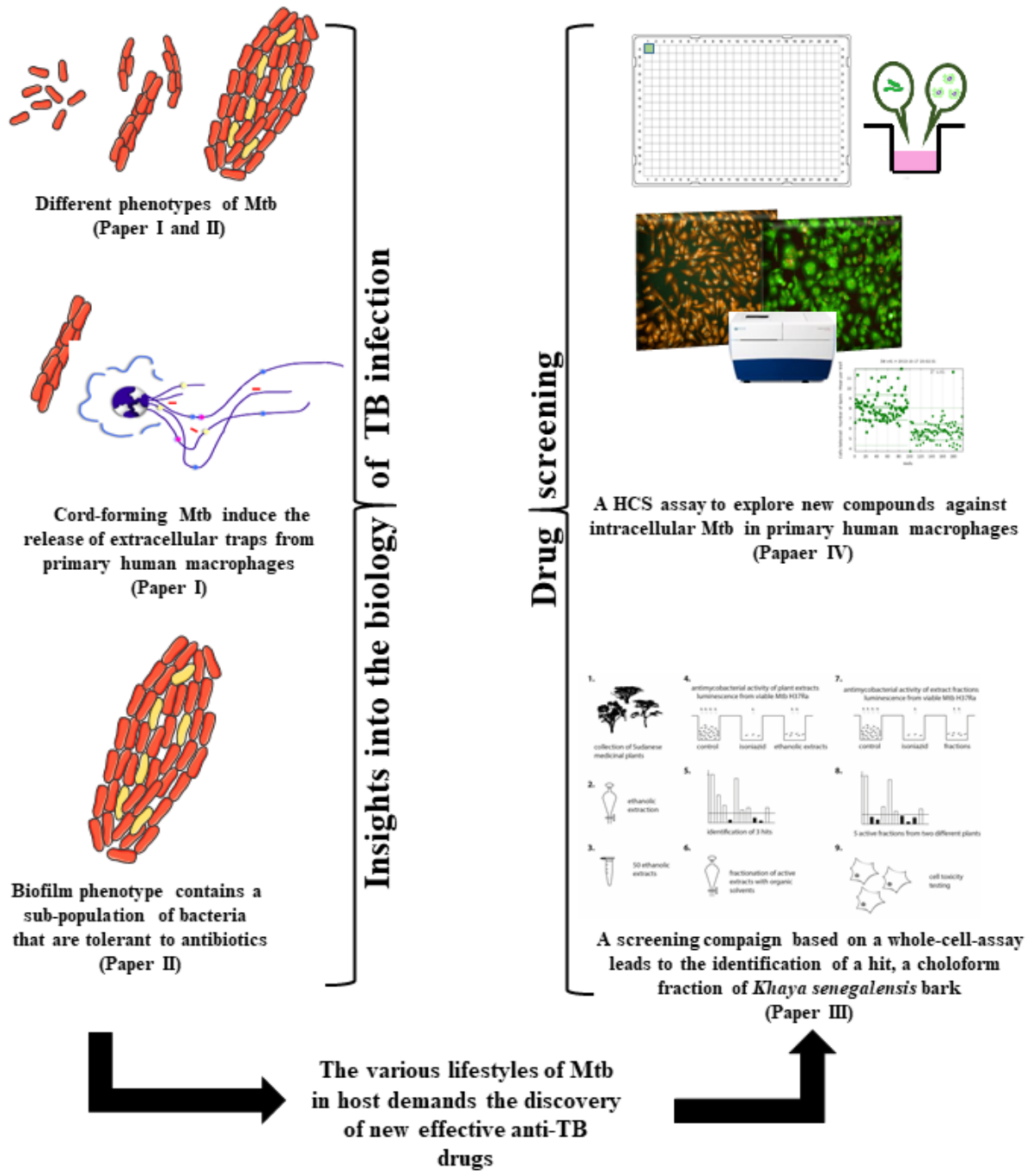

Figure 7. A schematic representation of the research work discussed in this thesis. 


\section{References}

1 Sakula A: Robert koch: centenary of the discovery of the tubercle bacillus, 1882. Can Vet J 1983;24:127-131.

2 Daniel TM: The history of tuberculosis. Respir Med 2006;100:1862-1870.

3 Barberis I, Bragazzi NL, Galluzzo L, Martini M: The history of tuberculosis: from the first historical records to the isolation of Koch's bacillus. J Prev Med Hyg 2017;58:E9-E12.

4 Donoghue HD: Insights gained from palaeomicrobiology into ancient and modern tuberculosis. Clin Microbiol Infect 2011;17:821-829.

5 Murray JF: A century of tuberculosis. Am J Respir Crit Care Med 2004;169:1181-1186.

6 Centre TC: A concurrent comparison of home and sanatorium treatment of pulmonary tuberculosis in South India. Bull World Health Organ 1959;21:51-144.

7 Global tuberculosis report, 2018,

8 Bansal R, Sharma D, Singh R: Tuberculosis and its Treatment: An Overview. Mini Rev Med Chem 2018;18:58-71.

9 Albanna AS, Menzies D: Drug-resistant tuberculosis: what are the treatment options? Drugs 2011;71:815-825.

10 Guenin-Macé L, Siméone R, Demangel C: Lipids of pathogenic Mycobacteria: contributions to virulence and host immune suppression. Transbound Emerg Dis 2009;56:255-268.

11 Behr MA: Evolution of Mycobacterium tuberculosis. Adv Exp Med Biol 2013;783:81-91.

12 Bañuls AL, Sanou A, Anh NT, Godreuil S: Mycobacterium tuberculosis: ecology and evolution of a human bacterium. J Med Microbiol 2015;64:1261-1269.

13 Brites D, Gagneux S: Co-evolution of Mycobacterium tuberculosis and Homo sapiens. Immunol Rev 2015;264:6-24.

14 Bottai D, Stinear TP, Supply P, Brosch R: Mycobacterial Pathogenomics and Evolution. Microbiol Spectr 2014;2:MGM2-0025-2013.

15 Angala SK, Belardinelli JM, Huc-Claustre E, Wheat WH, Jackson M: The cell envelope glycoconjugates of Mycobacterium tuberculosis. Crit Rev Biochem Mol Biol 2014:49:361-399.

16 Delogu G, Sali M, Fadda G: The biology of mycobacterium tuberculosis infection. Mediterr J Hematol Infect Dis 2013;5:e2013070.

17 Jackson M: The mycobacterial cell envelope-lipids. Cold Spring Harb Perspect Med $2014 ; 4$ 
18 Welin A, Winberg ME, Abdalla H, Särndahl E, Rasmusson B, Stendahl O, Lerm M: Incorporation of Mycobacterium tuberculosis lipoarabinomannan into macrophage membrane rafts is a prerequisite for the phagosomal maturation block. Infect Immun 2008;76:2882-2887.

19 Bailo R, Bhatt A, Aínsa JA: Lipid transport in Mycobacterium tuberculosis and its implications in virulence and drug development. Biochem Pharmacol 2015;96:159-167.

20 Lemassu A, Ortalo-Magné A, Bardou F, Silve G, Laneélle MA, Daffé M: Extracellular and surface-exposed polysaccharides of non-tuberculous mycobacteria. Microbiology 1996;142 ( Pt 6):1513-1520.

21 Sani M, Houben EN, Geurtsen J, Pierson J, de Punder K, van Zon M, Wever B, Piersma SR, Jiménez CR, Daffé M, Appelmelk BJ, Bitter W, van der Wel N, Peters PJ: Direct visualization by cryo-EM of the mycobacterial capsular layer: a labile structure containing ESX-1-secreted proteins. PLoS Pathog 2010;6:e1000794.

22 Daffé M, Etienne G: The capsule of Mycobacterium tuberculosis and its implications for pathogenicity. Tuber Lung Dis 1999;79:153-169.

23 Ligon LS, Hayden JD, Braunstein M: The ins and outs of Mycobacterium tuberculosis protein export. Tuberculosis (Edinb) 2012;92:121-132.

24 Simeone R, Bottai D, Brosch R: ESX/type VII secretion systems and their role in hostpathogen interaction. Curr Opin Microbiol 2009;12:4-10.

25 Bottai D, Serafini A, Cascioferro A, Brosch R, Manganelli R: Targeting type VII/ESX secretion systems for development of novel antimycobacterial drugs. Curr Pharm Des 2014;20:4346-4356.

26 Serafini A, Pisu D, Palù G, Rodriguez GM, Manganelli R: The ESX-3 secretion system is necessary for iron and zinc homeostasis in Mycobacterium tuberculosis. PLoS One 2013;8:e78351.

27 Fry DE: Extra-Pulmonary Tuberculosis and Its Surgical Treatment. Surg Infect (Larchmt) 2016;17:394-401.

28 Turner RD, Chiu C, Churchyard GJ, Esmail H, Lewinsohn DM, Gandhi NR, Fennelly KP: Tuberculosis Infectiousness and Host Susceptibility. J Infect Dis 2017;216:S636-S643.

29 Fogel N: Tuberculosis: a disease without boundaries. Tuberculosis (Edinb) 2015;95:527531.

30 Ducati RG, Ruffino-Netto A, Basso LA, Santos DS: The resumption of consumption -- a review on tuberculosis. Mem Inst Oswaldo Cruz 2006;101:697-714.

31 Lee SH: Tuberculosis Infection and Latent Tuberculosis. Tuberc Respir Dis (Seoul) 2016;79:201-206.

32 Orme IM, Basaraba RJ: The formation of the granuloma in tuberculosis infection. Semin Immunol 2014;26:601-609. 
33 Silva Miranda M, Breiman A, Allain S, Deknuydt F, Altare F: The tuberculous granuloma: an unsuccessful host defence mechanism providing a safety shelter for the bacteria? Clin Dev Immunol 2012;2012:139127.

34 Basaraba RJ: Experimental tuberculosis: the role of comparative pathology in the discovery of improved tuberculosis treatment strategies. Tuberculosis (Edinb) 2008;88 Suppl 1:S35-47.

35 Gengenbacher M, Kaufmann SH: Mycobacterium tuberculosis: success through dormancy. FEMS Microbiol Rev 2012;36:514-532.

36 Schorey JS, Schlesinger LS: Innate Immune Responses to Tuberculosis. Microbiol Spectr $2016 ; 4$

37 Tsai MC, Chakravarty S, Zhu G, Xu J, Tanaka K, Koch C, Tufariello J, Flynn J, Chan J: Characterization of the tuberculous granuloma in murine and human lungs: cellular composition and relative tissue oxygen tension. Cell Microbiol 2006;8:218-232.

38 Guirado E, Schlesinger LS: Modeling the Mycobacterium tuberculosis Granuloma - the Critical Battlefield in Host Immunity and Disease. Front Immunol 2013;4:98.

39 Driver ER, Ryan GJ, Hoff DR, Irwin SM, Basaraba RJ, Kramnik I, Lenaerts AJ: Evaluation of a mouse model of necrotic granuloma formation using $\mathrm{C} 3 \mathrm{HeB} / \mathrm{FeJ}$ mice for testing of drugs against Mycobacterium tuberculosis. Antimicrob Agents Chemother 2012;56:3181-3195.

40 Harper J, Skerry C, Davis SL, Tasneen R, Weir M, Kramnik I, Bishai WR, Pomper MG, Nuermberger EL, Jain SK: Mouse model of necrotic tuberculosis granulomas develops hypoxic lesions. J Infect Dis 2012;205:595-602.

41 Russell DG: Who puts the tubercle in tuberculosis? Nat Rev Microbiol 2007;5:39-47.

42 Pagán AJ, Ramakrishnan L: Immunity and Immunopathology in the Tuberculous Granuloma. Cold Spring Harb Perspect Med 2014;5

43 Parasa VR, Rahman MJ, Ngyuen Hoang AT, Svensson M, Brighenti S, Lerm M: Modeling Mycobacterium tuberculosis early granuloma formation in experimental human lung tissue. Dis Model Mech 2014;7:281-288.

44 Volkman HE, Clay H, Beery D, Chang JC, Sherman DR, Ramakrishnan L: Tuberculous granuloma formation is enhanced by a mycobacterium virulence determinant. PLoS Biol 2004;2:e367.

45 Davis JM, Ramakrishnan L: The role of the granuloma in expansion and dissemination of early tuberculous infection. Cell 2009;136:37-49.

46 Brighenti S, Andersson J: Local immune responses in human tuberculosis: learning from the site of infection. J Infect Dis 2012;205 Suppl 2:S316-324.

47 Fenhalls G, Stevens L, Moses L, Bezuidenhout J, Betts JC, Helden Pv P, Lukey PT, Duncan K: In situ detection of Mycobacterium tuberculosis transcripts in human lung 
granulomas reveals differential gene expression in necrotic lesions. Infect Immun 2002;70:6330-6338.

48 Ong CW, Elkington PT, Friedland JS: Tuberculosis, pulmonary cavitation, and matrix metalloproteinases. Am J Respir Crit Care Med 2014;190:9-18.

49 Ong CW, Elkington PT, Brilha S, Ugarte-Gil C, Tome-Esteban MT, Tezera LB, Pabisiak PJ, Moores RC, Sathyamoorthy T, Patel V, Gilman RH, Porter JC, Friedland JS: Neutrophil-Derived MMP-8 Drives AMPK-Dependent Matrix Destruction in Human Pulmonary Tuberculosis. PLoS Pathog 2015;11:e1004917.

50 Al-Zamel FA: Detection and diagnosis of Mycobacterium tuberculosis. Expert Rev Anti Infect Ther 2009;7:1099-1108.

51 Pai M, O'Brien R: New diagnostics for latent and active tuberculosis: state of the art and future prospects. Semin Respir Crit Care Med 2008;29:560-568.

52 Yan L, Xiao H, Zhang Q: Systematic review: Comparison of Xpert MTB/RIF, LAMP and SAT methods for the diagnosis of pulmonary tuberculosis. Tuberculosis (Edinb) 2016;96:75-86.

53 Janin YL: Antituberculosis drugs: ten years of research. Bioorg Med Chem 2007;15:24792513.

54 Zhang Y: Advances in the treatment of tuberculosis. Clin Pharmacol Ther 2007;82:595600 .

55 Rodrigues LC, Pereira SM, Cunha SS, Genser B, Ichihara MY, de Brito SC, Hijjar MA, Dourado I, Cruz AA, Sant'Anna C, Bierrenbach AL, Barreto ML: Effect of BCG revaccination on incidence of tuberculosis in school-aged children in Brazil: the BCGREVAC cluster-randomised trial. Lancet 2005;366:1290-1295.

56 Zhu B, Dockrell HM, Ottenhoff THM, Evans TG, Zhang Y: Tuberculosis vaccines: Opportunities and challenges. Respirology 2018;23:359-368.

57 Hasenberg M, Stegemann-Koniszewski S, Gunzer M: Cellular immune reactions in the lung. Immunol Rev 2013;251:189-214.

58 Holt PG, Strickland DH, Wikström ME, Jahnsen FL: Regulation of immunological homeostasis in the respiratory tract. Nat Rev Immunol 2008;8:142-152.

59 Kato A, Schleimer RP: Beyond inflammation: airway epithelial cells are at the interface of innate and adaptive immunity. Curr Opin Immunol 2007;19:711-720.

60 Scordo JM, Knoell DL, Torrelles JB: Alveolar Epithelial Cells in Mycobacterium tuberculosis Infection: Active Players or Innocent Bystanders? J Innate Immun 2016;8:314.

61 Li Y, Wang Y, Liu X: The role of airway epithelial cells in response to mycobacteria infection. Clin Dev Immunol 2012;2012:791392. 
62 Repasy T, Lee J, Marino S, Martinez N, Kirschner DE, Hendricks G, Baker S, Wilson AA, Kotton DN, Kornfeld $\mathrm{H}$ : Intracellular bacillary burden reflects a burst size for Mycobacterium tuberculosis in vivo. PLoS Pathog 2013;9:e1003190.

63 Martineau AR, Newton SM, Wilkinson KA, Kampmann B, Hall BM, Nawroly N, Packe GE, Davidson RN, Griffiths CJ, Wilkinson RJ: Neutrophil-mediated innate immune resistance to mycobacteria. J Clin Invest 2007;117:1988-1994.

64 Kisich KO, Higgins M, Diamond G, Heifets L: Tumor necrosis factor alpha stimulates killing of Mycobacterium tuberculosis by human neutrophils. Infect Immun 2002;70:4591-4599.

65 Corleis B, Korbel D, Wilson R, Bylund J, Chee R, Schaible UE: Escape of Mycobacterium tuberculosis from oxidative killing by neutrophils. Cell Microbiol 2012;14:1109-1121.

66 Hedlund S, Persson A, Vujic A, Che KF, Stendahl O, Larsson M: Dendritic cell activation by sensing Mycobacterium tuberculosis-induced apoptotic neutrophils via DC-SIGN. Hum Immunol 2010;71:535-540.

67 Andersson H, Andersson B, Eklund D, Ngoh E, Persson A, Svensson K, Lerm M, Blomgran R, Stendahl O: Apoptotic neutrophils augment the inflammatory response to Mycobacterium tuberculosis infection in human macrophages. PLoS One 2014;9:e101514.

68 Tan BH, Meinken C, Bastian M, Bruns H, Legaspi A, Ochoa MT, Krutzik SR, Bloom BR, Ganz T, Modlin RL, Stenger S: Macrophages acquire neutrophil granules for antimicrobial activity against intracellular pathogens. J Immunol 2006;177:1864-1871.

69 Gopal R, Monin L, Torres D, Slight S, Mehra S, McKenna KC, Fallert Junecko BA, Reinhart TA, Kolls J, Báez-Saldaña R, Cruz-Lagunas A, Rodríguez-Reyna TS, Kumar NP, Tessier P, Roth J, Selman M, Becerril-Villanueva E, Baquera-Heredia J, Cumming B, Kasprowicz VO, Steyn AJ, Babu S, Kaushal D, Zúñiga J, Vogl T, Rangel-Moreno J, Khader SA: S100A8/A9 proteins mediate neutrophilic inflammation and lung pathology during tuberculosis. Am J Respir Crit Care Med 2013;188:1137-1146.

70 Eum SY, Kong JH, Hong MS, Lee YJ, Kim JH, Hwang SH, Cho SN, Via LE, Barry CE: Neutrophils are the predominant infected phagocytic cells in the airways of patients with active pulmonary TB. Chest 2010;137:122-128.

71 Braian C, Hogea V, Stendahl O: Mycobacterium tuberculosis- induced neutrophil extracellular traps activate human macrophages. J Innate Immun 2013;5:591-602.

72 Sia JK, Georgieva M, Rengarajan J: Innate Immune Defenses in Human Tuberculosis: An Overview of the Interactions between Mycobacterium tuberculosis and Innate Immune Cells. J Immunol Res 2015;2015:747543.

73 Schierloh P, Yokobori N, Alemán M, Musella RM, Beigier-Bompadre M, Saab MA, Alves L, Abbate E, de la Barrera SS, Sasiain MC: Increased susceptibility to apoptosis of CD56dimCD16+ NK cells induces the enrichment of IFN-gamma-producing CD56bright cells in tuberculous pleurisy. J Immunol 2005;175:6852-6860. 
74 Vankayalapati R, Wizel B, Weis SE, Safi H, Lakey DL, Mandelboim O, Samten B, Porgador A, Barnes PF: The NKp46 receptor contributes to NK cell lysis of mononuclear phagocytes infected with an intracellular bacterium. J Immunol 2002;168:3451-3457.

75 Dhiman R, Indramohan M, Barnes PF, Nayak RC, Paidipally P, Rao LV, Vankayalapati R: IL-22 produced by human NK cells inhibits growth of Mycobacterium tuberculosis by enhancing phagolysosomal fusion. J Immunol 2009;183:6639-6645.

76 Jasenosky LD, Scriba TJ, Hanekom WA, Goldfeld AE: T cells and adaptive immunity to Mycobacterium tuberculosis in humans. Immunol Rev 2015;264:74-87.

77 Lin PL, Rutledge T, Green AM, Bigbee M, Fuhrman C, Klein E, Flynn JL: CD4 T cell depletion exacerbates acute Mycobacterium tuberculosis while reactivation of latent infection is dependent on severity of tissue depletion in cynomolgus macaques. AIDS Res Hum Retroviruses 2012;28:1693-1702.

78 Srivastava S, Ernst JD: Cell-to-cell transfer of M. tuberculosis antigens optimizes CD4 T cell priming. Cell Host Microbe 2014;15:741-752.

79 Khader SA, Partida-Sanchez S, Bell G, Jelley-Gibbs DM, Swain S, Pearl JE, Ghilardi N, Desauvage FJ, Lund FE, Cooper AM: Interleukin 12p40 is required for dendritic cell migration and $\mathrm{T}$ cell priming after Mycobacterium tuberculosis infection. J Exp Med 2006;203:1805-1815.

80 Blomgran R, Ernst JD: Lung neutrophils facilitate activation of naive antigen-specific CD4+ T cells during Mycobacterium tuberculosis infection. J Immunol 2011;186:71107119.

81 Divangahi M, Desjardins D, Nunes-Alves C, Remold HG, Behar SM: Eicosanoid pathways regulate adaptive immunity to Mycobacterium tuberculosis. Nat Immunol 2010;11:751-758.

82 Rozot V, Patrizia A, Vigano S, Mazza-Stalder J, Idrizi E, Day CL, Perreau M, LazorBlanchet C, Ohmiti K, Goletti D, Bart PA, Hanekom W, Scriba TJ, Nicod L, Pantaleo G, Harari A: Combined use of Mycobacterium tuberculosis-specific CD4 and CD8 T-cell responses is a powerful diagnostic tool of active tuberculosis. Clin Infect Dis 2015;60:432437.

83 Guirado E, Schlesinger LS, Kaplan G: Macrophages in tuberculosis: friend or foe. Semin Immunopathol 2013;35:563-583.

84 Sica A, Erreni M, Allavena P, Porta C: Macrophage polarization in pathology. Cell Mol Life Sci 2015;72:4111-4126.

85 Cassetta L, Cassol E, Poli G: Macrophage polarization in health and disease. ScientificWorldJournal 2011;11:2391-2402.

86 Huang Z, Luo Q, Guo Y, Chen J, Xiong G, Peng Y, Ye J, Li J: Mycobacterium tuberculosis-Induced Polarization of Human Macrophage Orchestrates the Formation and Development of Tuberculous Granulomas In Vitro. PLoS One 2015;10:e0129744. 
87 Redente EF, Higgins DM, Dwyer-Nield LD, Orme IM, Gonzalez-Juarrero M, Malkinson AM: Differential polarization of alveolar macrophages and bone marrow-derived monocytes following chemically and pathogen-induced chronic lung inflammation. J Leukoc Biol 2010;88:159-168.

88 Andrade MR, Amaral EP, Ribeiro SC, Almeida FM, Peres TV, Lanes V, D'Império-Lima MR, Lasunskaia EB: Pathogenic Mycobacterium bovis strains differ in their ability to modulate the proinflammatory activation phenotype of macrophages. BMC Microbiol 2012;12:166.

89 Armstrong L, Medford AR, Uppington KM, Robertson J, Witherden IR, Tetley TD, Millar AB: Expression of functional toll-like receptor-2 and -4 on alveolar epithelial cells. Am J Respir Cell Mol Biol 2004;31:241-245.

90 Muir A, Soong G, Sokol S, Reddy B, Gomez MI, Van Heeckeren A, Prince A: Toll-like receptors in normal and cystic fibrosis airway epithelial cells. Am J Respir Cell Mol Biol 2004;30:777-783.

91 Mishra A, Akhtar S, Jagannath C, Khan A: Pattern recognition receptors and coordinated cellular pathways involved in tuberculosis immunopathogenesis: Emerging concepts and perspectives. Mol Immunol 2017;87:240-248.

92 Mortaz E, Adcock IM, Tabarsi P, Masjedi MR, Mansouri D, Velayati AA, Casanova JL, Barnes PJ: Interaction of Pattern Recognition Receptors with Mycobacterium Tuberculosis. J Clin Immunol 2015;35:1-10.

93 Bulut Y, Michelsen KS, Hayrapetian L, Naiki Y, Spallek R, Singh M, Arditi M: Mycobacterium tuberculosis heat shock proteins use diverse Toll-like receptor pathways to activate pro-inflammatory signals. J Biol Chem 2005;280:20961-20967.

94 Quesniaux V, Fremond C, Jacobs M, Parida S, Nicolle D, Yeremeev V, Bihl F, Erard F, Botha T, Drennan M, Soler MN, Le Bert M, Schnyder B, Ryffel B: Toll-like receptor pathways in the immune responses to mycobacteria. Microbes Infect 2004;6:946-959.

95 Fremond CM, Yeremeev V, Nicolle DM, Jacobs M, Quesniaux VF, Ryffel B: Fatal Mycobacterium tuberculosis infection despite adaptive immune response in the absence of MyD88. J Clin Invest 2004;114:1790-1799.

96 Xu Y, Jagannath C, Liu XD, Sharafkhaneh A, Kolodziejska KE, Eissa NT: Toll-like receptor 4 is a sensor for autophagy associated with innate immunity. Immunity 2007;27:135-144.

97 Kleinnijenhuis J, Oosting M, Joosten LA, Netea MG, Van Crevel R: Innate immune recognition of Mycobacterium tuberculosis. Clin Dev Immunol 2011;2011:405310.

98 Stamm CE, Collins AC, Shiloh MU: Sensing of Mycobacterium tuberculosis and consequences to both host and bacillus. Immunol Rev 2015;264:204-219.

99 Pathak SK, Basu S, Basu KK, Banerjee A, Pathak S, Bhattacharyya A, Kaisho T, Kundu M, Basu J: Direct extracellular interaction between the early secreted antigen ESAT- 6 of Mycobacterium tuberculosis and TLR2 inhibits TLR signaling in macrophages. Nat Immunol 2007;8:610-618. 
100 Welin A, Lerm M: Inside or outside the phagosome? The controversy of the intracellular localization of Mycobacterium tuberculosis. Tuberculosis (Edinb) 2012;92:113-120.

101 Landes MB, Rajaram MV, Nguyen H, Schlesinger LS: Role for NOD2 in Mycobacterium tuberculosis-induced iNOS expression and NO production in human macrophages. $\mathbf{J}$ Leukoc Biol 2015;97:1111-1119.

102 Gandotra S, Jang S, Murray PJ, Salgame P, Ehrt S: Nucleotide-binding oligomerization domain protein 2-deficient mice control infection with Mycobacterium tuberculosis. Infect Immun 2007;75:5127-5134.

103 Kleinnijenhuis J, Joosten LA, van de Veerdonk FL, Savage N, van Crevel R, Kullberg BJ, van der Ven A, Ottenhoff TH, Dinarello CA, van der Meer JW, Netea MG: Transcriptional and inflammasome-mediated pathways for the induction of IL-1beta production by Mycobacterium tuberculosis. Eur J Immunol 2009;39:1914-1922.

104 Juárez E, Carranza C, Hernández-Sánchez F, Loyola E, Escobedo D, León-Contreras JC, Hernández-Pando R, Torres M, Sada E: Nucleotide-oligomerizing domain-1 (NOD1) receptor activation induces pro-inflammatory responses and autophagy in human alveolar macrophages. BMC Pulm Med 2014;14:152.

105 Mishra BB, Moura-Alves P, Sonawane A, Hacohen N, Griffiths G, Moita LF, Anes E: Mycobacterium tuberculosis protein ESAT-6 is a potent activator of the NLRP3/ASC inflammasome. Cell Microbiol 2010;12:1046-1063.

106 Eklund D, Welin A, Andersson H, Verma D, Söderkvist P, Stendahl O, Särndahl E, Lerm M: Human gene variants linked to enhanced NLRP3 activity limit intramacrophage growth of Mycobacterium tuberculosis. J Infect Dis 2014;209:749-753.

107 Master SS, Rampini SK, Davis AS, Keller C, Ehlers S, Springer B, Timmins GS, Sander P, Deretic V: Mycobacterium tuberculosis prevents inflammasome activation. Cell Host Microbe 2008;3:224-232.

108 El-Etr SH, Cirillo JD: Entry mechanisms of mycobacteria. Front Biosci 2001;6:D737-747.

109 Cywes C, Hoppe HC, Daffé M, Ehlers MR: Nonopsonic binding of Mycobacterium tuberculosis to complement receptor type 3 is mediated by capsular polysaccharides and is strain dependent. Infect Immun 1997;65:4258-4266.

110 Killick KE, Ní Cheallaigh C, O'Farrelly C, Hokamp K, MacHugh DE, Harris J: Receptormediated recognition of mycobacterial pathogens. Cell Microbiol 2013;15:1484-1495.

111 Puig-Kröger A, Serrano-Gómez D, Caparrós E, Domínguez-Soto A, Relloso M, Colmenares M, Martínez-Muñoz L, Longo N, Sánchez-Sánchez N, Rincon M, Rivas L, Sánchez-Mateos P, Fernández-Ruiz E, Corbí AL: Regulated expression of the pathogen receptor dendritic cell-specific intercellular adhesion molecule 3 (ICAM-3)-grabbing nonintegrin in THP-1 human leukemic cells, monocytes, and macrophages. J Biol Chem 2004;279:25680-25688.

112 Schäfer G, Jacobs M, Wilkinson RJ, Brown GD: Non-opsonic recognition of Mycobacterium tuberculosis by phagocytes. J Innate Immun 2009;1:231-243. 
113 Stenger S: Immunological control of tuberculosis: role of tumour necrosis factor and more. Ann Rheum Dis 2005;64 Suppl 4:iv24-28.

114 Tsao TC, Hong J, Huang C, Yang P, Liao SK, Chang KS: Increased TNF-alpha, IL-1 beta and IL-6 levels in the bronchoalveolar lavage fluid with the upregulation of their mRNA in macrophages lavaged from patients with active pulmonary tuberculosis. Tuber Lung Dis 1999;79:279-285.

115 Flynn JL, Goldstein MM, Chan J, Triebold KJ, Pfeffer K, Lowenstein CJ, Schreiber R, Mak TW, Bloom BR: Tumor necrosis factor-alpha is required in the protective immune response against Mycobacterium tuberculosis in mice. Immunity 1995;2:561-572.

116 Roach DR, Bean AG, Demangel C, France MP, Briscoe H, Britton WJ: TNF regulates chemokine induction essential for cell recruitment, granuloma formation, and clearance of mycobacterial infection. J Immunol 2002;168:4620-4627.

117 Clay H, Volkman HE, Ramakrishnan L: Tumor necrosis factor signaling mediates resistance to mycobacteria by inhibiting bacterial growth and macrophage death. Immunity 2008;29:283-294.

118 Cooper AM, Mayer-Barber KD, Sher A: Role of innate cytokines in mycobacterial infection. Mucosal Immunol 2011;4:252-260.

119 Bourigault ML, Segueni N, Rose S, Court N, Vacher R, Vasseur V, Erard F, Le Bert M, Garcia I, Iwakura Y, Jacobs M, Ryffel B, Quesniaux VF: Relative contribution of IL-1 $\alpha$, IL-1 $\beta$ and TNF to the host response to Mycobacterium tuberculosis and attenuated $\mathrm{M}$. bovis BCG. Immun Inflamm Dis 2013;1:47-62.

120 Mayer-Barber KD, Barber DL, Shenderov K, White SD, Wilson MS, Cheever A, Kugler D, Hieny S, Caspar P, Núñez G, Schlueter D, Flavell RA, Sutterwala FS, Sher A: Caspase1 independent IL-1beta production is critical for host resistance to mycobacterium tuberculosis and does not require TLR signaling in vivo. J Immunol 2010;184:3326-3330.

121 Law K, Weiden M, Harkin T, Tchou-Wong K, Chi C, Rom WN: Increased release of interleukin-1 beta, interleukin-6, and tumor necrosis factor-alpha by bronchoalveolar cells lavaged from involved sites in pulmonary tuberculosis. Am J Respir Crit Care Med 1996;153:799-804.

122 Tominaga K, Yoshimoto T, Torigoe K, Kurimoto M, Matsui K, Hada T, Okamura H, Nakanishi K: IL-12 synergizes with IL-18 or IL-1beta for IFN-gamma production from human T cells. Int Immunol 2000;12:151-160.

123 Sugawara I, Yamada H, Kaneko H, Mizuno S, Takeda K, Akira S: Role of interleukin-18 (IL-18) in mycobacterial infection in IL-18-gene-disrupted mice. Infect Immun 1999;67:2585-2589.

124 Kinjo Y, Kawakami K, Uezu K, Yara S, Miyagi K, Koguchi Y, Hoshino T, Okamoto M, Kawase Y, Yokota K, Yoshino K, Takeda K, Akira S, Saito A: Contribution of IL-18 to Th1 response and host defense against infection by Mycobacterium tuberculosis: a comparative study with IL-12p40. J Immunol 2002;169:323-329. 
125 Schneider BE, Korbel D, Hagens K, Koch M, Raupach B, Enders J, Kaufmann SH, Mittrücker HW, Schaible UE: A role for IL-18 in protective immunity against Mycobacterium tuberculosis. Eur J Immunol 2010;40:396-405.

126 Travar M, Petkovic M, Verhaz A: Type I, II, and III Interferons: Regulating Immunity to Mycobacterium tuberculosis Infection. Arch Immunol Ther Exp (Warsz) 2016;64:19-31.

127 Chen L, Suzuki Y, Wheelock EF: Interferon-gamma synergizes with tumor necrosis factor and with interleukin 1 and requires the presence of both monokines to induce antitumor cytotoxic activity in macrophages. J Immunol 1987;139:4096-4101.

128 Liang L, Shi R, Liu X, Yuan X, Zheng S, Zhang G, Wang W, Wang J, England K, Via LE, Cai Y, Goldfeder LC, Dodd LE, Barry CE, Chen RY: Interferon-gamma response to the treatment of active pulmonary and extra-pulmonary tuberculosis. Int $\mathrm{J}$ Tuberc Lung Dis 2017;21:1145-1149.

129 Hossain MM, Norazmi MN: Pattern recognition receptors and cytokines in Mycobacterium tuberculosis infection--the double-edged sword? Biomed Res Int 2013;2013:179174.

130 Zhang M, Lin Y, Iyer DV, Gong J, Abrams JS, Barnes PF: T-cell cytokine responses in human infection with Mycobacterium tuberculosis. Infect Immun 1995;63:3231-3234.

131 Ting LM, Kim AC, Cattamanchi A, Ernst JD: Mycobacterium tuberculosis inhibits IFNgamma transcriptional responses without inhibiting activation of STAT1. J Immunol 1999;163:3898-3906.

132 Zhang M, Gately MK, Wang E, Gong J, Wolf SF, Lu S, Modlin RL, Barnes PF: Interleukin 12 at the site of disease in tuberculosis. J Clin Invest 1994;93:1733-1739.

133 Flynn JL, Goldstein MM, Triebold KJ, Sypek J, Wolf S, Bloom BR: IL-12 increases resistance of $\mathrm{BALB} / \mathrm{c}$ mice to Mycobacterium tuberculosis infection. J Immunol $1995 ; 155: 2515-2524$.

134 Saunders BM, Frank AA, Orme IM, Cooper AM: Interleukin-6 induces early gamma interferon production in the infected lung but is not required for generation of specific immunity to Mycobacterium tuberculosis infection. Infect Immun 2000;68:3322-3326.

135 Schindler R, Mancilla J, Endres S, Ghorbani R, Clark SC, Dinarello CA: Correlations and interactions in the production of interleukin-6 (IL-6), IL-1, and tumor necrosis factor (TNF) in human blood mononuclear cells: IL-6 suppresses IL-1 and TNF. Blood 1990;75:40-47.

136 Kahnert A, Seiler P, Stein M, Bandermann S, Hahnke K, Mollenkopf H, Kaufmann SH: Alternative activation deprives macrophages of a coordinated defense program to Mycobacterium tuberculosis. Eur J Immunol 2006;36:631-647.

137 Martinez OM, Gibbons RS, Garovoy MR, Aronson FR: IL-4 inhibits IL-2 receptor expression and IL-2-dependent proliferation of human T cells. J Immunol 1990;144:22112215. 
138 van Crevel R, Karyadi E, Preyers F, Leenders M, Kullberg BJ, Nelwan RH, van der Meer JW: Increased production of interleukin 4 by CD4+ and CD8+ T cells from patients with tuberculosis is related to the presence of pulmonary cavities. J Infect Dis 2000;181:11941197.

139 Nolan A, Fajardo E, Huie ML, Condos R, Pooran A, Dawson R, Dheda K, Bateman E, Rom WN, Weiden MD: Increased production of IL-4 and IL-12p40 from bronchoalveolar lavage cells are biomarkers of Mycobacterium tuberculosis in the sputum. PLoS One 2013;8:e59461.

140 Essner R, Rhoades K, McBride WH, Morton DL, Economou JS: IL-4 down-regulates IL1 and TNF gene expression in human monocytes. J Immunol 1989;142:3857-3861.

141 de Waal Malefyt R, Haanen J, Spits H, Roncarolo MG, te Velde A, Figdor C, Johnson K, Kastelein R, Yssel H, de Vries JE: Interleukin 10 (IL-10) and viral IL-10 strongly reduce antigen-specific human $\mathrm{T}$ cell proliferation by diminishing the antigen-presenting capacity of monocytes via downregulation of class II major histocompatibility complex expression. J Exp Med 1991;174:915-924.

142 Abdalla AE, Lambert N, Duan X, Xie J: Interleukin-10 Family and Tuberculosis: An Old Story Renewed. Int J Biol Sci 2016;12:710-717.

143 Higgins DM, Sanchez-Campillo J, Rosas-Taraco AG, Lee EJ, Orme IM, GonzalezJuarrero M: Lack of IL-10 alters inflammatory and immune responses during pulmonary Mycobacterium tuberculosis infection. Tuberculosis (Edinb) 2009;89:149-157.

144 North RJ: Mice incapable of making IL-4 or IL-10 display normal resistance to infection with Mycobacterium tuberculosis. Clin Exp Immunol 1998;113:55-58.

145 Weiss G, Schaible UE: Macrophage defense mechanisms against intracellular bacteria. Immunol Rev 2015;264:182-203.

146 Amer AO, Swanson MS: A phagosome of one's own: a microbial guide to life in the macrophage. Curr Opin Microbiol 2002;5:56-61.

147 Wong D, Bach H, Sun J, Hmama Z, Av-Gay Y: Mycobacterium tuberculosis protein tyrosine phosphatase (PtpA) excludes host vacuolar-H+-ATPase to inhibit phagosome acidification. Proc Natl Acad Sci U S A 2011;108:19371-19376.

148 Spargo BJ, Crowe LM, Ioneda T, Beaman BL, Crowe JH: Cord factor (alpha,alphatrehalose 6,6'-dimycolate) inhibits fusion between phospholipid vesicles. Proc Natl Acad Sci U S A 1991;88:737-740.

149 Rajni, Rao N, Meena LS: Biosynthesis and Virulent Behavior of Lipids Produced by Mycobacterium tuberculosis: LAM and Cord Factor: An Overview. Biotechnol Res Int 2011;2011:274693.

150 Walburger A, Koul A, Ferrari G, Nguyen L, Prescianotto-Baschong C, Huygen K, Klebl B, Thompson C, Bacher G, Pieters J: Protein kinase G from pathogenic mycobacteria promotes survival within macrophages. Science 2004;304:1800-1804. 
151 Viswanathan G, Jafurulla M, Kumar GA, Raghunand TR, Chattopadhyay A: Dissecting the membrane cholesterol requirement for mycobacterial entry into host cells. Chem Phys Lipids 2015;189:19-27.

152 de Chastellier C, Thilo L: Cholesterol depletion in Mycobacterium avium-infected macrophages overcomes the block in phagosome maturation and leads to the reversible sequestration of viable mycobacteria in phagolysosome-derived autophagic vacuoles. Cell Microbiol 2006;8:242-256.

153 Pieters J: Mycobacterium tuberculosis and the macrophage: maintaining a balance. Cell Host Microbe 2008;3:399-407.

154 Gatfield J, Pieters J: Essential role for cholesterol in entry of mycobacteria into macrophages. Science 2000;288:1647-1650.

155 Jayachandran R, Sundaramurthy V, Combaluzier B, Mueller P, Korf H, Huygen K, Miyazaki T, Albrecht I, Massner J, Pieters J: Survival of mycobacteria in macrophages is mediated by coronin 1-dependent activation of calcineurin. Cell 2007;130:37-50.

156 Stamm LM, Morisaki JH, Gao LY, Jeng RL, McDonald KL, Roth R, Takeshita S, Heuser $\mathrm{J}$, Welch MD, Brown EJ: Mycobacterium marinum escapes from phagosomes and is propelled by actin-based motility. J Exp Med 2003;198:1361-1368.

157 Rook GA, Steele J, Fraher L, Barker S, Karmali R, O'Riordan J, Stanford J: Vitamin D3, gamma interferon, and control of proliferation of Mycobacterium tuberculosis by human monocytes. Immunology 1986;57:159-163.

158 Crowle AJ, Ross EJ, May MH: Inhibition by 1,25(OH)2-vitamin D3 of the multiplication of virulent tubercle bacilli in cultured human macrophages. Infect Immun 1987;55:29452950.

159 Shin DM, Yuk JM, Lee HM, Lee SH, Son JW, Harding CV, Kim JM, Modlin RL, Jo EK: Mycobacterial lipoprotein activates autophagy via TLR2/1/CD14 and a functional vitamin D receptor signalling. Cell Microbiol 2010;12:1648-1665.

160 Liu PT, Modlin RL: Human macrophage host defense against Mycobacterium tuberculosis. Curr Opin Immunol 2008;20:371-376.

161 Rabin N, Zheng Y, Opoku-Temeng C, Du Y, Bonsu E, Sintim HO: Biofilm formation mechanisms and targets for developing antibiofilm agents. Future Med Chem 2015;7:493512.

162 López D, Vlamakis H, Kolter R: Biofilms. Cold Spring Harb Perspect Biol 2010;2:a000398.

163 Defraine V, Fauvart M, Michiels J: Fighting bacterial persistence: Current and emerging anti-persister strategies and therapeutics. Drug Resist Updat 2018;38:12-26.

164 Fisher RA, Gollan B, Helaine S: Persistent bacterial infections and persister cells. Nat Rev Microbiol 2017;15:453-464. 
165 Morikawa M: Beneficial biofilm formation by industrial bacteria Bacillus subtilis and related species. J Biosci Bioeng 2006;101:1-8.

166 Esteban J, García-Coca M: Biofilms. Front Microbiol 2017;8:2651.

167 Islam MS, Richards JP, Ojha AK: Targeting drug tolerance in mycobacteria: a perspective from mycobacterial biofilms. Expert Rev Anti Infect Ther 2012;10:1055-1066.

168 Zambrano MM, Kolter R: Mycobacterial biofilms: a greasy way to hold it together. Cell 2005;123:762-764.

169 Recht J, Martínez A, Torello S, Kolter R: Genetic analysis of sliding motility in Mycobacterium smegmatis. J Bacteriol 2000;182:4348-4351.

170 Martínez A, Torello S, Kolter R: Sliding motility in mycobacteria. J Bacteriol 1999;181:7331-7338.

171 Ojha AK, Baughn AD, Sambandan D, Hsu T, Trivelli X, Guerardel Y, Alahari A, Kremer L, Jacobs WR, Hatfull GF: Growth of Mycobacterium tuberculosis biofilms containing free mycolic acids and harbouring drug-tolerant bacteria. Mol Microbiol 2008;69:164174.

172 Trivedi A, Mavi PS, Bhatt D, Kumar A: Thiol reductive stress induces cellulose-anchored biofilm formation in Mycobacterium tuberculosis. Nat Commun 2016;7:11392.

173 Richards JP, Ojha AK: Mycobacterial Biofilms. Microbiol Spectr 2014;2

174 Hall-Stoodley L, Brun OS, Polshyna G, Barker LP: Mycobacterium marinum biofilm formation reveals cording morphology. FEMS Microbiol Lett 2006;257:43-49.

175 Julián E, Roldán M, Sánchez-Chardi A, Astola O, Agustí G, Luquin M: Microscopic cords, a virulence-related characteristic of Mycobacterium tuberculosis, are also present in nonpathogenic mycobacteria. J Bacteriol 2010;192:1751-1760.

176 Bloch H: Studies on the virulence of tubercle bacilli; isolation and biological properties of a constituent of virulent organisms. J Exp Med 1950;91:197-218, pl.

177 Noll H, Bloch H, Asselineau J, Lederer E: The chemical structure of the cord factor of Mycobacterium tuberculosis. Biochim Biophys Acta 1956;20:299-309.

178 Indrigo J, Hunter RL, Actor JK: Cord factor trehalose 6,6'-dimycolate (TDM) mediates trafficking events during mycobacterial infection of murine macrophages. Microbiology 2003; 149:2049-2059.

179 Behling CA, Bennett B, Takayama K, Hunter RL: Development of a trehalose 6,6'dimycolate model which explains cord formation by Mycobacterium tuberculosis. Infect Immun 1993;61:2296-2303.

180 Behling CA, Perez RL, Kidd MR, Staton GW, Hunter RL: Induction of pulmonary granulomas, macrophage procoagulant activity, and tumor necrosis factor-alpha by trehalose glycolipids. Ann Clin Lab Sci 1993;23:256-266. 
181 Perez RL, Roman J, Roser S, Little C, Olsen M, Indrigo J, Hunter RL, Actor JK: Cytokine message and protein expression during lung granuloma formation and resolution induced by the mycobacterial cord factor trehalose-6,6'-dimycolate. J Interferon Cytokine Res 2000;20:795-804.

182 Arora R, Armitige L, Wanger A, Hunter RL, Hwang SA: Association of pellicle growth morphological characteristics and clinical presentation of Mycobacterium tuberculosis isolates. Tuberculosis (Edinb) 2016;101S:S63-S68.

183 Hunter RL, Olsen M, Jagannath C, Actor JK: Trehalose 6,6'-dimycolate and lipid in the pathogenesis of caseating granulomas of tuberculosis in mice. Am $J$ Pathol 2006; 168:1249-1261.

184 Hunter RL, Olsen MR, Jagannath C, Actor JK: Multiple roles of cord factor in the pathogenesis of primary, secondary, and cavitary tuberculosis, including a revised description of the pathology of secondary disease. Ann Clin Lab Sci 2006;36:371-386.

185 Bloch H, Noll H: Studies on the virulence of tubercle bacilli; variations in virulence effected by tween 80 and thiosemicarbazone. J Exp Med 1953;97:1-16.

186 Masaki S, Sugimori G, Okamoto A, Imose J, Hayashi Y: Effect of Tween 80 on the growth of Mycobacterium avium complex. Microbiol Immunol 1990;34:653-663.

187 Ortalo-Magné A, Lemassu A, Lanéelle MA, Bardou F, Silve G, Gounon P, Marchal G, Daffé M: Identification of the surface-exposed lipids on the cell envelopes of Mycobacterium tuberculosis and other mycobacterial species. J Bacteriol 1996;178:456461.

188 Catherinot E, Roux AL, Macheras E, Hubert D, Matmar M, Dannhoffer L, Chinet T, Morand P, Poyart C, Heym B, Rottman M, Gaillard JL, Herrmann JL: Acute respiratory failure involving an R variant of Mycobacterium abscessus. J Clin Microbiol 2009;47:271274.

189 Howard ST, Rhoades E, Recht J, Pang X, Alsup A, Kolter R, Lyons CR, Byrd TF: Spontaneous reversion of Mycobacterium abscessus from a smooth to a rough morphotype is associated with reduced expression of glycopeptidolipid and reacquisition of an invasive phenotype. Microbiology 2006;152:1581-1590.

190 Middlebrook G, Dubos RJ, Pierce C: Virulence and Morphological Characteristics of Mammalian Tubercle Bacilli. J Exp Med 1947;86:175-184.

191 Darzins E, Fahr G: Cord-forming property, lethality and pathogenicity of Mycobacteria. Dis Chest 1956;30:642-648.

192 Basaraba RJ, Ojha AK: Mycobacterial Biofilms: Revisiting Tuberculosis Bacilli in Extracellular Necrotizing Lesions. Microbiol Spectr 2017;5

193 Lenaerts AJ, Hoff D, Aly S, Ehlers S, Andries K, Cantarero L, Orme IM, Basaraba RJ: Location of persisting mycobacteria in a Guinea pig model of tuberculosis revealed by r207910. Antimicrob Agents Chemother 2007;51:3338-3345. 
194 Marsollier L, Aubry J, Coutanceau E, André JP, Small PL, Milon G, Legras P, Guadagnini S, Carbonnelle B, Cole ST: Colonization of the salivary glands of Naucoris cimicoides by Mycobacterium ulcerans requires host plasmatocytes and a macrolide toxin, mycolactone. Cell Microbiol 2005;7:935-943.

195 Bosio S, Leekha S, Gamb SI, Wright AJ, Terrell CL, Miller DV: Mycobacterium fortuitum prosthetic valve endocarditis: a case for the pathogenetic role of biofilms. Cardiovasc Pathol 2012;21:361-364.

196 Moraco AH, Kornfeld H: Cell death and autophagy in tuberculosis. Semin Immunol 2014;26:497-511.

197 Gutierrez MG, Master SS, Singh SB, Taylor GA, Colombo MI, Deretic V: Autophagy is a defense mechanism inhibiting BCG and Mycobacterium tuberculosis survival in infected macrophages. Cell 2004;119:753-766.

198 Yuk JM, Shin DM, Lee HM, Yang CS, Jin HS, Kim KK, Lee ZW, Lee SH, Kim JM, Jo EK: Vitamin D3 induces autophagy in human monocytes/macrophages via cathelicidin. Cell Host Microbe 2009;6:231-243.

$199 \mathrm{Xu} \mathrm{Y,} \mathrm{Fattah} \mathrm{EA,} \mathrm{Liu} \mathrm{XD,} \mathrm{Jagannath} \mathrm{C,} \mathrm{Eissa} \mathrm{NT:} \mathrm{Harnessing} \mathrm{of} \mathrm{TLR-mediated}$ autophagy to combat mycobacteria in macrophages. Tuberculosis (Edinb) 2013;93 Suppl:S33-37.

200 Zhang L, Zhang H, Zhao Y, Mao F, Wu J, Bai B, Xu Z, Jiang Y, Shi C: Effects of Mycobacterium tuberculosis ESAT-6/CFP-10 fusion protein on the autophagy function of mouse macrophages. DNA Cell Biol 2012;31:171-179.

201 Behar SM, Martin CJ, Booty MG, Nishimura T, Zhao X, Gan HX, Divangahi M, Remold HG: Apoptosis is an innate defense function of macrophages against Mycobacterium tuberculosis. Mucosal Immunol 2011;4:279-287.

202 Ramakrishnan L: Looking within the zebrafish to understand the tuberculous granuloma. Adv Exp Med Biol 2013;783:251-266.

203 Brinkmann V, Reichard U, Goosmann C, Fauler B, Uhlemann Y, Weiss DS, Weinrauch Y, Zychlinsky A: Neutrophil extracellular traps kill bacteria. Science 2004;303:15321535 .

204 Steinberg BE, Grinstein S: Unconventional roles of the NADPH oxidase: signaling, ion homeostasis, and cell death. Sci STKE 2007;2007:pe11.

205 Mesa MA, Vasquez G: NETosis. Autoimmune Dis 2013;2013:651497.

206 Wartha F, Henriques-Normark B: ETosis: a novel cell death pathway. Sci Signal 2008;1:pe25.

207 Vorobjeva NV, Pinegin BV: Neutrophil extracellular traps: mechanisms of formation and role in health and disease. Biochemistry (Mosc) 2014;79:1286-1296.

208 von Köckritz-Blickwede M, Nizet V: Innate immunity turned inside-out: antimicrobial defense by phagocyte extracellular traps. J Mol Med (Berl) 2009;87:775-783. 
209 Guimarães-Costa AB, Nascimento MT, Wardini AB, Pinto-da-Silva LH, Saraiva EM: ETosis: A Microbicidal Mechanism beyond Cell Death. J Parasitol Res 2012;2012:929743.

210 Remijsen Q, Kuijpers TW, Wirawan E, Lippens S, Vandenabeele P, Vanden Berghe T: Dying for a cause: NETosis, mechanisms behind an antimicrobial cell death modality. Cell Death Differ 2011;18:581-588.

211 Wang Y, Li M, Stadler S, Correll S, Li P, Wang D, Hayama R, Leonelli L, Han H, Grigoryev SA, Allis CD, Coonrod SA: Histone hypercitrullination mediates chromatin decondensation and neutrophil extracellular trap formation. J Cell Biol 2009;184:205-213.

212 Yousefi S, Gold JA, Andina N, Lee JJ, Kelly AM, Kozlowski E, Schmid I, Straumann A, Reichenbach J, Gleich GJ, Simon HU: Catapult-like release of mitochondrial DNA by eosinophils contributes to antibacterial defense. Nat Med 2008;14:949-953.

213 Kawasaki H, Iwamuro S: Potential roles of histones in host defense as antimicrobial agents. Infect Disord Drug Targets 2008;8:195-205.

214 Ramos-Kichik V, Mondragón-Flores R, Mondragón-Castelán M, Gonzalez-Pozos S, Muñiz-Hernandez S, Rojas-Espinosa O, Chacón-Salinas R, Estrada-Parra S, EstradaGarcía I: Neutrophil extracellular traps are induced by Mycobacterium tuberculosis. Tuberculosis (Edinb) 2009;89:29-37.

215 Buchanan JT, Simpson AJ, Aziz RK, Liu GY, Kristian SA, Kotb M, Feramisco J, Nizet $\mathrm{V}$ : DNase expression allows the pathogen group A Streptococcus to escape killing in neutrophil extracellular traps. Curr Biol 2006;16:396-400.

216 Berends ET, Horswill AR, Haste NM, Monestier M, Nizet V, von Köckritz-Blickwede M: Nuclease expression by Staphylococcus aureus facilitates escape from neutrophil extracellular traps. J Innate Immun 2010;2:576-586.

217 Schechter MC, Buac K, Adekambi T, Cagle S, Celli J, Ray SM, Mehta CC, Rada B, Rengarajan J: Neutrophil extracellular trap (NET) levels in human plasma are associated with active TB. PLoS One 2017;12:e0182587.

218 van der Meer AJ, Zeerleder S, Blok DC, Kager LM, Lede IO, Rahman W, Afroz R, Ghose A, Visser CE, Zahed ASM, Husain MA, Alam KM, Barua PC, Hassan M, Tayab MA, Dondorp AM, van der Poll T: Neutrophil extracellular traps in patients with pulmonary tuberculosis. Respir Res 2017;18:181.

219 Farrera C, Fadeel B: Macrophage clearance of neutrophil extracellular traps is a silent process. J Immunol 2013;191:2647-2656.

220 Chow OA, von Köckritz-Blickwede M, Bright AT, Hensler ME, Zinkernagel AS, Cogen AL, Gallo RL, Monestier M, Wang Y, Glass CK, Nizet V: Statins enhance formation of phagocyte extracellular traps. Cell Host Microbe 2010;8:445-454.

221 Boe DM, Curtis BJ, Chen MM, Ippolito JA, Kovacs EJ: Extracellular traps and macrophages: new roles for the versatile phagocyte. J Leukoc Biol 2015;97:1023-1035. 
222 Aulik NA, Hellenbrand KM, Czuprynski CJ: Mannheimia haemolytica and its leukotoxin cause macrophage extracellular trap formation by bovine macrophages. Infect Immun 2012;80:1923-1933.

223 Wong KW, Jacobs WR: Mycobacterium tuberculosis exploits human interferon $\gamma$ to stimulate macrophage extracellular trap formation and necrosis. $J$ Infect Dis 2013;208:109-119.

224 Doster RS, Rogers LM, Gaddy JA, Aronoff DM: Macrophage Extracellular Traps: A Scoping Review. J Innate Immun 2018;10:3-13.

225 Liu P, Wu X, Liao C, Liu X, Du J, Shi H, Wang X, Bai X, Peng P, Yu L, Wang F, Zhao Y, Liu M: Escherichia coli and Candida albicans induced macrophage extracellular traplike structures with limited microbicidal activity. PLoS One 2014;9:e90042.

226 Je S, Quan H, Yoon Y, Na Y, Kim BJ, Seok SH: Mycobacterium massiliense Induces Macrophage Extracellular Traps with Facilitating Bacterial Growth. PLoS One 2016;11:e0155685.

227 Branzk N, Lubojemska A, Hardison SE, Wang Q, Gutierrez MG, Brown GD, Papayannopoulos V: Neutrophils sense microbe size and selectively release neutrophil extracellular traps in response to large pathogens. Nat Immunol 2014;15:1017-1025.

228 Jonsson BE, Bylund J, Johansson BR, Telemo E, Wold AE: Cord-forming mycobacteria induce DNA meshwork formation by human peripheral blood mononuclear cells. Pathog Dis 2013;67:54-66.

229 Strull GE, Dym H: Tuberculosis: diagnosis and treatment of resurgent disease. J Oral Maxillofac Surg 1995;53:1334-1340.

230 Grosset JH: Present status of chemotherapy for tuberculosis. Rev Infect Dis 1989;11 Suppl 2:S347-352.

231 Mitchison DA: The diagnosis and therapy of tuberculosis during the past 100 years. Am J Respir Crit Care Med 2005;171:699-706.

232 Sotgiu G, Centis R, D'ambrosio L, Migliori GB: Tuberculosis treatment and drug regimens. Cold Spring Harb Perspect Med 2015;5:a017822.

233 Thomas JP, Baughn CO, Wilkinson RG, Shepherd RG: A new synthetic compound with antituberculous activity in mice: ethambutol (dextro-2,2'-(ethylenediimino)-di-l-butanol). Am Rev Respir Dis 1961;83:891-893.

234 Unissa AN, Subbian S, Hanna LE, Selvakumar N: Overview on mechanisms of isoniazid action and resistance in Mycobacterium tuberculosis. Infect Genet Evol 2016;45:474-492.

235 Winder FG, Collins PB: Inhibition by isoniazid of synthesis of mycolic acids in Mycobacterium tuberculosis. J Gen Microbiol 1970;63:41-48.

236 Vilchèze C, Jacobs WR: Resistance to Isoniazid and Ethionamide in Mycobacterium tuberculosis: Genes, Mutations, and Causalities. Microbiol Spectr 2014;2:MGM2-00142013. 
237 Wehrli W, Staehelin M: Actions of the rifamycins. Bacteriol Rev 1971;35:290-309.

238 Levin ME, Hatfull GF: Mycobacterium smegmatis RNA polymerase: DNA supercoiling, action of rifampicin and mechanism of rifampicin resistance. Mol Microbiol 1993;8:277285 .

239 Getahun H, Chaisson RE, Raviglione M: Latent Mycobacterium tuberculosis Infection. N Engl J Med 2015;373:1179-1180.

240 Telenti A, Imboden P, Marchesi F, Lowrie D, Cole S, Colston MJ, Matter L, Schopfer K, Bodmer T: Detection of rifampicin-resistance mutations in Mycobacterium tuberculosis. Lancet 1993;341:647-650.

241 Salfinger M, Heifets LB: Determination of pyrazinamide MICs for Mycobacterium tuberculosis at different $\mathrm{pHs}$ by the radiometric method. Antimicrob Agents Chemother 1988;32:1002-1004.

242 McCune RM, Feldmann FM, Lambert HP, McDermott W: Microbial persistence. I. The capacity of tubercle bacilli to survive sterilization in mouse tissues. J Exp Med 1966;123:445-468.

243 Mccune RM, Mcdermott W, Tompsett R: The fate of Mycobacterium tuberculosis in mouse tissues as determined by the microbial enumeration technique. II. The conversion of tuberculous infection to the latent state by the administration of pyrazinamide and a companion drug. J Exp Med 1956;104:763-802.

244 Tarshis MS, Weed WA: Lack of significant in vitro sensitivity of Mycobacterium tuberculosis to pyrazinamide on three different solid media. Am Rev Tuberc 1953;67:391395.

245 Byrne ST, Denkin SM, Zhang Y: Aspirin and ibuprofen enhance pyrazinamide treatment of murine tuberculosis. J Antimicrob Chemother 2007;59:313-316.

246 Zhang Y, Mitchison D: The curious characteristics of pyrazinamide: a review. Int J Tuberc Lung Dis 2003;7:6-21.

247 Zhang Y, Scorpio A, Nikaido H, Sun Z: Role of acid pH and deficient efflux of pyrazinoic acid in unique susceptibility of Mycobacterium tuberculosis to pyrazinamide. $\mathrm{J}$ Bacteriol 1999;181:2044-2049.

248 Zhang Y, Wade MM, Scorpio A, Zhang H, Sun Z: Mode of action of pyrazinamide: disruption of Mycobacterium tuberculosis membrane transport and energetics by pyrazinoic acid. J Antimicrob Chemother 2003;52:790-795.

249 Zimhony O, Cox JS, Welch JT, Vilchèze C, Jacobs WR: Pyrazinamide inhibits the eukaryotic-like fatty acid synthetase I (FASI) of Mycobacterium tuberculosis. Nat Med 2000;6:1043-1047.

250 Scorpio A, Zhang Y: Mutations in pncA, a gene encoding pyrazinamidase/nicotinamidase, cause resistance to the antituberculous drug pyrazinamide in tubercle bacillus. Nat Med 1996;2:662-667. 
251 Forbes M, Kuck NA, Peets EA: Effect Of Ethambutol On Nucleic Acid Metabolism In Mycobacterium Smegmatis And Its Reversal By Polyamines And Divalent Cations. J Bacteriol 1965;89:1299-1305.

252 Takayama K, Kilburn JO: Inhibition of synthesis of arabinogalactan by ethambutol in Mycobacterium smegmatis. Antimicrob Agents Chemother 1989;33:1493-1499.

253 Goude R, Amin AG, Chatterjee D, Parish T: The arabinosyltransferase EmbC is inhibited by ethambutol in Mycobacterium tuberculosis. Antimicrob Agents Chemother 2009;53:4138-4146.

254 Silve G, Valero-Guillen P, Quemard A, Dupont MA, Daffe M, Laneelle G: Ethambutol inhibition of glucose metabolism in mycobacteria: a possible target of the drug. Antimicrob Agents Chemother 1993;37:1536-1538.

255 Safi H, Lingaraju S, Amin A, Kim S, Jones M, Holmes M, McNeil M, Peterson SN, Chatterjee D, Fleischmann R, Alland D: Evolution of high-level ethambutol-resistant tuberculosis through interacting mutations in decaprenylphosphoryl- $\beta$-D-arabinose biosynthetic and utilization pathway genes. Nat Genet 2013;45:1190-1197.

256 Chakraborty S, Rhee KY: Tuberculosis Drug Development: History and Evolution of the Mechanism-Based Paradigm. Cold Spring Harb Perspect Med 2015;5:a021147.

257 Gawad J, Bonde C: Current Affairs, Future Perspectives of Tuberculosis and Antitubercular Agents. Indian J Tuberc 2018;65:15-22.

258 Matteelli A, Migliori GB, Cirillo D, Centis R, Girard E, Raviglion M: Multidrug-resistant and extensively drug-resistant Mycobacterium tuberculosis: epidemiology and control. Expert Rev Anti Infect Ther 2007;5:857-871.

259 Gurumurthy P, Ramachandran G, Hemanth Kumar AK, Rajasekaran S, Padmapriyadarsini C, Swaminathan S, Venkatesan P, Sekar L, Kumar S, Krishnarajasekhar OR, Paramesh P: Malabsorption of rifampin and isoniazid in HIV-infected patients with and without tuberculosis. Clin Infect Dis 2004;38:280-283.

260 Boritsch EC, Brosch R: Evolution of Mycobacterium tuberculosis: New Insights into Pathogenicity and Drug Resistance. Microbiol Spectr 2016;4

261 Jiang JR, Yen SY, Wang JY: Increased prevalence of primary drug-resistant pulmonary tuberculosis in immunocompromised patients. Respirology 2011;16:308-313.

262 Volmink J, Garner P: Directly observed therapy for treating tuberculosis. Cochrane Database Syst Rev 2003:CD003343.

263 Seung KJ, Keshavjee S, Rich ML: Multidrug-Resistant Tuberculosis and Extensively Drug-Resistant Tuberculosis. Cold Spring Harb Perspect Med 2015;5:a017863.

264 Miotto P, Cirillo DM, Migliori GB: Drug resistance in Mycobacterium tuberculosis: molecular mechanisms challenging fluoroquinolones and pyrazinamide effectiveness. Chest 2015;147:1135-1143. 
265 Johnson JL, Hadad DJ, Boom WH, Daley CL, Peloquin CA, Eisenach KD, Jankus DD, Debanne SM, Charlebois ED, Maciel E, Palaci M, Dietze R: Early and extended early bactericidal activity of levofloxacin, gatifloxacin and moxifloxacin in pulmonary tuberculosis. Int J Tuberc Lung Dis 2006;10:605-612.

266 Miyazaki E, Miyazaki M, Chen JM, Chaisson RE, Bishai WR: Moxifloxacin (BAY128039), a new 8-methoxyquinolone, is active in a mouse model of tuberculosis. Antimicrob Agents Chemother 1999;43:85-89.

267 Ji B, Lounis N, Maslo C, Truffot-Pernot C, Bonnafous P, Grosset J: In vitro and in vivo activities of moxifloxacin and clinafloxacin against Mycobacterium tuberculosis. Antimicrob Agents Chemother 1998;42:2066-2069.

268 Nuermberger EL, Yoshimatsu T, Tyagi S, O'Brien RJ, Vernon AN, Chaisson RE, Bishai WR, Grosset JH: Moxifloxacin-containing regimen greatly reduces time to culture conversion in murine tuberculosis. Am J Respir Crit Care Med 2004;169:421-426.

269 Pletz MW, De Roux A, Roth A, Neumann KH, Mauch H, Lode H: Early bactericidal activity of moxifloxacin in treatment of pulmonary tuberculosis: a prospective, randomized study. Antimicrob Agents Chemother 2004;48:780-782.

270 Conde MB, Efron A, Loredo C, De Souza GR, Graça NP, Cezar MC, Ram M, Chaudhary MA, Bishai WR, Kritski AL, Chaisson RE: Moxifloxacin versus ethambutol in the initial treatment of tuberculosis: a double-blind, randomised, controlled phase II trial. Lancet 2009;373:1183-1189.

271 Ramachandran G, Swaminathan S: Safety and tolerability profile of second-line antituberculosis medications. Drug Saf 2015;38:253-269.

272 Mitchison D, Davies G: The chemotherapy of tuberculosis: past, present and future. Int J Tuberc Lung Dis 2012;16:724-732.

273 Reddy VM, O'Sullivan JF, Gangadharam PR: Antimycobacterial activities of riminophenazines. J Antimicrob Chemother 1999;43:615-623.

274 Yano T, Kassovska-Bratinova S, Teh JS, Winkler J, Sullivan K, Isaacs A, Schechter NM, Rubin H: Reduction of clofazimine by mycobacterial type 2 NADH:quinone oxidoreductase: a pathway for the generation of bactericidal levels of reactive oxygen species. J Biol Chem 2011;286:10276-10287.

275 Xu J, Lu Y, Fu L, Zhu H, Wang B, Mdluli K, Upton AM, Jin H, Zheng M, Zhao W, Li P: In vitro and in vivo activity of clofazimine against Mycobacterium tuberculosis persisters. Int J Tuberc Lung Dis 2012;16:1119-1125.

276 Mdluli K, Kaneko T, Upton A: The tuberculosis drug discovery and development pipeline and emerging drug targets. Cold Spring Harb Perspect Med 2015;5

277 Blair HA, Scott LJ: Delamanid: a review of its use in patients with multidrug-resistant tuberculosis. Drugs 2015;75:91-100. 
278 Matsumoto M, Hashizume H, Tomishige T, Kawasaki M, Tsubouchi H, Sasaki H, Shimokawa Y, Komatsu M: OPC-67683, a nitro-dihydro-imidazooxazole derivative with promising action against tuberculosis in vitro and in mice. PLoS Med 2006;3:e466.

279 Saliu OY, Crismale C, Schwander SK, Wallis RS: Bactericidal activity of OPC-67683 against drug-tolerant Mycobacterium tuberculosis. J Antimicrob Chemother 2007;60:994998.

280 Diacon AH, Dawson R, Hanekom M, Narunsky K, Venter A, Hittel N, Geiter LJ, Wells CD, Paccaly AJ, Donald PR: Early bactericidal activity of delamanid (OPC-67683) in smear-positive pulmonary tuberculosis patients. Int J Tuberc Lung Dis 2011;15:949-954.

281 TMC-207. Tuberculosis (Edinb) 2008;88:168-169.

282 Chahine EB, Karaoui LR, Mansour H: Bedaquiline: a novel diarylquinoline for multidrugresistant tuberculosis. Ann Pharmacother 2014;48:107-115.

283 Rustomjee R, Diacon AH, Allen J, Venter A, Reddy C, Patientia RF, Mthiyane TC, De Marez T, van Heeswijk R, Kerstens R, Koul A, De Beule K, Donald PR, McNeeley DF: Early bactericidal activity and pharmacokinetics of the diarylquinoline TMC207 in treatment of pulmonary tuberculosis. Antimicrob Agents Chemother 2008;52:2831-2835.

284 Diacon AH, Pym A, Grobusch M, Patientia R, Rustomjee R, Page-Shipp L, Pistorius C, Krause R, Bogoshi M, Churchyard G, Venter A, Allen J, Palomino JC, De Marez T, van Heeswijk RP, Lounis N, Meyvisch P, Verbeeck J, Parys W, de Beule K, Andries K, Mc Neeley DF: The diarylquinoline TMC207 for multidrug-resistant tuberculosis. N Engl J Med 2009;360:2397-2405.

285 Diacon AH, Pym A, Grobusch MP, de los Rios JM, Gotuzzo E, Vasilyeva I, Leimane V, Andries K, Bakare N, De Marez T, Haxaire-Theeuwes M, Lounis N, Meyvisch P, De Paepe E, van Heeswijk RP, Dannemann B, Group T-CS: Multidrug-resistant tuberculosis and culture conversion with bedaquiline. N Engl J Med 2014;371:723-732.

286 Stover CK, Warrener P, VanDevanter DR, Sherman DR, Arain TM, Langhorne MH, Anderson SW, Towell JA, Yuan Y, McMurray DN, Kreiswirth BN, Barry CE, Baker WR: A small-molecule nitroimidazopyran drug candidate for the treatment of tuberculosis. Nature 2000;405:962-966.

287 Singh R, Manjunatha U, Boshoff HI, Ha YH, Niyomrattanakit P, Ledwidge R, Dowd CS, Lee IY, Kim P, Zhang L, Kang S, Keller TH, Jiricek J, Barry CE: PA-824 kills nonreplicating Mycobacterium tuberculosis by intracellular NO release. Science 2008;322:1392-1395.

288 Tyagi S, Nuermberger E, Yoshimatsu T, Williams K, Rosenthal I, Lounis N, Bishai W, Grosset J: Bactericidal activity of the nitroimidazopyran PA-824 in a murine model of tuberculosis. Antimicrob Agents Chemother 2005;49:2289-2293.

289 Dutta NK, Karakousis PC: PA-824 is as effective as isoniazid against latent tuberculosis infection in $\mathrm{C} 3 \mathrm{HeB} / \mathrm{FeJ}$ mice. Int J Antimicrob Agents 2014;44:564-566.

290 Diacon AH, Dawson R, von Groote-Bidlingmaier F, Symons G, Venter A, Donald PR, van Niekerk C, Everitt D, Winter H, Becker P, Mendel CM, Spigelman MK: 14-day 
bactericidal activity of PA-824, bedaquiline, pyrazinamide, and moxifloxacin combinations: a randomised trial. Lancet 2012;380:986-993.

291 Swinney DC, Anthony J: How were new medicines discovered? Nat Rev Drug Discov 2011;10:507-519.

292 Swinney DC: Phenotypic vs. target-based drug discovery for first-in-class medicines. Clin Pharmacol Ther 2013;93:299-301.

293 Zheng W, Thorne N, McKew JC: Phenotypic screens as a renewed approach for drug discovery. Drug Discov Today 2013;18:1067-1073.

294 Ou-Yang SS, Lu JY, Kong XQ, Liang ZJ, Luo C, Jiang H: Computational drug discovery. Acta Pharmacol Sin 2012;33:1131-1140.

295 Zuniga ES, Early J, Parish T: The future for early-stage tuberculosis drug discovery. Future Microbiol 2015;10:217-229.

296 Fernandez P, Saint-Joanis B, Barilone N, Jackson M, Gicquel B, Cole ST, Alzari PM: The Ser/Thr protein kinase PknB is essential for sustaining mycobacterial growth. J Bacteriol 2006;188:7778-7784.

297 Cole ST: Inhibiting Mycobacterium tuberculosis within and without. Philos Trans R Soc Lond B Biol Sci 2016;371

298 Andries K, Verhasselt P, Guillemont J, Göhlmann HW, Neefs JM, Winkler H, Van Gestel J, Timmerman P, Zhu M, Lee E, Williams P, de Chaffoy D, Huitric E, Hoffner S, Cambau E, Truffot-Pernot C, Lounis N, Jarlier V: A diarylquinoline drug active on the ATP synthase of Mycobacterium tuberculosis. Science 2005;307:223-227.

299 Franzblau SG, DeGroote MA, Cho SH, Andries K, Nuermberger E, Orme IM, Mdluli K, Angulo-Barturen I, Dick T, Dartois V, Lenaerts AJ: Comprehensive analysis of methods used for the evaluation of compounds against Mycobacterium tuberculosis. Tuberculosis (Edinb) 2012;92:453-488.

300 Trofimov V, Costa-Gouveia J, Hoffmann E, Brodin P: Host-pathogen systems for early drug discovery against tuberculosis. Curr Opin Microbiol 2017;39:143-151.

301 Dhiman R, Singh R: Recent advances for identification of new scaffolds and drug targets for Mycobacterium tuberculosis. IUBMB Life 2018;70:905-916.

302 Gillespie SH, Crook AM, McHugh TD, Mendel CM, Meredith SK, Murray SR, Pappas F, Phillips PP, Nunn AJ, Consortium R: Four-month moxifloxacin-based regimens for drugsensitive tuberculosis. N Engl J Med 2014;371:1577-1587.

303 Gasparri F: An overview of cell phenotypes in HCS: limitations and advantages. Expert Opin Drug Discov 2009;4:643-657.

304 Mattiazzi Usaj M, Styles EB, Verster AJ, Friesen H, Boone C, Andrews BJ: High-Content Screening for Quantitative Cell Biology. Trends Cell Biol 2016;26:598-611. 
305 An WF, Tolliday N: Cell-based assays for high-throughput screening. Mol Biotechnol 2010;45:180-186.

306 Sukuru SC, Jenkins JL, Beckwith RE, Scheiber J, Bender A, Mikhailov D, Davies JW, Glick M: Plate-based diversity selection based on empirical HTS data to enhance the number of hits and their chemical diversity. J Biomol Screen 2009;14:690-699.

307 Chinsembu KC: Tuberculosis and nature's pharmacy of putative anti-tuberculosis agents. Acta Trop 2016;153:46-56.

308 Tabuti JR, Kukunda CB, Waako PJ: Medicinal plants used by traditional medicine practitioners in the treatment of tuberculosis and related ailments in Uganda. $J$ Ethnopharmacol 2010;127:130-136.

309 Alvin A, Miller KI, Neilan BA: Exploring the potential of endophytes from medicinal plants as sources of antimycobacterial compounds. Microbiol Res 2014;169:483-495.

310 Okunade AL, Elvin-Lewis MP, Lewis WH: Natural antimycobacterial metabolites: current status. Phytochemistry 2004;65:1017-1032.

311 Hughes JP, Rees S, Kalindjian SB, Philpott KL: Principles of early drug discovery. Br J Pharmacol 2011;162:1239-1249.

312 Hughes D, Karlén A: Discovery and preclinical development of new antibiotics. Ups J Med Sci 2014;119:162-169.

313 Ufimtseva E, Eremeeva N, Petrunina E, Umpeleva T, Karskanova S, Bayborodin S, Vakhrusheva D, Kravchenko M, Skornyakov S: Ex vivo expansion of alveolar macrophages with Mycobacterium tuberculosis from the resected lungs of patients with pulmonary tuberculosis. PLoS One 2018;13:e0191918.

314 Wong KW, Jacobs WR, Jr.: Mycobacterium tuberculosis exploits human interferon gamma to stimulate macrophage extracellular trap formation and necrosis. J Infect Dis 2013;208:109-119.

315 Fuchs TA, Abed U, Goosmann C, Hurwitz R, Schulze I, Wahn V, Weinrauch Y, Brinkmann V, Zychlinsky A: Novel cell death program leads to neutrophil extracellular traps. J Cell Biol 2007;176:231-241.

316 Glickman MS, Cox JS, Jacobs WR: A novel mycolic acid cyclopropane synthetase is required for cording, persistence, and virulence of Mycobacterium tuberculosis. Mol Cell 2000;5:717-727.

317 Ufimtseva E: Mycobacterium-Host Cell Relationships in Granulomatous Lesions in a Mouse Model of Latent Tuberculous Infection. Biomed Res Int 2015;2015:948131.

318 Cos P, Vlietinck AJ, Berghe DV, Maes L: Anti-infective potential of natural products: how to develop a stronger in vitro 'proof-of-concept'. J Ethnopharmacol 2006;106:290302.

319 Sorrentino F, Gonzalez del Rio R, Zheng X, Presa Matilla J, Torres Gomez P, Martinez Hoyos M, Perez Herran ME, Mendoza Losana A, Av-Gay Y: Development of an 
Intracellular Screen for New Compounds Able To Inhibit Mycobacterium tuberculosis Growth in Human Macrophages. Antimicrob Agents Chemother 2016;60:640-645.

320 Christophe T, Jackson M, Jeon HK, Fenistein D, Contreras-Dominguez M, Kim J, Genovesio A, Carralot JP, Ewann F, Kim EH, Lee SY, Kang S, Seo MJ, Park EJ, Skovierová H, Pham H, Riccardi G, Nam JY, Marsollier L, Kempf M, Joly-Guillou ML, Oh T, Shin WK, No Z, Nehrbass U, Brosch R, Cole ST, Brodin P: High content screening identifies decaprenyl-phosphoribose $2^{\prime}$ epimerase as a target for intracellular antimycobacterial inhibitors. PLoS Pathog 2009;5:e1000645.

321 Yamori S, Ichiyama S, Shimokata K, Tsukamura M: Bacteriostatic and bactericidal activity of antituberculosis drugs against Mycobacterium tuberculosis, Mycobacterium avium-Mycobacterium intracellulare complex and Mycobacterium kansasii in different growth phases. Microbiol Immunol 1992;36:361-368.

322 Jagannath C, Reddy MV, Kailasam S, O'Sullivan JF, Gangadharam PR: Chemotherapeutic activity of clofazimine and its analogues against Mycobacterium tuberculosis. In vitro, intracellular, and in vivo studies. Am J Respir Crit Care Med 1995;151:1083-1086. 


\title{
Acknowledgments
}

\begin{abstract}
Alhamdulillah!
All Praise is due to Allah alone. Ph.D. is a long journey with turns of success and failure and finally ends to the completion of the course. I also pass through this long journey and with the contribution of many peoples, who encourage, support and motivate me, am finally achieve this milestone. I would like to thank all the precious people who join me on this journey.

Firstly, I would like to express my gratitude to my mentor and supervisor, Maria Lerm, for her ceaseless support, motivation and always be grateful for trusting my abilities. I am so thankful to her for accepting me as a student and providing me an opportunity to work in a friendly, interesting environment with the challenging problems. It was my loftiest dream to complete my Ph.D. in her group, which ultimately came true because of her support. Her energetic and ambitious personality always inspire me and I learned from her how to make a balance between work and life. Lastly, her friendly and polite personality always encourages me to discuss any problem, either related to research or daily life, with her and thank you again for always providing me moral support in such situations.
\end{abstract}

A special thanks to all my co-supervisors for your input and encouragement during my work. Thomas Lundbäck and Annika Jenmalm for your guidance in developing an assay for screening and also expanding my knowledge about drug discovery platform. Lena Serrander, for your support and cooperation.

Thank you, Magdalena Otrocka, for the analysis of all my 384 well plates. For always taking out time for me from your busy schedule and increasing my knowledge about the screening project.

I would also like to thank Thomas Schön, for your valuable inputs both in my experiments and writing of screening manuscript. Olle Stendahl, for introducing me to the TB group. You were the one who interviewed me first and initiated my journey. Kajsa Holmgren, my first mentor, for your care, advice and guidance in such a polite way. Vesa Loitto, for teaching me microscopy. Robert Blomgran, for always asking valuable questions about my projects. Venkata Ramanarao Parasa, for sharing your research experiences with me. Deepti Verma, for always being a great friend and bringing me the liveliest world with all your enthusiasm. Henrik Andersson, for teaching me the statistics.

I am very grateful to my former colleagues for helping me at the initial phase of my journey. Daniel and Amanda, for providing me with all strengths in the lab work during my master thesis. Amanda, I also admire your co-operation for the ImageStream analysis. Johanna, to support me to learn so many things in the research from the lab work to the use of instruments. With your help, things became much easier for me. Susmita, for spending so much precious time with me. I enjoyed a lot in your company. Hansi, for discussing your lab experience with me. 
To my office colleagues, Clara, for her contributions, support and for always reviewing my writings. I am a big fan of your calm and organized personality. I am glad we have shared the same lab. Jyotirmoy, for you I can say that you are the right person at the right time. Thank you so much for improving my knowledge about computer and for answering all my stupid questions and for giving me noble ideas related to my work and above all, for listening to my endless talks.

To my research group fellows, Blanka, for solving all the problems we encounter in TB lab. Nina, for always being so enthusiastic, support and encouragement.

To my other very close friends and colleagues. Anna-Maria, for teaching me Swedish patiently. Also to the enormous support you gave me in all things related to my research and for making the environment so friendly with your smiling face. Shambhuparsad, for always inquiring about my thesis writing and encouraging me.

To Valerie, for helping me in the cording project and Zina for helping me in the buffy coat separation.

I want to say a bundle of thanks to Martin for helping me so much during your stay in Sweden. You helped me a lot in my screening project, without you it would not be possible. For supporting in the data analysis, writing the manuscript and also making beautiful figures for my thesis.

To all members of the Medical Microbiology department who help me in one way or another in this journey of research. Mary Esping for your support in all administration tasks.

To my sweet friend Mina, for taking out time from your busy schedule to draw figures for my thesis. They are wonderful!

I'm extremely thankful to my parents whose love, guidance, prayers and moral support always strengthen me to handle the consequences.

To my sister, for a good listener and to my brothers, for giving me confidence and play a significant role throughout my life.

My heartful appreciation goes to my beloved husband Irshad Hussain, my companion for encouraging, listening and giving me time to focus my work. Without his support, I would never achieve my dreams.

And last but by no mean least my lovely children Musab and Aiza, to understand my situation in the last year of Ph.D. I know it became a bit tough in the end, but with your support finally, I did it.

\section{Sadaf Kalsum}




\section{Papers}

The papers associated with this thesis have been removed for copyright reasons. For more details about these see:

http://urn.kb.se/resolve?urn=urn:nbn:se:liu:diva-153735 


\section{FACULITY OF MEDICINE AND HEALTH SCIENCES}

Linköping University Medical dissertations No. 1657, 2019

Department of Clinical and Experimental Medicine

Linköping University

SE-581 83 Linköping, Sweden

www.liu.se 